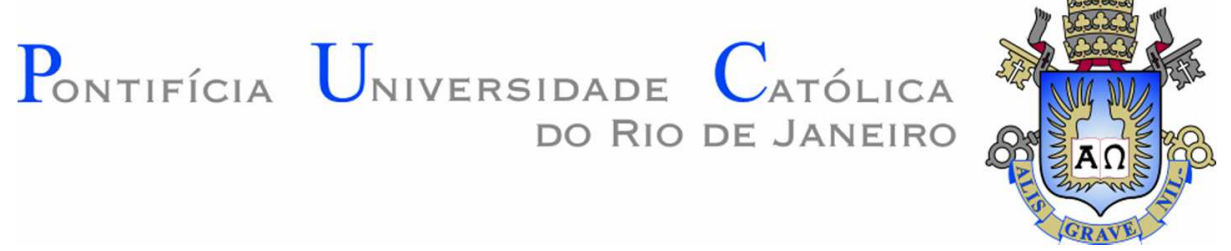

Julia Pithan de Oliveira

\title{
Design equations for local buckling of Castellated beams subjected to pure bending
}

\section{Dissertação de Mestrado}

Dissertation presented to the Programa de Pós-graduação em Engenharia Civil of PUC-Rio in partial fulfillment of the requirements for the degree of Mestre em Engenharia Civil.

Advisor: Prof ${ }^{a}$. Elisa Dominguez Sotelino Co-advisor: Prof. Daniel Carlos Taissum Cardoso

Rio de Janeiro

August 2017 


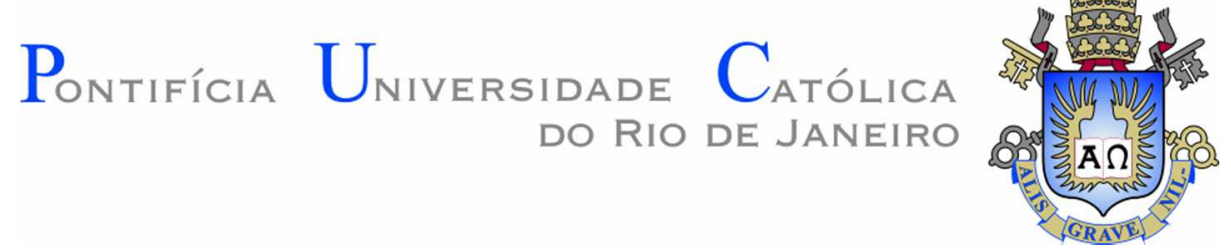

Julia Pithan de Oliveira

\section{Design equations for local buckling of castellated beams subjected to pure bending}

Dissertation presented to the Programa de Pósgraduação em Engenharia Civil of PUC-Rio in partial fulfillment of the requirements for the degree of Mestre em Engenharia Civil. Approved by the undersigned Examination Committee.

Prof ${ }^{2}$. Elisa Dominguez Sotelino

Advisor

Departamento de Engenharia Civil e Ambiental - PUC-Rio

Prof. Daniel Carlos Taissum Cardoso

Co-Advisor

Departamento de Engenharia Civil e Ambiental- PUC-Rio

Prof. Paulo Batista Gonçalves

Departamento de Engenharia Civil e Ambiental - PUC-Rio

Prof. Pedro Colmar Gonçalves da Silva Vellasco

Universidade do Estado do Rio de Janeiro - UERJ

Prof. Márcio da Silveira Carvalho

Vice Dean of Graduate Studies

Centro Técnico Científico- PUC-Rio

Rio de Janeiro, August 2nd, 2017. 
All rights reserved.

\section{Julia Pithan de Oliveira}

Bachelor in civil engineering at Pontifícia Universidade Católica do Rio de Janeiro, in 2015. Worked with mobility projects, as well as retrofit and design of structures. Her areas of interest encompass the design and dimensioning of steel structures, structural stability and computational modeling.

Bibliographic data

Oliveira, Julia Pithan de

Design equations for local buckling of castellated beams subjected to pure bending / Julia Pithan de Oliveira ; advisor: Elisa Dominguez Sotelino ; coadvisor: Daniel Carlos Taissum Cardoso. - 2017.

114 f. : il. color. ; $30 \mathrm{~cm}$

Dissertação (mestrado)-Pontifícia Universidade Católica do Rio de Janeiro, Departamento de Engenharia Civil, 2017.

Inclui bibliografia

1. Engenharia civil - Teses. 2. Vigas casteladas. 3. Flambagem local. 4. Estabilidade estrutural. 5. Furos. 6. Modelagem computacional. I. Dominguez Sotelino, Elisa. II. Cardoso, Daniel Carlos Taissum. III. Pontifícia Universidade Católica do Rio de Janeiro. Departamento de Engenharia Civil. IV. Título. 


\section{Acknowledgment}

The space dedicated to gratitude is represented a bit in these pages, and represent the many contributions to my evolution as a research and, mostly, as a person.

Firstly, I would like to thank CNPq for the scholarship granted, which enabled the research that gave origin to this dissertation.

To the Graduate Program in Civil Engineering of the Pontifical Catholic University of Rio de Janeiro, I thank the possibility of developing the dissertation in this center of excellence, which has welcomed me since my graduation. To all professors of the department for all the dedication and attention in which they dedicate the students.

I also want to thank all the staff of the department, always attentive and patient, especially Rita, Rafael and Lenilson.

Pedro Vellasco and Paulo Batista for accepting to participate in this dissertation, stimulating the production of a more complete work.

My advisor Elisa, who, in addition to fulfilling her role as a teacher, guided me in the master's and in life. Thank you for the advice, encouragement and conversations during this experience. When important decisions had to be taken, she was able to lead the situation by pointing the most reasonable path, without compromising the quality of scientific work.

To my co-supervisor Daniel Cardoso, a dedicated professional and incredible teacher with whom I had the pleasure of having contact. His theoretical baggage on various subjects was essential for the development of the work. In the work of guidance, his serenity and objectivity were precise. 
To João Braga and Daniel Linhares for the weekly discussions, participating and contributing to the development of this work. I would like to thank João for the ABAQUS's sophisticated knowledge and for his help in this process.

To my great friend Julia Genovesi, for the enthusiastic discussions, always helping me to solve any problem. Anna and Julia, companion of all hours. Thank you for the partnership in life and for all the attention.

To my dear friends who very much shared this experience of accomplishing the master's degree in PUC: Julia Genovesi, Anna Luiza Santos, Renan Marks, Marcelo Betz, Fernanda Alonso, Gisele Sintra, Leticia Oliveira, Rebecca Mansur, Larissa Macedo, Rodrigo Soares, Paula Helene and Raylane Castoldi.

To my boyfriend, Chico, fellow of all hours. Certainly this endeavor would have been much harder without you. Your courage, intelligence and generosity inspire me deeply. You can be sure that your love, support and affection made this journey infinitely less arduous.

To the other friends and companions who, directly or indirectly, helped me during the course of this work.

To my family, Anna, Fernando, Felipe, Bela, Gloria, for all support deposited. Your sacrifices, love and investments have turned into determination.

Anyway, thank you to everyone who, in a way, was part of that journey. 


\section{Abstract}

Oliveira, Julia Pithan; Sotelino, Elisa Dominguez (Advisor); Cardoso, Daniel Carlos Taissum (Co-advisor). Design Equations for Local Buckling of Castellated Beams Subjected to Pure Bending. Rio de Janeiro, 2017. 114p. Dissertação de Mestrado - Departamento de Engenharia Civil e Ambiental, Pontifícia Universidade Católica do Rio de Janeiro.

The motivation for this work is to develop a simple yet sufficiently accurate equation that can be used in the design of castellated beams subjected to pure bending, considering the contribution of the web-flange coupling effect in the local buckling. To accomplish this, an energy method - Rayleigh quotient - is adopted to determine the approximate critical stress equation. In this method, the strain energy and the potential work are calculated for an assumed approximate and kinematically admissible continuous deflected shape. Thus, the accuracy of the result is dependent on the quality of the assumed buckled shape. These shape functions were chosen based on the results obtained from numerical models created using ABAQUS software and verified with GBTUL, considering full interaction between web and flange. The developed closed-form expressions were based on classical plate stability approximations, validated with parametric studies performed using ABAQUS and GBTUL. The results indicate that the proposed equation can effectively calculate the critical stress of castellated beams due to local instability. The validated expression and its associated limits are intended to be general within the typical limits of practical applications.

\section{Keywords}

Castellated beams; Local buckling; Structural stability; Holes; Computational Modelling. 


\section{Resumo}

Oliveira, Julia Pithan; Sotelino, Elisa Dominguez; Cardoso, Daniel Carlos Taissum. Equações de projeto para flambagem local de vigas casteladas sujeitas à flexão pura. Rio de Janeiro, 2017. 114p. Dissertação de Mestrado - Departamento de Engenharia Civil e Ambiental, Pontifícia Universidade Católica do Rio de Janeiro.

A motivação para este trabalho é desenvolver equações simples, porém suficientemente precisas, que possam ser usadas para projetos de vigas casteladas submetidas à flexão pura, considerando a contribuição do conjunto mesa-alma na flambagem local do elemento. Métodos energéticos - Quociente Rayleigh - são adotados para determinar a equação da tensão crítica aproximada. Neste método, a energia de deformação e o trabalho externo são calculados assumindo uma forma de deflexão aproximada, cinemática admissível e contínua. Assim, a precisão do resultado depende da qualidade da forma de deflexão adotada. Estas funções de forma foram escolhidas com base nos resultados obtidos a partir de modelos numéricos criados usando o software ABAQUS e verificados com o software GBTUL, considerando para analise a interação completa entre a alma e a mesa. As expressões desenvolvidas foram baseadas em aproximações clássicas de estabilidade de placas, validadas com estudos paramétricos realizados com os softwares ABAQUS e GBTUL. Os resultados indicaram que a equação proposta pode efetivamente calcular a tensão crítica relativa a instabilidade local de vigas casteladas. A expressão validada e os limites associados são destinados a ser gerais dentro dos limites típicos das aplicações práticas.

\section{Palavras-chave}

Vigas casteladas; flambagem local; estabilidade estrutural; furos; modelagem computacional. 


\section{Table of contents}

$\begin{array}{ll}1 \text { Introduction } & 20\end{array}$

$\begin{array}{ll}\text { 1.1. Motivation } & 20\end{array}$

1.2. Objective and scope of work 23

$\begin{array}{ll}\text { 1.3. Dissertation Structure } & 24\end{array}$

2 Literature Review $\quad 25$

2.1. Castellated beams 25

2.1.1. Definition 26

2.1.2. Design considerations 27

$\begin{array}{ll}\text { 2.1.3. Litzka-Schnittführung } & 28\end{array}$

2.2. Instability: General Concepts 29

2.3. Approximate methods for assessing critical load 33

2.3.1. Principle of stationary energy 33

2.3.2. Deflection shape and Rayleigh quotient 36

$\begin{array}{ll}\text { 2.4. Theory and stability of plates } & 38\end{array}$

2.4.1. Plate buckling theory 38

2.4.2. Energy equations for plate buckling 40

2.4.3. Plate assembly buckling (local buckling) 41

2.4.4. Local buckling of plates with holes and castellated beams 48

2.5. Finite Element Method (FEM) 51

2.5.1. FEM model 52

2.5.2. Types of elements 53

2.5.3. Constraints 55

2.5.4. Numerical integration 55

2.5.5. FEM Convergence requirements 56 
3.1. GBTUL 58

3.2. ABAQUS FEM 60

3.2.1. ABAQUS Scripting Interface - Python 61

3.2.2. Type of elements 61

3.2.3. Boundary conditions and load application 62

3.2.4. Castellated dimensions 64

3.2.5. Finite element Mesh 65

3.2.6. Program output 66

4 Prediction Equation for $\sigma \mathrm{cr} \quad 68$

4.1. Coordinate system and notation 69

4.2. General criteria for local instability 71

4.3. Energy formulation 72

4.4. Local buckling critical stress 73

4.4.1. Assumed buckling shape 73

4.4.2. Behavior governed by web (web buckling) 76

4.4.3. Behavior governed by the flange (flange buckling) 78

4.5. Dimensional limits of $\alpha$ and $\beta \quad 80$

4.6. Summary of results obtained 83

5 Analysis of results $\quad 86$

5.1. Validation as a Tee section 87

5.2. Proposed equation validation 91

5.3. Standards recommendations and analytical solution 99

6 Conclusions and further investigations 103 
$\begin{array}{lr}\text { 6.1. Conclusions } & 103\end{array}$

$\begin{array}{ll}\text { 6.2. Future research works } & 104\end{array}$

References 105

Appendix A ABAQUS elastic buckling results and GBTUL output 109

Appendix B Steps of deflection field for the web

Appendix C Step by step of algebraic manipulations of $\sigma \mathrm{cr}$ equations 113 


\section{List of figures}

Figure 1.1 - Castellation process [2]. $\quad 21$

Figure 1.2 - Tunnel structure using castellated profiles [3]. 21

Figure 1.3 - Bridge superstructure with castellated beams [3]. 22

Figure 2.1 - Comparison of total depth with castellated and

$\begin{array}{lr}\text { conventional solutions[6]. } & 25\end{array}$

$\begin{array}{ll}\text { Figure 2.2 - Manufacturing of castellated beam. } & 27\end{array}$

Figure 2.3 - Other examples of available web patterns - [9] 27

Figure 2.4 - Litzka-Schnittführung. 28

Figure 2.5 - Three states of equilibrium. 29

Figure 2.6 - System with two bars and a spring: (a) original straight

configuration (b) buckled configuration. 30

Figure 2.7 - Bifurcation buckling: (a) stable post-buckling path

(b) unstable post-buckling path. 31

Figure 2.8 - Two bars and spring system with initial imperfection. 32

Figure 2.9 - Effects of imperfections on an idealized system:

(a) stable post-buckling path; (b) unstable post-buckling path. 32

Figure 2.10 - Virtual displacement of mass particle under a set of forces. 34

Figure 2.11 - System with more than one mass particle under a set of forces. 34

Figure 2.12 - Buckling mode of a fixed-free column 37

Figure 2.13 - Buckling mode [12]. 39

Figure 2.14- Plate buckling coefficient, k, for different boundary

conditions, $\mathrm{m}=$ number of buckled half-waves along the length

of the plate [12].

Figure 2.15 - Values of critical buckling coefficient kcr for different

boundary conditions [12].

Figure 2.16 - Representation of the method: Discrete plate analysis 
assuming simplified support edge conditions

Figure 2.17 - Representation of the method: Discrete plate analysis

assuming rotational restraint between adjacent plates

Figure 2.18 - Tee section [14]

Figure 2.19 - Compressive-buckling coefficients for flat rectangular

plates for various amounts of edge rotational restraint[19].

Figure 2.20 - Representation of full section analysis

Figure 2.21 - Minimum value of $\mathrm{K}$ for centrally loaded columns of

I-section [20]

Figure 2.22 - Plate buckling- Moen and Schafer [29]

Figure 2.23 - Buckling coefficient $\mathrm{k}$ when the center of the circular hole lies on the plate majos axis and at cross line of maximum amplitude;

El Sawy e Nazmy [30].

Figure 2.24 - Half beam idealization- Hosain, Cheng and Neis [34]

Figure 2.25 - Transformation of arbitrary system of coordinates into parametric space.

Figure 2.26 - Example of mesh with triangular elements.

Figure 2.27- Aspect ratio (a/b)

Figure 3.1 -. GBTUL cross-section deformation modes considered for T-section members [5]. 58

Figure 3.2 - Boundary conditions applied on GBTUL [5].

Figure 3.3- Signature curve for T-section members obtained with

GBTUL-modes participations for governing local buckling mode [5].

Figure 3.4 - Deflection shape of upper Tee [5].

Figure 3.5 - ABAQUS model - lateral restraint of single hole beam.

Figure 3.6 - ABAQUS model - lateral restraint of the 5 hole beam.

Figure 3.7- Boundary conditions - single hole beam.

Figure 3.8 - Boundary conditions - 5 hole beam. 64

Figure 3.9 - Nomenclature and dimensions 65

Figure 3.10 - Mesh and aspect ratio 66 
Figure 3.11 - Mesh detail at hole zones. 66

Figure 3.12 - Buckling shape - single hole beam. 67

Figure 3.13 - Buckling shape - 5 holes beam. 67

Figure 4.1 - Tee-section simplification $\quad 69$

Figure 4.2 - Geometry of a typical castellated beam 70

$\begin{array}{ll}\text { Figure 4.3 - Local Reference System } & 70\end{array}$

Figure 4.4 - Buckling shape (a) Web buckling (b) Flange buckling 71

Figure 4.5 - GBTUL - deflection shape 73

$\begin{array}{ll}\text { Figure } 4.6 \text { - Transverse buckling } & 73\end{array}$

$\begin{array}{ll}\text { Figure } 4.7 \text { - Frame element. } & 74\end{array}$

$\begin{array}{ll}\text { Figure } 4.8 \text { - Frame interaction. } & 74\end{array}$

Figure 4.9 - Rotational Spring stiffness 75

Figure 4.10: Tee section representation $\quad 76$

Figure 4.11 - WLB ABAQUS output 77

Figure 4.12 - GBTUL transverse deflection $\quad 78$

$\begin{array}{ll}\text { Figure 4.13 - FLB ABAQUS output } & 78\end{array}$

Figure 4.14 - Analysis of $\sigma \mathrm{cr}$ with parameter $\beta$ ranging from 0 to $1 \quad 80$

Figure 4.15 - Analysis of $\sigma \mathrm{cr}$ with parameter $\beta$ ranging from 0 to 2.

Figure 4.16 - Analysis of $\sigma \mathrm{cr}$ with parameter $\alpha \quad 82$

Figure 4.17 - Local buckling coefficient $\xi=1 . \quad 84$

Figure 4.18 - Local buckling coefficient $\xi=1.5$. 84

Figure 4.19 - Local buckling coefficient $\xi=1.8$. 85

Figure 5.1 - Web buckling - ABAQUS and GBTUL results. 87

Figure 5.2 - Flange buckling - ABAQUS and GBTUL results. 88

Figure 5.3 - Web buckling - normalized results $-\xi=1.0 \quad 89$

Figure 5.4 - Web buckling - normalized results $-\xi=1.5$

Figure 5.5 - Web buckling - normalized results $-\xi=1.8 \quad 89$

Figure 5.6 - Flange buckling - normalized results - $\xi=1.0 \quad 90$

Figure 5.7 - Flange buckling - normalized results $-\xi=1.5 \quad 90$

Figure 5.8 - Flange buckling - normalized results $-\xi=1.8 \quad 90$ 
Figure 5.9 - Web buckling - proposed equation x GBTUL

Figure 5.10 - Web buckling normalized results-

Proposed equation x GBTUL $-\xi=1.0$

Figure 5.11 - Web buckling normalized results -

Proposed equation x GBTUL $-\xi=1.5$

Figure 5.12 - Web buckling normalized results -

Proposed equation x GBTUL $-\xi=1.8 \quad 92$

Figure 5.13 - Web buckling - proposed equation x ABAQUS 93

Figure 5.14 - Web buckling normalized results -

Proposed equation x ABAQUS $-\xi=1.0 \quad 93$

Figure 5.15 - Web buckling normalized results -

Proposed equation x ABAQUS $-\xi=1.5 \quad 94$

Figure 5.16 - Web buckling normalized results -

Proposed equation x ABAQUS $-\xi=1.8 \quad 94$

Figure 5.17 - Flange buckling - proposed equation x GBTUL 95

Figure 5.18 - Flange buckling normalized results -

Proposed equation x GBTUL $-\xi=1.0$

Figure 5.19 - Flange buckling - normalized results -

proposed equation $x$ GBTUL $-\xi=1.5$

Figure 5.20 - Flange buckling - normalized results -

proposed equation $x$ GBTUL $-\xi=1.8$

Figure 5.21 - Flange buckling -

Proposed equation x ABAQUS

Figure 5.22 - Flange buckling normalized results -

Proposed equation $\mathrm{x}$ ABAQUS $-\xi=1.0$

Figure 5.23 - Flange buckling normalized results -

Proposed equation $\mathrm{x}$ ABAQUS $-\xi=1.5$

Figure 5.24 - Flange buckling - normalized results -

proposed equation x ABAQUS $-\xi=1.8 \quad 98$

Figure 5.25 - Terminology used in AISC Design Guide 31 [6]. 99 
$\begin{array}{ll}\text { Figure 5.26 - Timoshenko analysis } & 100\end{array}$

Figure 5.27 - Comparison of results $-\xi=1.0 \quad 101$

Figure 5.28 - Comparison of results $-\xi=1.5 \quad 101$

Figure 5.29 - Comparison of results $-\xi=1.8 \quad 102$

Figure 5.30 - GBTUL (a) Web local buckling (b) Flange local buckling 102 


\section{List of tables}

Table 1 - Equations for Critical local buckling coefficients, kcr

Table 2 - Values of $k_{c r}$ coefficient

Table 3 - Results obtained for critical buckling governed by the web

109

Table 4 - Results obtained for critical buckling governed by the flange 


\section{List of abbreviations}

NBR8800: Brazilian Standard for Steel Structures and Mixed Structures of Steel AISC: American Institute of Steel Construction

EUROCODE: European committee for standardization

MEF: Finite element method

GBT: Generalized beams theory 


\section{List of symbols}

$\sigma c r:$ Critical Stress

$\delta_{\mathrm{r}}$ : Displacement

$\sigma_{\mathrm{xx}}, \sigma_{\mathrm{yy}}, \sigma_{\mathrm{xy}}:$ Stress on the plane axis

$\varepsilon_{\mathrm{xx}}, \varepsilon_{\mathrm{yy}}, \varepsilon_{\mathrm{xy}}:$ In-plane strains

$v$ : Poisson coefficient

$\xi$ : Geometric parameter, ratio of the thickness

$\eta$ : Geometric parameter, ratio of the width

$\alpha$ : Geometric parameter, total height ratio with hole height

$\beta$ : Geometric parameter, ratio of hole length

$\mathrm{k}_{\mathrm{cr}}$ : Critical local buckling coefficients

$f_{\text {ir: }}$ Force component

W: Virtual work

U: Strain energy

V: Potential energy

I: Moment of inertia of the section around flexural axis

E: Modulus of elasticity

G: Transverse modulus of elasticity

$\mathrm{J}$ : Polar moment of inertia

tf: Flange thickness

$\mathrm{t}_{\mathrm{w}}$ : Web thickness

$b_{f}$ : Flange width

$b_{\mathrm{w}}$ : Web width

$\mathrm{H}_{\text {hole: }}$ Hole height

$\mathrm{H}$ : Beam height

L: Weld Length (Variable)

$D_{w}$ : Longitudinal bending stiffness of the web 
$\mathrm{N}_{\mathrm{xx}}, \mathrm{N}_{\mathrm{yy}}, \mathrm{N}_{\mathrm{xy}}$ : In-plane forces

S4: Shell element with four nodes

S4R: Shell element with four nodes and reduced integration

S8R: Eight-node shell element with reduced integration

S8R5: Shell element with eight nodes and reduced integration, with five degrees of freedom per node

WLB: Critical behavior governed by the web buckling

FLB: Critical behavior governed by the flange buckling 


\section{Introduction}

\subsection{Motivation}

The primary use for castellated beams is in spanning long distances utilizing a lighter weight section, since they are originated by the expansion of I-profile. There are potentially many constructions that can be realized by using these elements, as: parking garages, industrial and warehouse facilities, office buildings, schools, and hospitals.

Space and height restrictions are frequently imposed to architectural projects, due to technical, economical and aesthetical reasons, as well as regional regulations, that can require restrictions to the total height of the building.

The necessity of settling an always growing number of electrical and hydraulics pipes increases the complexity of incorporating facilities design to the available space. In commercial structures, HVAC (heating, ventilation and air conditioning) systems require larger shafts pipe diameters, that can reach $75 \%$ of the required structural height [1].

In bridge engineering, besides making it possible to reach larger spans, web openings are commonly used to ensure access for bridge maintenance and inspection. In these cases, the web opening height can represent $60 \%$ of the total height of the beam. In box girders, the web opening width can be three times greater than the opening height.

There are several solutions that can be used in order to overcome these obstacles, among which are stub-girders, beams with variable inertia, trusses, beams with web openings, among others.

Modern technology used by today's steel mills allow welded profiles to be easily created from laminated elements, making use of its web and flange thicknesses. Castellated beams lie in this category. Its good bearing capacity, along 
with its characteristics that allows the passing of service lines through the openings, make them an interesting solution for the construction market. Figure 1.1 shows the process of fabrication of a castellated beam. Figure 1.2 and Figure 1.3 show examples of the use of castellated beams.

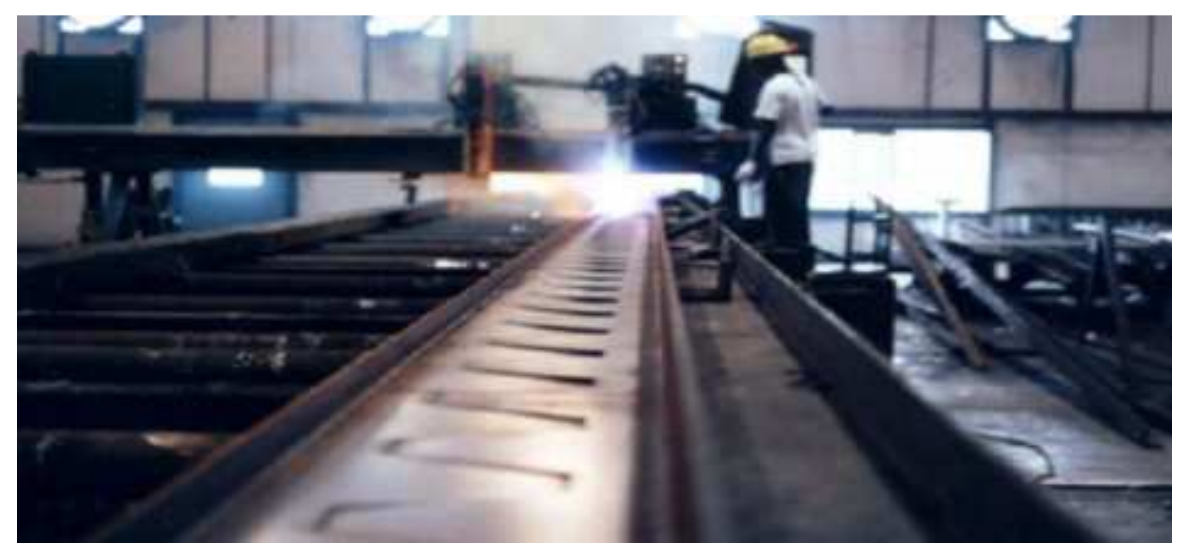

Figure 1.1 - Castellation process [2].

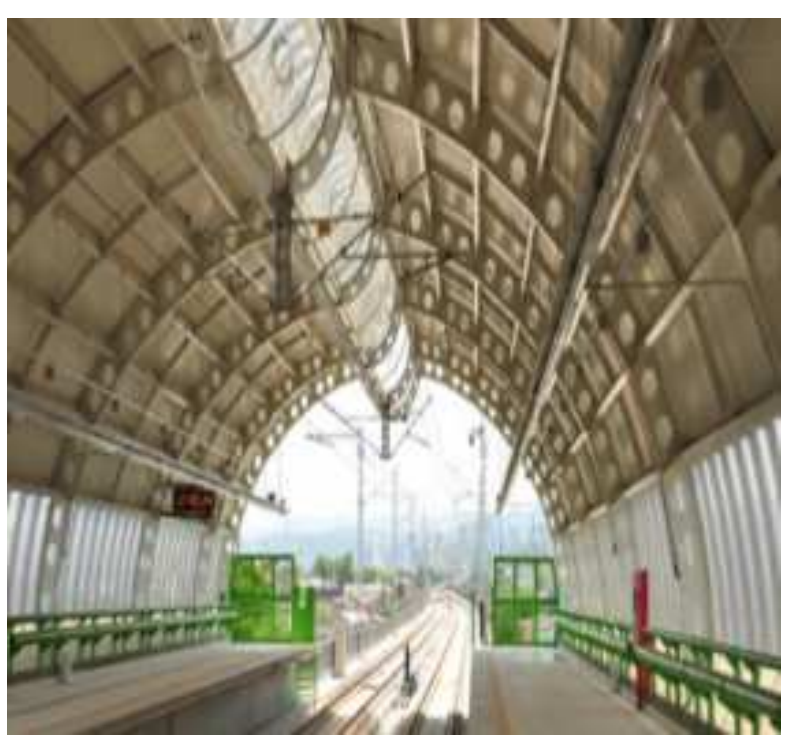

Figure 1.2 - Tunnel structure using castellated profiles [3]. 


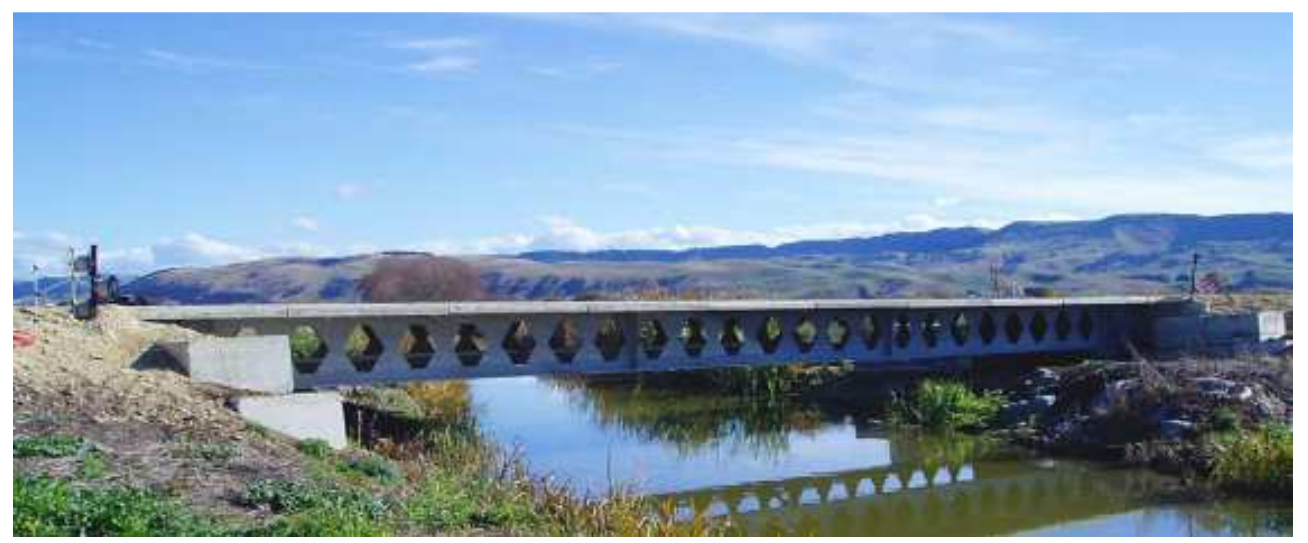

Figure 1.3 - Bridge superstructure with castellated beams [3].

Because castellated beams are expanded web members, they are often characterized as being slander structures. The employment of this kind of structures has grown significantly due to the increasing need to promote cost savings by reducing material usage. The main characteristic of this type of structure is that its cross-section has a large moment of inertia relative to its area. Thus, in terms of strength, they can reach larger spans with relatively little material consumption. However, this kind of structural element is much more prone to suffer from instability.

The main benefits of adopting castellated beams are as follows:

- Web expansion, promoting improvement of bending capacity and stiffness, due to the higher moment of inertia.

- Optimization of structure weight, associated with material cost reduction.

- Compatibility with different mechanical, electrical, and HVAC systems; the openings in the beams may be utilized for the installation of conduit, HVAC and sprinkler piping, and any other utility system.

The size and position of the hole on the web may weaken some parts of the member and lead to instability issues. Stress concentration occurs near the hole, which favors the occurrence of local buckling. In order to obtain the ultimate strength of such an element, it is necessary to consider its linear elastic buckling properties. This research focuses on local instability. 
The critical load is an important parameter for obtaining the design load. As the slenderness of a structural element increases, its collapse mechanism may undergo significant qualitative changes. As the element becomes slender, it loses its stability through buckling and may collapse due to the presence of large lateral deflections and their associated second order effects.

Thus, when a plate element is subjected to direct compression, bending, shearing, or a combination of these stresses in its plane, theoretical critical loads calculation indicates if the plate may buckle locally before the element as a whole becomes unstable, or before the material yield stress is reached.

The advent of computers has enabled the use of numerical methods to solve a wide variety of problems, such as those related to structural analysis. With these powerful tools, experiments can be calibrated with numerical simulation, allowing for greater levels of reliability. They enable the analyzes of different scenarios because of the facility in which parameters can be changed. Consequently, using numerical simulation one can attain cheap and trustworthy results.

\subsection{Objective and scope of work}

This research investigated the effect of local buckling on the behavior of castellated beams subjected to pure bending. This was achieved with the aid of a software that implements the finite element method as well as other computational tools. The main goal was to obtain a simple design equation for the critical load, taking into account the coupling effect between web and flange in the element's local buckling. The equation for the critical load was developed using an energy method. Since the beams considered herein were slender, only buckling in elastic range was considered.

Due to the wide variety of perforation sizes and configurations for different geometries of castellated beams, it is a cumbersome task to provide a practical design procedure to assess the local stability of these sections. Under pure bending, the region below the neutral axis (bottom tee) is subjected to tension, and has no out-of-plane deflections. Accordingly, the study considered a simplification, in 
which the castellated beam buckling is approximated by that of a Tee section subjected to a combined bending and compression.

A comparison was made between the critical stress obtained using a finite element model of a castellated beam using the software ABAQUS [4], with the critical stress obtained using a Tee section beam model, as described above, using the software GBTUL [5]. Once it was confirmed that the simplification with the Tee-section provided good results, a closed-form expression based on classical plate stability approximations was developed. The expression was then validated with parametric studies carried out using the software package ABAQUS.

The validated expression is intended to be general and its associated limits are such that they meet the limits common in engineering practice. This expression can be considered as a step towards the development of more comprehensive design guidelines for castellated beams.

\subsection{Dissertation Structure}

The dissertation is organized in six chapters as follows. Chapter 1 presents the motivation for the research as well as the main objectives of the present work. Chapter 2 provides some of the fundamental concepts as well as literature review of related works. Chapter 3 introduces the computational tools adopted in this work, namely ABAQUS and GBTUL. It also presents the comparison between the preliminary studies of the tee section simplification carried out with GBTUL and the analyses using the ABAQUS software. Chapter 4 discusses the methodology adopted for predicting the critical stress for castellated beams. Chapter 5 presents the validation of the developed equation through a comparison of the results obtained with ABAQUS, GBTUL and the proposed equation. Finally, Chapter 6 gives the main conclusions drawn from the present work and provides suggestions for future research work. 


\section{2}

\section{Literature Review}

\subsection{Castellated beams}

The employment of castellated beams in steel construction occurred due to two demands of the construction sector: to promote web openings to pass the building's service lines and to provide alternatives for construction solutions. In other words, the main goal of castellated beams is to create beams with expanded web, which can overcome larger spans keeping the same weight and still can accommodate service pipes, decreasing significantly the height necessary to settle the facilities infrastructure, as can be seen in Figure 2.1.
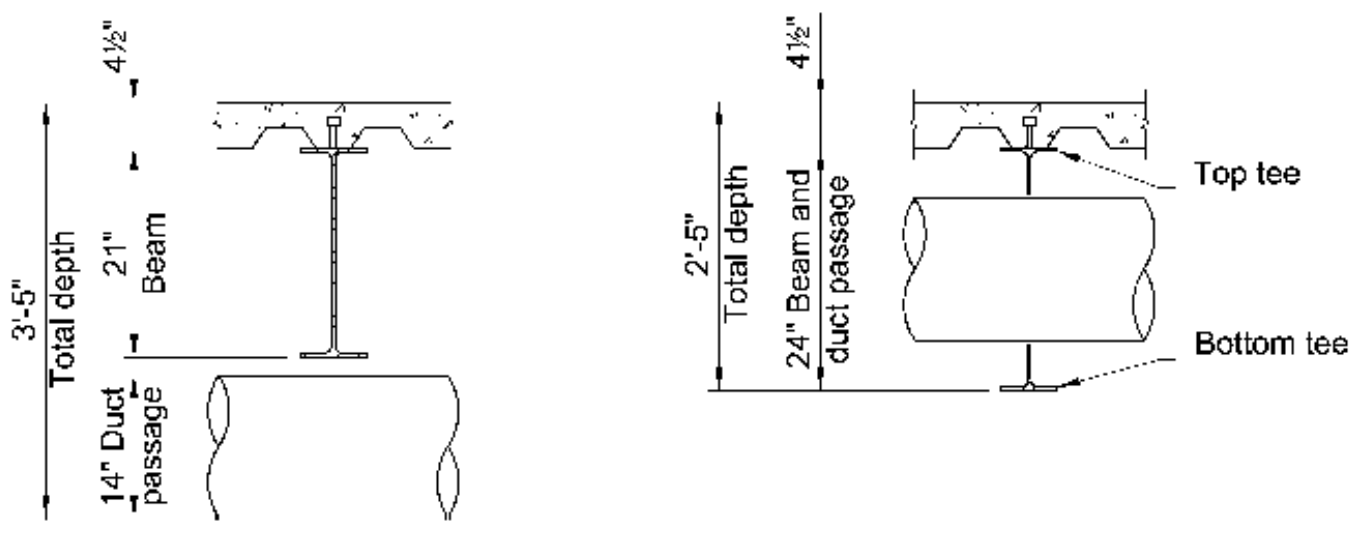

Figure 2.1 - Comparison of total depth with castellated and conventional solutions[6].

According to Knowles[7] the castellation process began with an engineering problem of a monorail crane and the solution to the problem is attributed to Geoffrey Murray Boyd. The crane opening restricted the maximum flange width of the beam. The rolled beams chosen respected the flange width limitation, but were not stiff enough for the desired span. Therefore, Murray Boyd first thought of welding one beam above other in order to increase the height and consequently the stiffness. He decided then to cut, reassemble and weld the web. To demonstrate the 
viability of his idea he used a reduced model made with cardboard. This is how the Boyd beam (Castellated beam) was created.

The castellation process started by manually expanding the web. As labor force became more expensive, the castellation process became economically disadvantageous, only becoming popular again with the advent of automated manufacture, which made the price of castellated beams competitive again.

The beam was first used in 1910. Later on, in the early 1930's, it was employed as a roof beam, in Czech Republic. In 1939, the process of castellation was patented. According to Knowles[7], early attempts to devise methods calculate the load carrying capacity and deflection of castellated beams became available in 1942 (elastic analysis method) and in 1970 (plasticity analysis method).

\subsubsection{Definition}

Castellated beams are produced by making a cut along the web in a zigzag pattern and posteriorly reassembling the two parts leaving a gap between them. The final product consists of a beam with an expanded web, containing a series of web openings with hexagonal shape. Figure 2.2 illustrates the aforementioned assembling process. The two small pieces that remain at both ends of the new beam are waste.

There are other types of patterns available for the web cut, intending to provide the same benefits. However, the final products are slightly different, and other design provisions are necessary for them. Figure 2.3 illustrates some other available patterns.

Braga and Sotelino [8] investigated the stability of steel beams with web openings. Numerical studies were performed using finite element models implemented in the commercial software package ABAQUS. Three types of holes, e.g. circular, rectangular and hexagonal, were analyzed. A comparison of the results showed that the castellated beams had higher critical moments. 


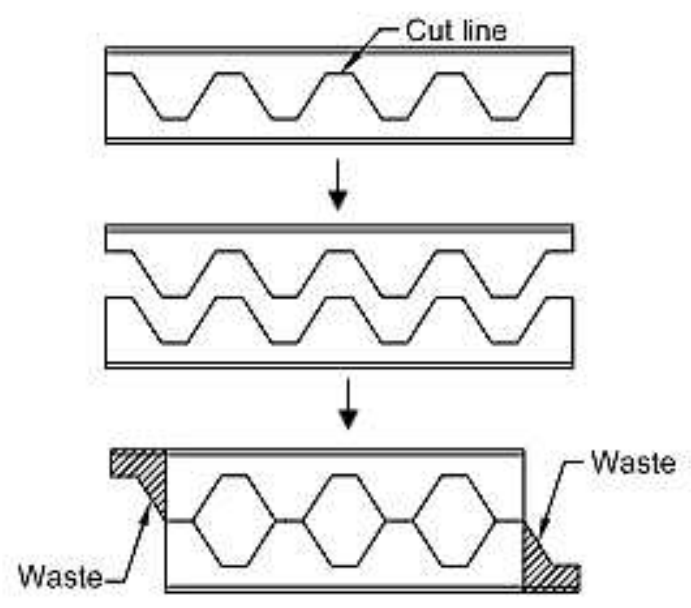

Figure 2.2 - Manufacturing of castellated beam.

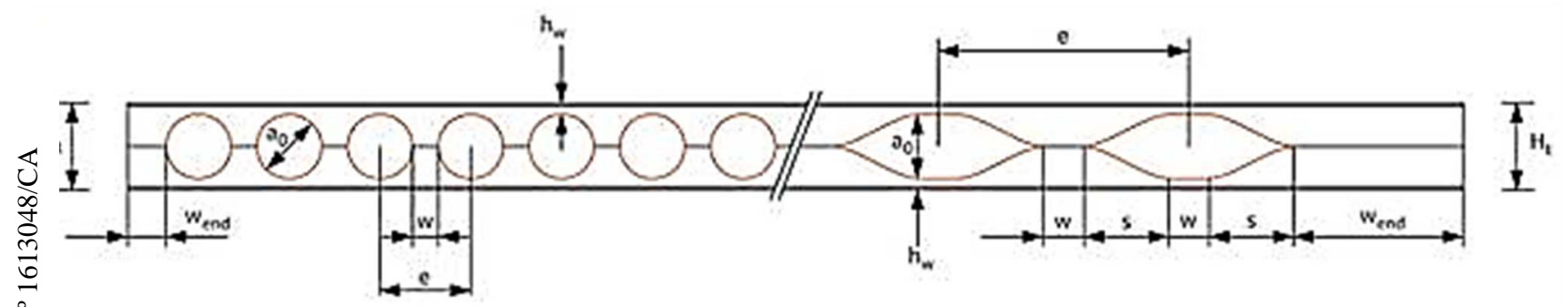

Figure 2.3 - Other examples of available web patterns - [9]

\subsubsection{Design considerations}

AISC Design Guide 31 [6] specification recommends that, when designing castellated beams, the following limit states should be analyzed:

- Compactness and local buckling

- Overall beam flexural strength

- Vierendeel bending of tees

- Web post buckling

- Axial tension/compression

- Horizontal and vertical shear

- Lateral-torsional buckling

These limit states are related to a general use and to load combination. In this work only instability problems caused by pure bending is considered. Thus, the 
number of possible failure types is significantly reduced, remaining only those related to local buckling.

\subsubsection{Litzka-Schnittführung}

Various choices have to be made when dimensioning castellated beams. A common type of beam, known as Litzka-Schnittführung (Figure 2.4), is characterized by the following three basic assumptions:

- The height ratio $\mathrm{H} / \mathrm{H}_{\mathrm{h}}$ is set at 1.5. In other words, the total beam depth $\mathrm{H}$ is one and a half times greater than the hole depth $\mathrm{H}_{\mathrm{h}}$.

- The pitch is assumed to be equal to the depth $\mathrm{H}$ of the castellated beam.

- The length of the hexagonal side is half the hole depth: $L=\frac{\mathrm{H}_{\mathrm{h}}}{2}$.

According to Amayreh [10], if the welded length is too short, then web weld will fail in horizontal shear, and if it is too long it will produce long tees, which may fail in Vierendeel bending. Thus, a reasonable balance between these two failure modes is $\mathrm{L}=\frac{\mathrm{H}_{\text {hole }}}{2}$.

- the angle $\alpha$ is set at $63.5^{\circ}$ (to be precise, $\tan \alpha=2$ ).

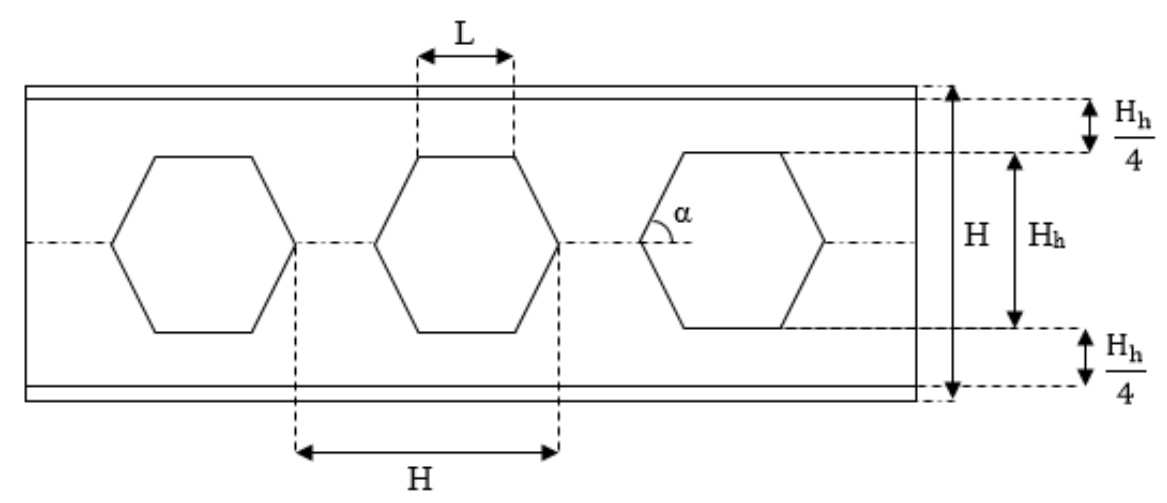

Figure 2.4 - Litzka-Schnittführung. 


\subsection{Instability: General Concepts}

The first investigations on the instability of structural members were conducted by the Swiss mathematician Leonard Euler, who published the famous critical load equation for columns in 1744. Since then, the continuous development of the industry and technology have led to lighter and stronger structures using slender elements. These elements are geometrically characterized by having high slenderness ratio, favoring the occurrence of instability. Thus, in order to safely adopt them, the analytical and numerical methods need to be improved accordingly.

Structural stability theories study the conditions under which a system in a given state of equilibrium tends to become unstable. In the words of German mathematician Johann Dirichlet Apud [11], "the equilibrium of a mechanical system is stable if, in displacing the points of the system from their equilibrium positions by an infinitesimal amount and giving each one a small velocity, the displacements of different points of the system remain, throughout the course of the motion, contained within small limits".

Stability concepts can be understood with the classical analogy of the ball over a curved surface. There are three possible states of equilibrium: stable, neutral and unstable, as illustrated in Figure 2.5.

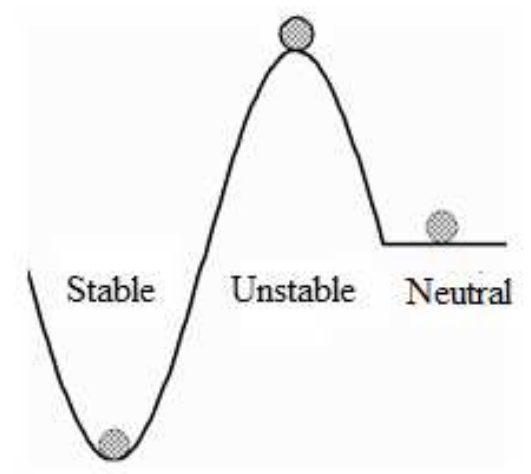

Figure 2.5 - Three states of equilibrium.

Considering Dirichlet's [11] definition, it can be observed that the ball on the left side of Figure 2.5 (concave surface) tends to return to its equilibrium position if subjected to an impulse, whereas the ball on center (convex surface) in initial equilibrium, has the tendency to develop large displacements, no matter the 
magnitude of applied impulse. Finally, the ball on the right side (flat surface) illustrates an intermediate case, called neutral state of equilibrium.

As in the ball analogy, structural stability problems are work-energy problems. Therefore, the system is at rest when its potential energy derivative is equal to zero, i.e., a region zero slope. Stable systems are those in which the potential energy is a relative minimum - case of the ball on the left - whilst unstable systems are characterized by a relative maximum. A system where the potential energy derivative is not null corresponds to an unbalanced system.

Structural instability is usually associated with members carrying compressive stresses (e.g. axially loaded columns, beams, plates and cylindrical shells) and consists of a sudden loss of original shape to another configuration in which equilibrium exists. The term buckling is usually adopted to describe this change from a straight to a deflected configuration in a structural member whereas bifurcation buckling is associated with the bifurcation of equilibrium, i.e., the condition for which the equilibrium state changes from stable to unstable. An illustrative example for an idealized perfect system comprised of two inextensible straight bars laterally braced by a spring at mid-length is shown in Figure 2.6.

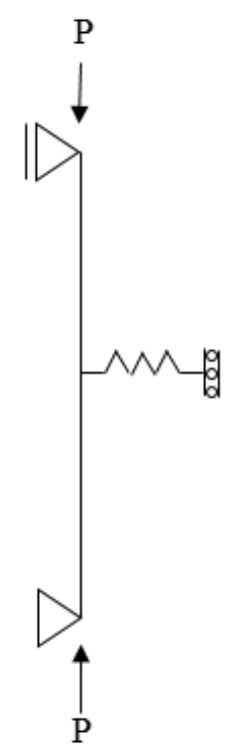

(a)

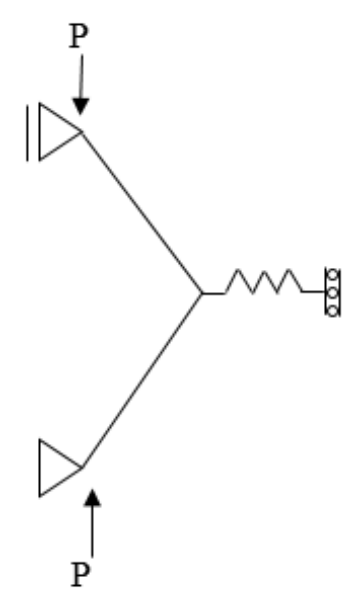

(b)

Figure 2.6 - System with two bars and a spring: (a) original straight configuration (b) buckled configuration. 
Initially, the bars are subject to pure compression, consequently exhibiting only axial deformations and an increase in $\mathrm{P}$ produces greater axial strains, but no lateral deflections. As $\mathrm{P}$ reaches a critical value Pcr, called critical load or bifurcation load, the system may remain in an unstable straight configuration or change to a bent (buckled) configuration in which lateral deflections grow quickly.

The post-buckling path can be stable, in which the load-carrying capacity of the structure still grows, although large deflections are required, or unstable, characterized by a decrease in resistance with lateral deflections. Figure 2.7 shows these two possibilities. A plate simply supported at the four edges and subject to inplane compression illustrates the case of a system with stable post-buckling path. Ziemian [12] states that, "as the plate buckles, the buckling deformations give rise to tensile membrane stress normal to the direction of loading which increase the stiffness of the plate and give it the capacity to resist additional load".

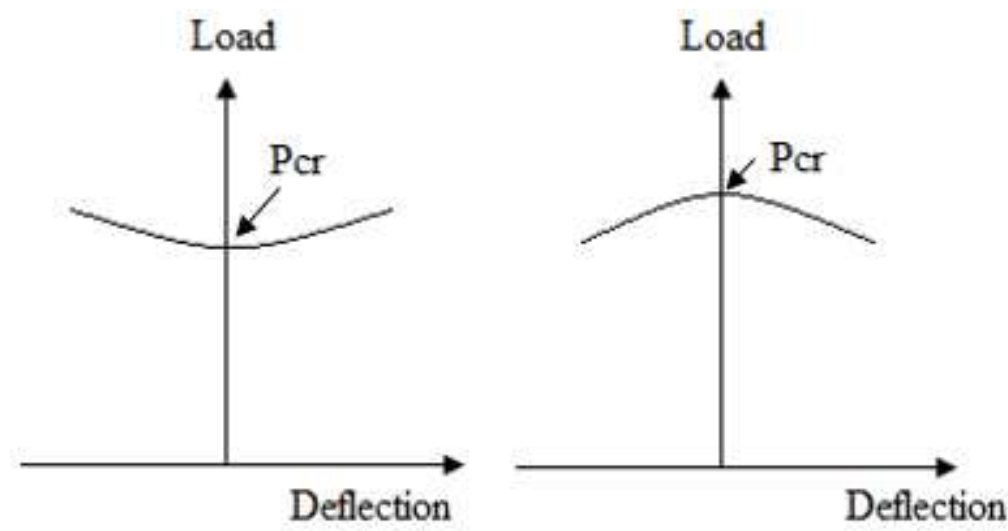

Figure 2.7 - Bifurcation buckling: (a) stable post-buckling path (b) unstable postbuckling path.

Considering that perfectly straight members do not exist in real structures, initial geometric imperfections must be considered when assessing actual member capacity. Figure 2.8 shows a two bars-spring system with an initial out-ofstraightness. 


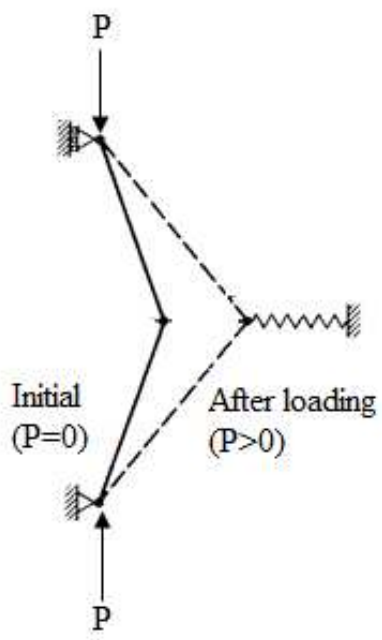

Figure 2.8 - Two bars and spring system with initial imperfection.

The presence of imperfections leads to second-order effects and, therefore, lateral deflections can be observed since the beginning of loading. This phenomenon softens the abrupt change in shape, but reduces member capacity. The dashed lines in Figure 2.9 illustrate the effect of imperfections on the idealized behavior (solid lines). Although ultimate and critical loads are different for a certain structural member, it is still important to know the bifurcation load for actual behavior prediction.

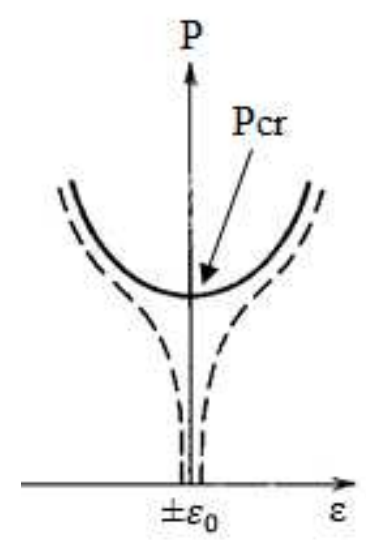

(a)

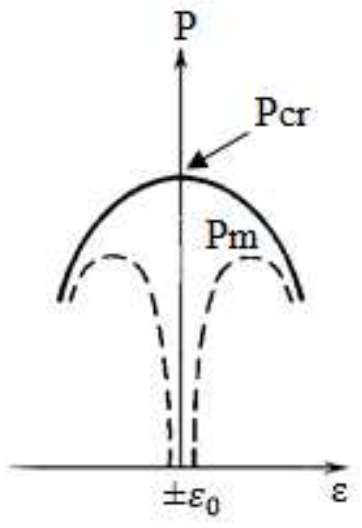

(b)

Figure 2.9 - Effects of imperfections on an idealized system: (a) stable postbuckling path; (b) unstable post-buckling path.

The previously developed study can be extended to bars and plates with some flexibility. As slenderness increases, its collapse mechanism undergoes 
significant qualitative changes. Under a compressive load, a column that is sufficiently slender will fail due to out of plane deflection rather than crushing of the material.

To understand the conditions leading to instability of a certain structure, it is important to know the constitutive relationships of the constituent material. In the case of steel members, modulus of elasticity, yielding stress, strain hardening branch and Poisson's ratio are the most important properties to be taken into account. Geometry also plays an important role and, along with the mechanical properties, defines the stiffness of the system.

\subsection{Approximate methods for assessing critical load}

The critical load of a member subject to compression can be obtained by solving the governing differential equation derived for the balance of internal forces for a deflected configuration. However, this methodology can be applied only in a few cases, such as for pinned-pinned column in which boundary conditions lead to a simple closed-form equation. In more complex problems, obtaining the exact analytical solution for bifurcation load requires significant effort and, sometimes, it is not even possible.

Hence, approximate methods may be adopted in order to find practical and sufficiently accurate solutions. These methods usually consist in approximating the exact deflected shape by a well-known continuous and kinematically admissible function (or series of functions). Among the approximate methods for assessing critical load of structures, one may cite Rayleigh Quotient and Rayleigh-Ritz, which are energy-based approaches based on the concept of total potential energy of the system. In the next sections, the principle of stationary energy and the Rayleigh Quotient method are presented in details.

\subsubsection{Principle of stationary energy}

Considering a mass particle in equilibrium subject to a set of forces, a virtual displacement $\left(\delta_{\mathrm{r}}\right)$ is assumed to occur, as shown in Figure 2.10. Therefore, for each force acting on the body, a virtual work is determined as the product of the force component in the direction of the virtual displacement and the virtual displacement 
itself. If the body is in equilibrium, the sum of the components of the force are equal to zero in any direction, and consequently the virtual work equals to zero as well. In other words:

$$
d W=\sum_{i=1}^{n} f_{i r} \delta_{r}=0
$$

where $f_{\text {ir }}$ is the component of force i parallel to direction r. $\delta_{r}$ is the virtual displacement and $d W$ is the virtual work caused by the virtual displacement.

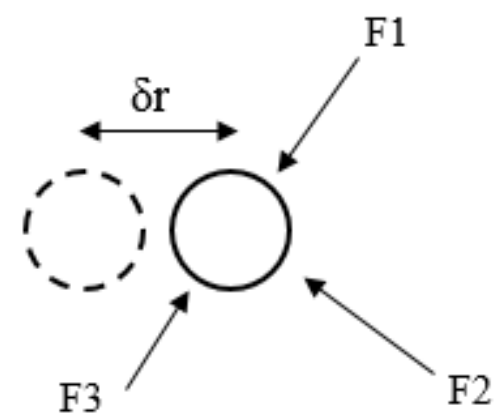

Figure 2.10 - Virtual displacement of mass particle under a set of forces.

Therefore, the principle of virtual displacement can be stated as Alexander Chajes[11] described on his book Principles of Structural Stability Theory: " $A$ particle of mass is in equilibrium if the total virtual work done by all the forces acting on the particle is equal to zero for any arbitrary virtual displacement".

The concept can be generalized for a system with two or more mass particles, linked by massless springs, as shown in Figure 2.11. In this case, the virtual work is separated into two different parts for which balance must be fulfilled: internal forces (spring forces) and external loads.

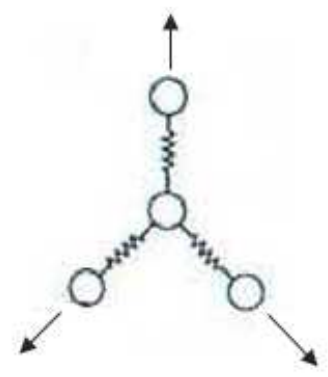

Figure 2.11 - System with more than one mass particle under a set of forces. 
By applying the mentioned concepts to the system above, one can observe that the internal virtual work is equal to the change in strain energy of the system in magnitude, but with opposite sign. Hence, the total potential energy of the system is referred to as $U+V$, where $\mathrm{U}$ is the strain energy of the system and $\mathrm{V}$ is the potential energy of the external loads. Therefore, the following condition should be satisfied.

$$
\delta(U+V)=0
$$

This principle can be generalized as follows Chajes [11] : "An elastic structure is in equilibrium if no change occurs in the total potential energy of the system when its displacement is changed by a small arbitrary amount'. For a continuous system with infinite degrees of freedom (DOF), there are infinite virtual displacements to be analyzed and hence the only way to guarantee that the system is actually in equilibrium is to apply Variational calculus. However, when the system has finite degrees of freedom, the number of verifications to be done is also finite, and as the number of DOF's decreases, the amount of handwork calculations decreases as well. For a single degree of freedom system subject to a virtual displacement $\delta x$, the following can be written:

$$
\frac{d(U+V)}{d x} \delta x=0
$$

Once $\delta x$ is taken as an arbitrary value, the equation above reduces to:

$$
\frac{d(U+V)}{d x}=0
$$

As can be observed, the necessary condition for equilibrium is obtained when the derivative of the total potential energy is equal to zero. This represents a point on a null slope region of the function, which may correspond to a minimum, maximum or neutral state of equilibrium, as shown in Figure 2.5. The second derivative indicates if the equilibrium is stable or not. 


\subsubsection{Deflection shape and Rayleigh quotient}

The approximate solution by the Rayleigh quotient passes through the assumption of an approximated buckled shape for the element. The admissible deflected functions $\mathrm{w}(\mathrm{x})$ must be continuous, with continuous slopes $\mathrm{w}$ '(x), and satisfy all the given kinematic boundary conditions.

Consequently, the procedure begins with the choice of a representative function for the buckling shape that fulfills geometric boundary conditions. Trigonometric and polynomial functions are generally adopted, once they are easy to differentiate and have been widely applied in literature to describe many buckling modes.

The simple application of the principle of stationary energy leads to the approximate solution. Rayleigh quotient (Eq.5) uses energy approach to determine the exact conditions of equilibrium and represents an upper-bound approximation of critical stress. The chosen function would be exact if it satisfied the boundary conditions and the equilibrium equations.

The Rayleigh quotient is represent as:

$$
P_{c r}=\frac{U}{W}
$$

Where $U$ is a positive-definite quadratic strain energy expression, independent of the loading parameter and $\mathrm{W}$ is a positive-definite quadratic expression defining the work produce by unit load.

The following example is given to illustrate the method. Considering a column fixed at the base and free at the top and subjected to a compression load $\mathrm{P}$, the buckling mode takes the form shown in Figure 2.12. 


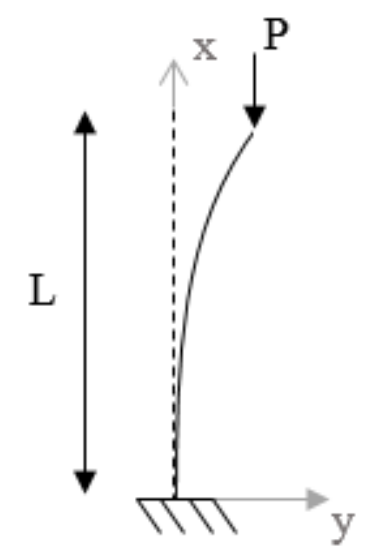

Figure 2.12 - Buckling mode of a fixed-free column

Appling Rayleigh quotient with the consideration of a quadratic function $\left(y(x)=A x^{2}\right)$ for approximate deflection shape leads to an approximate critical load $22 \%$ greater than the prediction obtained solving the differential equation for the problem. Although the deflected shape function adopted fulfills the boundary conditions of zero displacement and zero slope at $\mathrm{x}=0$, and is also similar to the exact shape, it does not represent well enough the actual behavior.

This is due to the fact that the system with infinity degrees of freedom was reduced to a system with only one degree of freedom $(\delta)$. Reliability can be improved by increasing the number of DOF's, which can be achieved by using higher-order functions. If a cubic equation is considered, the error decreases substantially to less than $1 \%$. Whence, attention must be paid on the precision of the solution, once the degree of the equation adopted can substantially affect the quality of the result. However, Rayleigh quotient is applied only for systems with one degree of freedom. 


\subsection{Theory and stability of plates}

\subsubsection{Plate buckling theory}

A plate is a structural element for which one dimension - the thickness - is much smaller than the other two dimensions. It can be subdivided into two different categories: thin and thick. Thin plates are elements where the effects of shear on the deformed shape of the element can be neglected, once they are insignificant when compared to the bending effects. Therefore, a linear strain distribution through thickness is a basic assumption to solve the problem. For thick plates, shear deformation becomes significant and the hypothesis previously mentioned does not apply. The theory developed for thin plates is also called classical plate theory (Kirchoff) and it is the one adopted in this work.

Stability theory applied to plate buckling was studied in 1891, when Bryan [13] presented an analysis for a rectangular plate simply supported on all edges and subjected to a uniformly distributed compression in-plane force parallel to the long edges. Bryan was not only the first to treat the stability problem of plates, but the importance of his classic research lies also in the fact that he was the first to apply an energy method to obtain a solution for the plate buckling problem.

Timoshenko [7] shows that the critical stress in a flat plate subjected to inplane compression is given in a general form, Eq. 16, regardless the load distribution and boundary conditions. Figure 2.13 exemplifies the buckling mode for a plate under compression. In Eq. 6, $b$ and $t$ are the width and thickness of the plate, respectively, while $v$ and $E$ are Poisson's ratio and modulus of elasticity of the material. This general expression can be easily demonstrated using energy methods, by applying the equality of strain energy and external loads potential [14].

$$
\sigma_{c r}=k \frac{\pi^{2} E}{12\left(1-v^{2}\right)(b / t)^{2}}
$$




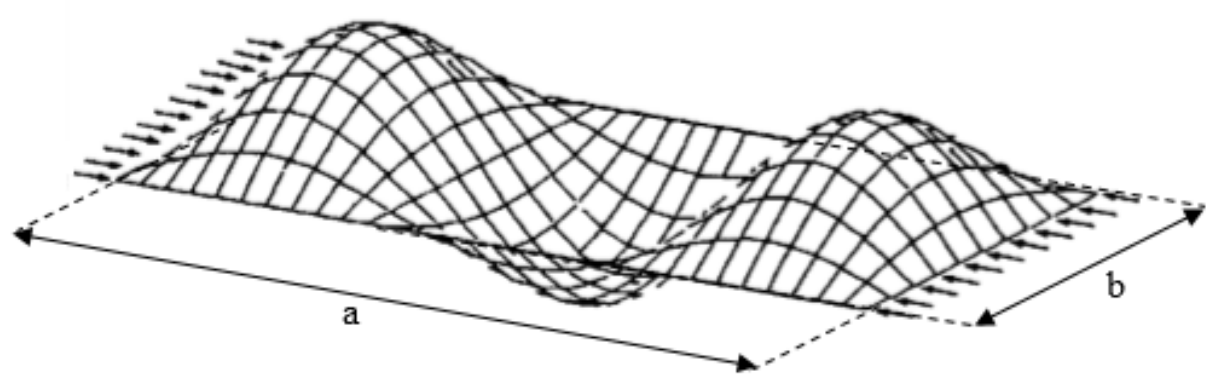

Figure 2.13 - Buckling mode [12].

The parameter $k$ in the Eq. 6 is the buckling coefficient that depends on the boundary conditions, loading distribution and also on the number of half-waves formed along length. As shown in Figure 2.14 for a plate with different boundary conditions, there is a critical half-wave length for which $\mathrm{k}$ reduces to a minimum, the critical buckling coefficient $\mathrm{k}_{\mathrm{cr}}$. Figure 2.15 shows transverse deflections and the values of $k_{\mathrm{cr}}$ for different boundary conditions, for a rectangular plate subject to uniform compression.

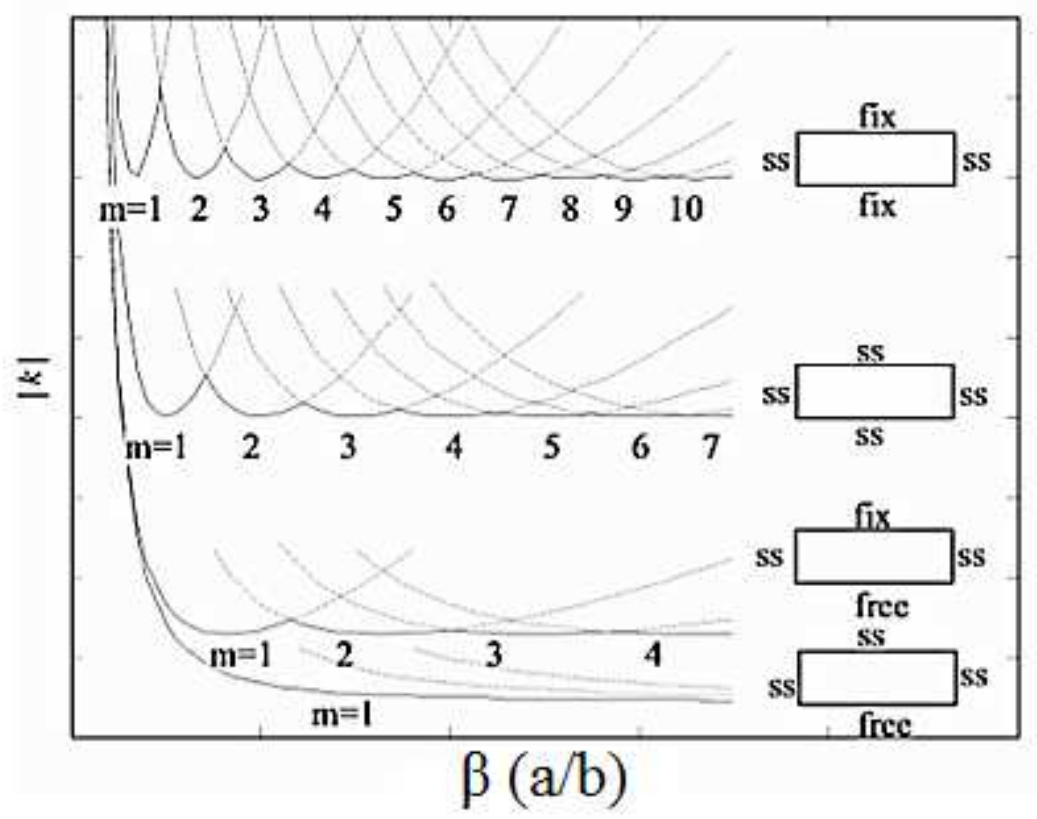

Figure 2.14- Plate buckling coefficient, $\mathrm{k}$, for different boundary conditions, $\mathrm{m}=$ number of buckled half-waves along the length of the plate [12]. 


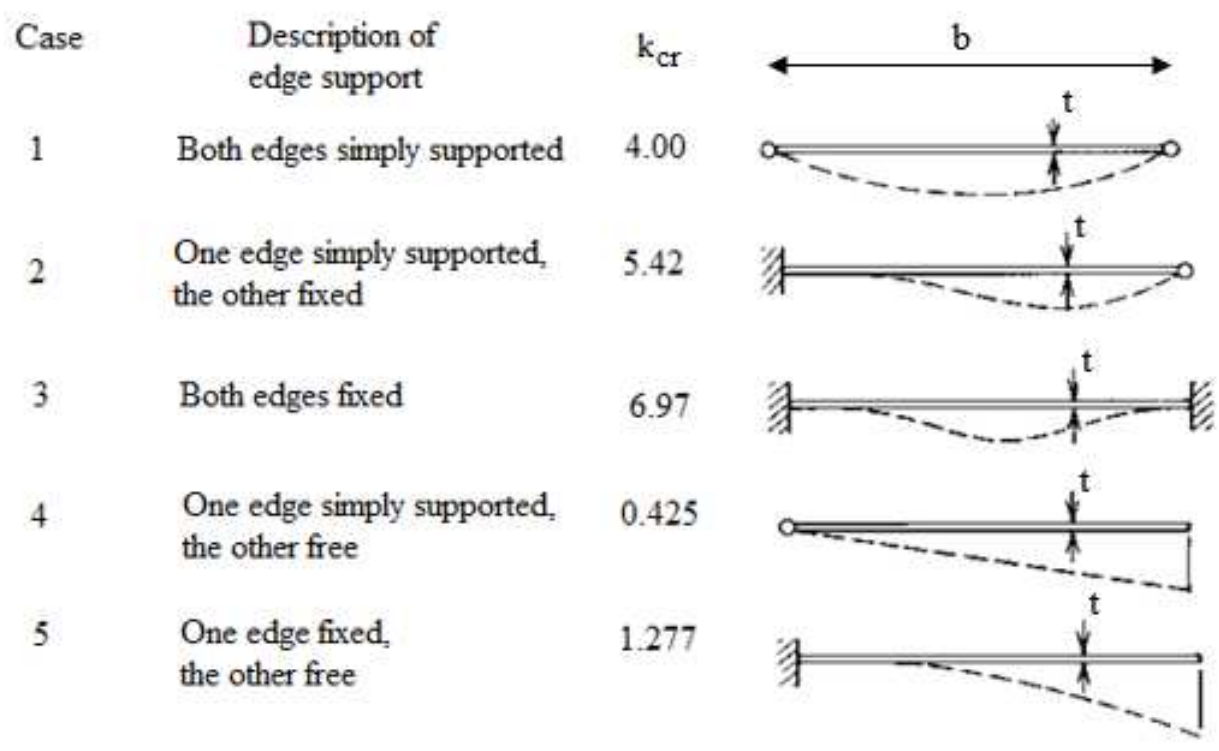

Figure 2.15 - Values of critical buckling coefficient kcr for different boundary conditions [12].

For load cases different from pure compression, there are other values for k. For more specific conditions, such as those that involve shear, one can consult [12].

\subsubsection{Energy equations for plate buckling}

Energy methods are very useful to investigate the stability. The potential energy expression for an elastic plate can be used to obtain expressions that represent its instability behavior.

If the plate is subjected to an out-of-plane displacement function $w(x, y)$, its strain energy takes a common form and is represented by the sum of the internal energies as given by Eq. 7:

$$
U=h \cdot \iint \frac{1}{2} \cdot\left(\sigma_{x x} \cdot \varepsilon_{x x}+\sigma_{y y} \cdot \varepsilon_{y y}+\tau_{x y} \cdot \gamma_{x y}\right) d x d y
$$


Where $\sigma_{x x}, \sigma_{y y}$ and $\sigma_{x y}$ represents the stresses on the plate due to the inplane forces $N_{x x}, N_{y y} e N_{x y}\left(N_{x x}=h \cdot \sigma_{\max , x x}, N_{y y}=h \cdot \sigma_{\max , y y}\right.$ and $N_{x x}=h$. $\left.\sigma_{\max , x y}\right) . \varepsilon_{x x}, \varepsilon_{y y} e \varepsilon_{x y}$ represent the finite in-plane strains of the plate.

Considering now only bending energy, the strain energy accumulated in an element is obtained by calculating the work done by the moment on the element's the in-plane rotation during bending [14]. The approximate curvature can be represented as $-\mathrm{d}^{2} \mathrm{w} / \mathrm{dx}^{2}$ and the strain energy can be expressed as:

$$
U=\frac{D}{2} \iint\left[\left(\frac{d^{2} w}{d x^{2}}\right)^{2}+\left(\frac{d^{2} w}{d y^{2}}\right)^{2}+2 v \frac{d^{2} w}{d x d y}\right] d x d y
$$

The potential energy of an uniformly distributed load due to the transverse displacement can be expressed as follows:

$$
W=\iint q \cdot w d x d y
$$

Where $\mathrm{W}$ is the potential of the externally applied load and $\mathrm{q}$ is the unit load applied.

\subsubsection{Plate assembly buckling (local buckling)}

The steel structural sections employed in practice are comprised of plate elements arranged in a variety of configurations. The local buckling behavior of structural members of this kind is governed by interaction between the plate components, assuming that rigid plate connections remain rigid after buckling.

Local instability is a phenomenon very common in these structures, due to the fact that these elements have relatively thin walls with respect to cross-section sizes. Local buckling involves out-of-plane deformations of the component plates with the junctions remaining essentially straight, thus exhibiting a loss of crosssectional shape.

The derivation of the exact solution for the local buckling of plate assemblies is extremely cumbersome due to the complexity involved in considering the interaction between connected plates. For practical purposes, this interaction is not taken into account in design standards and guidelines, often leading usually to very conservative estimates of the critical stress. 
Although many different approaches exist, these can be classified in three different groups [15] : i) discrete plates with edges simply supported at junctions, neglecting the rotational restraint provided by contiguous elements; ii) discrete plates with rotational springs at junctions; iii) full-section approach, considering the section as a whole, with compatibility of rotation between adjacent walls. In the next paragraphs, a brief literature review concerning analytical studies on local buckling of plate assemblies within each approach is presented.

\subsubsection{Discrete plate analysis assuming simplified support edge conditions}

In this kind of analysis, each plate of an assembly is considered as an independent element, without any rotational restraint provided by adjacent walls. Therefore, a simply supported condition is assumed, in which plate elements intersect each other. Finally, the critical stresses for each constituent plate can be obtained from Eq. 6, using critical buckling coefficients presented in Figure 2.15.

For instance, in a T-section subject to uniform compression, each half of the flange is assumed as a long plate under in-plane compression with one of the longitudinal edges restrained and the other free. The web is also considered as a long plate with similar edge conditions. Figure 2.16 illustrates this example. This approach leads to the usual local buckling classification in flange or web buckling, although their motions are not independent.

Most standards, such as the AISC [16] and the ABNT specifications [17], use this method of analysis to design steel members. Although this results in practical and simple equations, it is found to be excessively conservative and may be improved for more accurate results. 


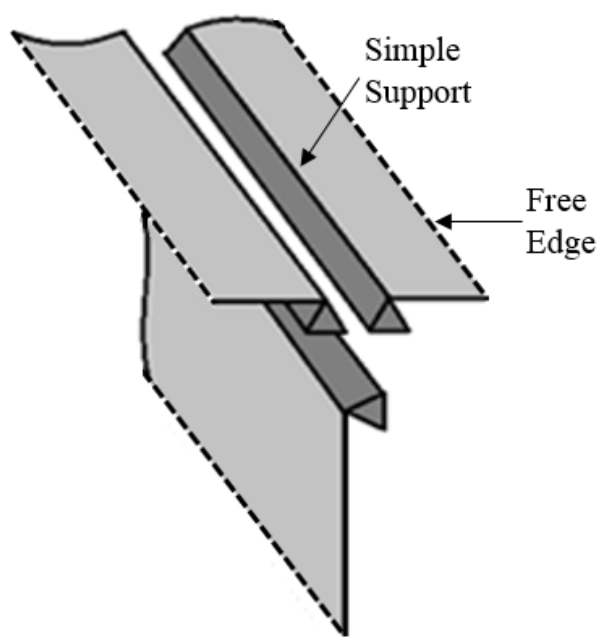

Figure 2.16 - Representation of the method: Discrete plate analysis assuming simplified support edge conditions

\subsubsection{Discrete plate analysis assuming rotational restraint between adjacent plates}

In this method, each plate element comprising cross section is still analyzed individually, but rotational springs are assumed along wall junctions, simulating the restraint provided by adjacent walls. However, this method does not guarantee rotation compatibility between adjacent plates. Considering again the case of a Tsection, each half flange is considered as a plate with one longitudinal edge free and the other elastically restrained by the web, as shown in Figure 2.17.

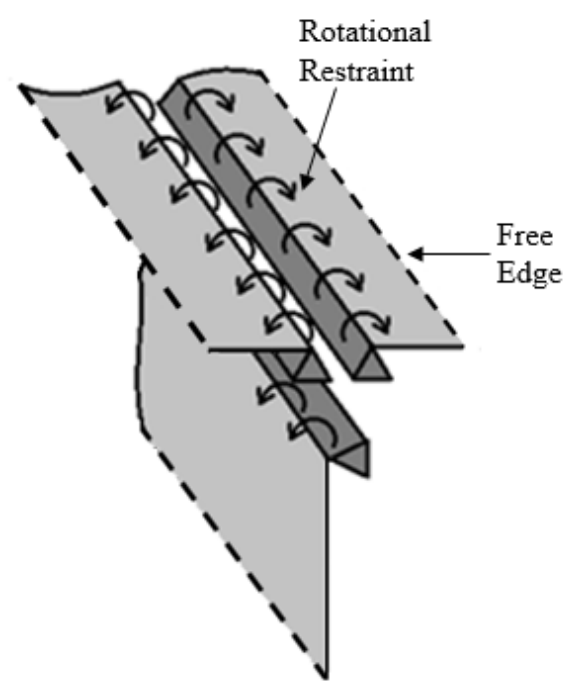

Figure 2.17 - Representation of the method: Discrete plate analysis assuming rotational restraint between adjacent plates 
This approach was first proposed by Bleich [18], who introduced formulae to determine the coefficient of restraint and obtained a transcendental equation as a solution for the problem. Bleich emphasizes that, even in case of thin and narrow flanges within the conventional range in steel construction, the restraining effect of the flange is significant.

Bleich's analysis considers proportionality between the edge moment $\mathrm{My}$ and the angle of rotation $\theta$. It was stated that the factor of proportionality depends on the dimensions of the restraining structure and also on the compressive stresses acting on the supporting structural elements. Finally, Bleich showed that the plate buckling reduces to Eq. 16, with buckling coefficient as a function of the coefficient of restraint.

In the limit case when constituent plates buckle simultaneously (same critical stress), there is no restraining effect and each element behaves as a plate having simply supported unloaded edges. The exact solution of this problem is feasible by considering the stability of entire plate assembly.

Timoshenko and Gere [14] obtained $\mathrm{K}_{\mathrm{cr}}$ values for a member having Tee cross section and subject to uniform compression after solving transcendental equations for the web. The rigidity of the flange was assumed constant regardless the load value and was represented by a rotational spring, due to the fact that the upper edge cannot be assumed to rotate freely during buckling, neither can be considered rigidly. So, the side $y=0$ was considered elastically built in while $y=b$ was assumed free (Figure 2.18).

Gerard and Becker [19] presented a rather comprehensive review relating to buckling and failure of plate elements. They provided abacus for plates with rotational restraint. Figure 2.19 is a summary chart, for various limiting conditions of edge and rotational restraint, depicting the variation of $\mathrm{K}_{\mathrm{cr}}$ as a function of plates length $(\mathrm{a} / \mathrm{b})$. 


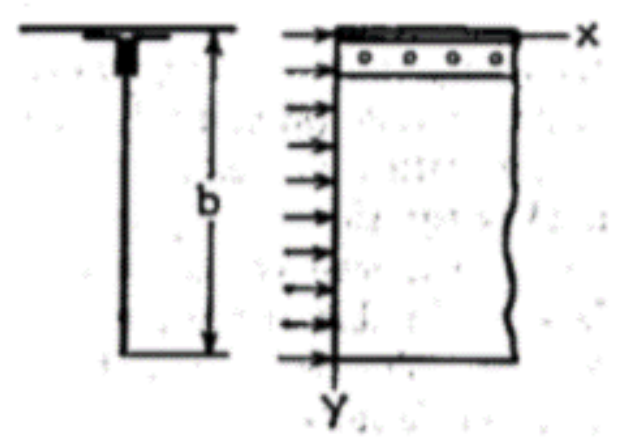

Figure 2.18 - Tee section [14]

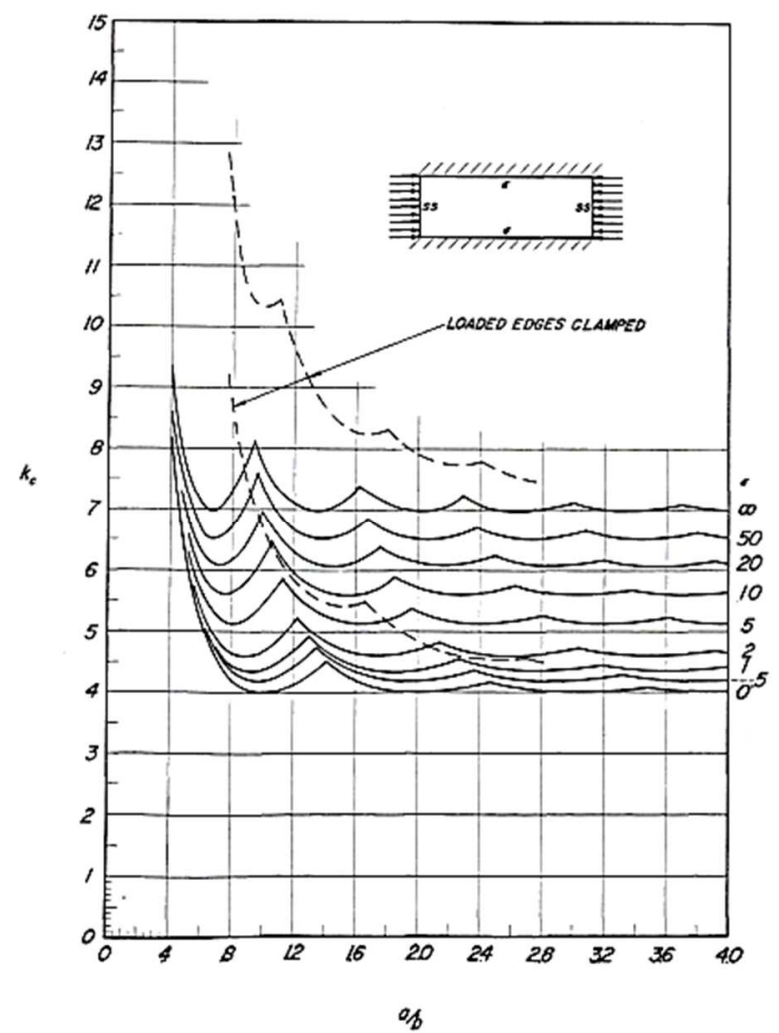

Figure 2.19 - Compressive-buckling coefficients for flat rectangular plates for various amounts of edge rotational restraint[19].

\subsubsection{Full section analysis}

This method consists in analyzing the section as a whole, hence taking into account the full interaction between flange and web, as presented in Figure 2.20. The main difference between this approach and the previously described is the ensured compatibility of rotation between adjacent walls. 


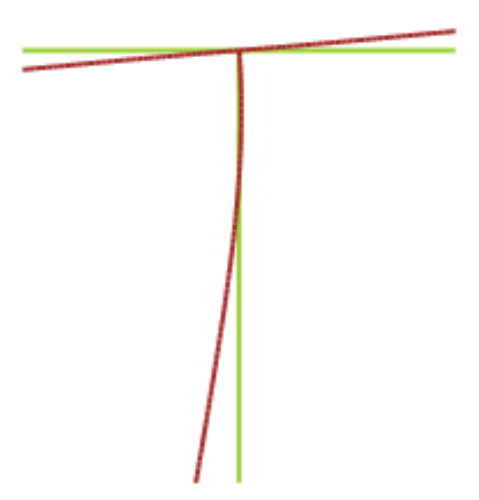

Figure 2.20 - Representation of full section analysis

In 1939, Stowell and Lundquist [20] used Timoshenko energy method to obtain curves for the critical buckling coefficient of several plate assemblies and accounting for inelastic behavior. The deflected shapes presented in Eqs. 10 and 11 were assumed in order to obtain kcr for each cross section analyzed.

$$
\begin{gathered}
w=\left[4 A \cdot \frac{y}{b}\left(1-\frac{y}{b}\right)+B \cdot \sin \left(\frac{\pi y}{b}\right)\right] \cdot \sin \left(\frac{n \pi x}{L}\right) \\
w=\left\{C \cdot \frac{y}{b}-\frac{D}{3.889}\left[\left(\frac{y}{b}\right)^{5}-4.963 \cdot\left(\frac{y}{b}\right)^{4}+9.852 \cdot\left(\frac{y}{b}\right)^{3}-9.778 \cdot\left(\frac{y}{b}\right)^{2}\right]\right\} \cdot \sin \left(\frac{n \pi x}{L}\right)
\end{gathered}
$$

Eq. 10 was applied to plates restrained along both edges, as the web of a channel or as the sides of the rectangular tube. Eq. 11 applies for plates restrained along only one edge, as one flange of the channel profile or the half-flange of the Isection. In both equations $\mathrm{A}, \mathrm{B}, \mathrm{C}$ and $\mathrm{D}$ represent the arbitrary deflection amplitudes, $\mathrm{y}$ is vertical direction coordinate, $\mathrm{x}$ is the coordinate on longitudinal direction, $b$ is the width of the member, $n$ is number of half-waves in length $L$.

For the channel, $\mathrm{Z}$ and I profiles the arbitrary deflection amplitudes (A, B, $\mathrm{C}$ and D) can be related through rotation compatibility condition (the corner angles are maintained during buckling) and that the moments at each corner were in equilibrium. The other variables were adjusted to obtain the minimum critical stress.

Nonetheless, the authors did not derive explicit equations and the critical buckling coefficients are presented in charts. Figure 2.21 give the computed value 
of $\mathrm{k}_{\mathrm{cr}}$ coefficient plotted by different values of $\frac{t_{w}}{t_{f}}$. When the webs are narrow in comparison with the flanges, the instability occurs first in the flange. As the web width increases, a point is reached where the webs became the weaker part of the cross section, governing the behavior.

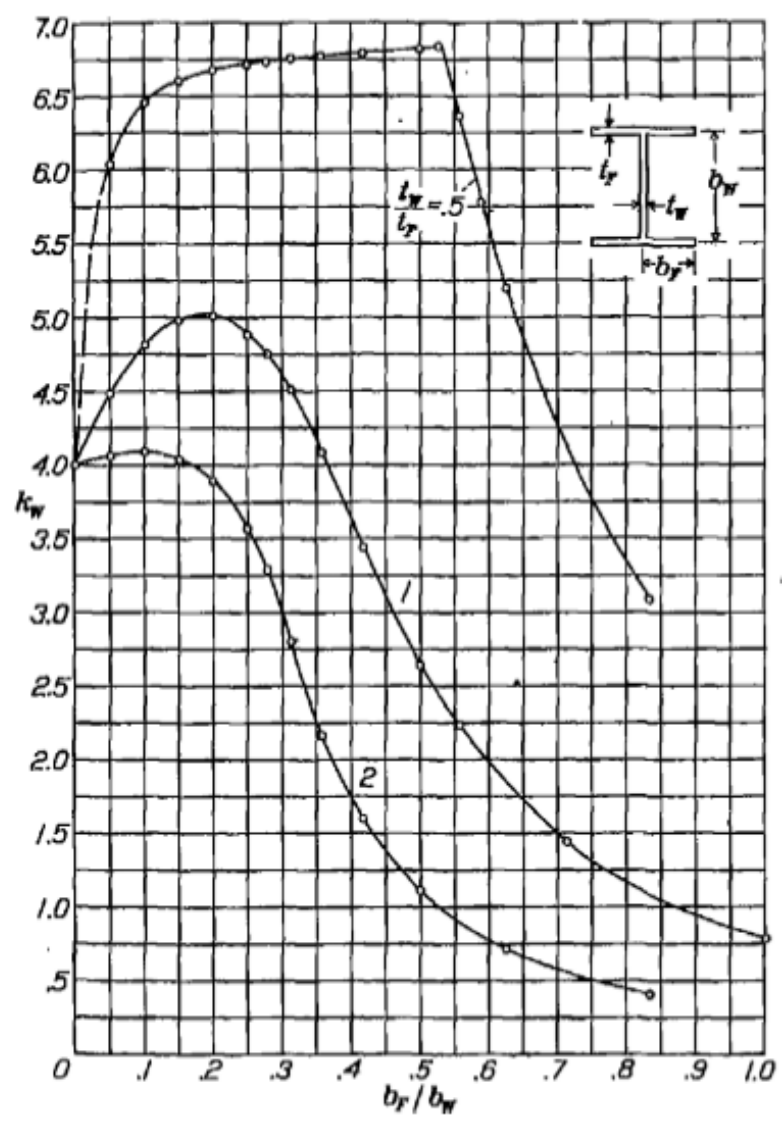

Figure 2.21 - Minimum value of K for centrally loaded columns of I-section [20]

In order to complement the search presented by Stowell and Lundquist, Kroll[21] presented a similar study for rectangular tubes, I-, Z-, and U-sections. Kroll used the principle of moment distribution (Cross method) to obtain charts for the critical local buckling coefficients. In this method, described in details by Lundquist [22] a fictitious unit moment per unit of length are applied at plate intersections and distributed among the plates according to their relative stiffness. According to Kroll [16], this method provided more accurate results than the energy approach. Japanese Handbook of Structural Stability (CRCJ, 1971) [23] include this methodology. 
Cardoso et al. [24] developed a comprehensive study of typical pultruded fiber reinforced polymer sections. The Rayleigh energy method was used to determine local buckling critical loads and approximate deflected-shape functions were chosen taking into account the compatibility of rotation between plate elements. Results were compared with numerical analyses with Finite Strip Method [25] and good agreement was achieved. Although the material studied is orthotropic, the authors show that the method also provides excellent results for isotropic material. A similar approach is used in the present work.

Dawe and Kulak [26] developed a computational procedure to study the local buckling of I-sections.a similar study. Based on an energetic formulation for plates, the method allows determining critical stresses considering the interaction between web and flange, residual stresses and inelastic material behavior. The results were compared with computational and experimental analyzes, with good agreement being achieved.

Finite Strip Method, Generalized Beam Theory and Finite Element Method are some of the existing numerical methods available that allow full section analyzes. There are several programs that perform finite element analysis, including full element interaction, such as: Robot Structural Analysis Professional, ABAQUS [4] (FEM), Ansys [27] (FEM), CUFSM [28] (finite stripes), GBTUL [5] (GBT), etc.

GBTUL (GBT) and ABAQUS (FEM), described in chapter 3, were used to implement this work.

\subsubsection{Local buckling of plates with holes and castellated beams}

Moen and Schafer [29] conducted a study where finite element analysis was employed to investigate the influence of hole size and spacing on the buckling behavior of thin walled plates. Based on the results, the authors were able to propose simple equations to determine the critical stress, $\mathrm{f}_{\mathrm{cr}}$, depending upon the range of hole geometry compared with the plate geometry, either in pure in-plane compression or bending. 
In the aforementioned work, the authors also observed two possible modes: i) local buckling of the unstiffened strip above the hole (Figure 2.22a); or ii) plate buckling of the region far from the hole (Figure 2.22b). Considering larger holes the critical buckling occurs on the full section of the plate. When hole width is small relative to plate width, buckling is concentrated at the strip up the hole.

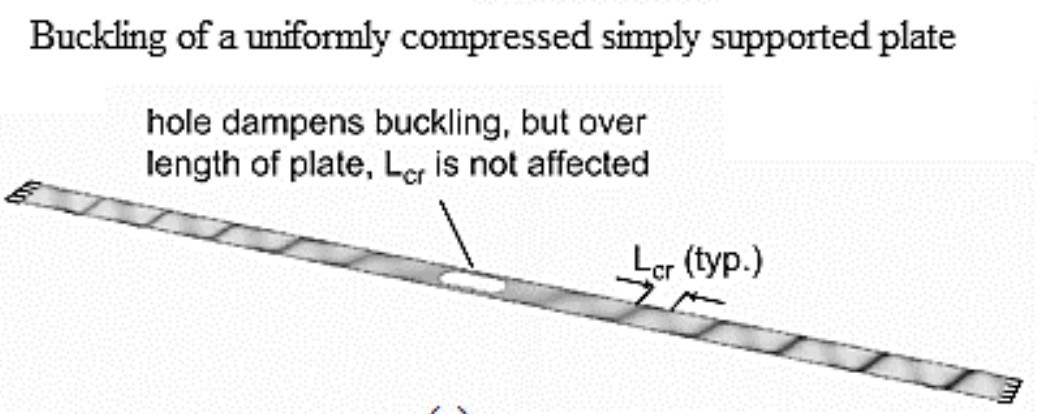

(a)

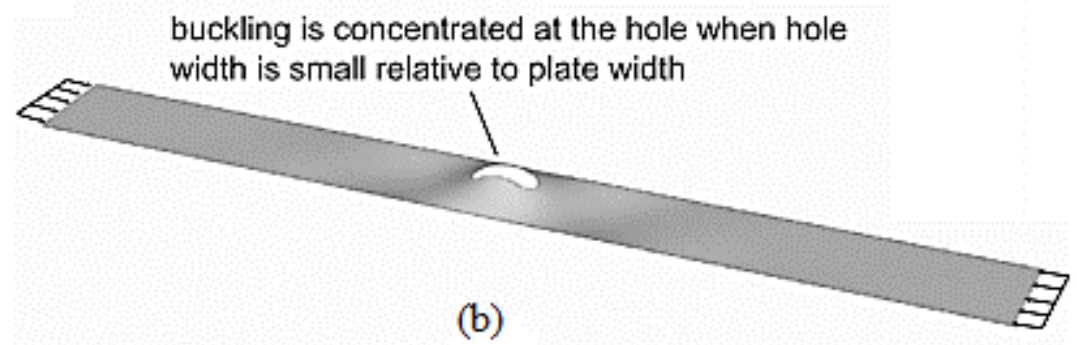

Figure 2.22 - Plate buckling- Moen and Schafer [29]

El Sawy and Nazmy [30] conducted similar studies on the stability of plates with holes, where FEM was used to examine the elastic buckling coefficient of simply supported rectangular perforated plates uniaxially compressed along its longitudinal direction. On their study, the authors measured the influence of the hole position, geometry and size on the element behavior, as well as the aspect ratio. They concluded about the best practices on positioning circular and rectangular with curved corners holes, and verified the coefficient $\mathrm{k}$ of a rectangular plate with an integer aspect ratio (where the element can be divided into a number of square panels) can be taken, conservatively, as the same coefficient of a perforated square plate with the same dimension of the panel, as exemplified in Figure 2.23.

Kang and Leissa [31], Komur and Sonmez [32] and Maiorana [33] developed the elastic buckling of rectangular plates field of study, under any in- 
plane stress field (bending and compression). The effect of bending moment on the stability of the plate was studied and it was informed some practical indications on the best position of the circular hole and the best position and orientation of rectangular holes in steel plates.

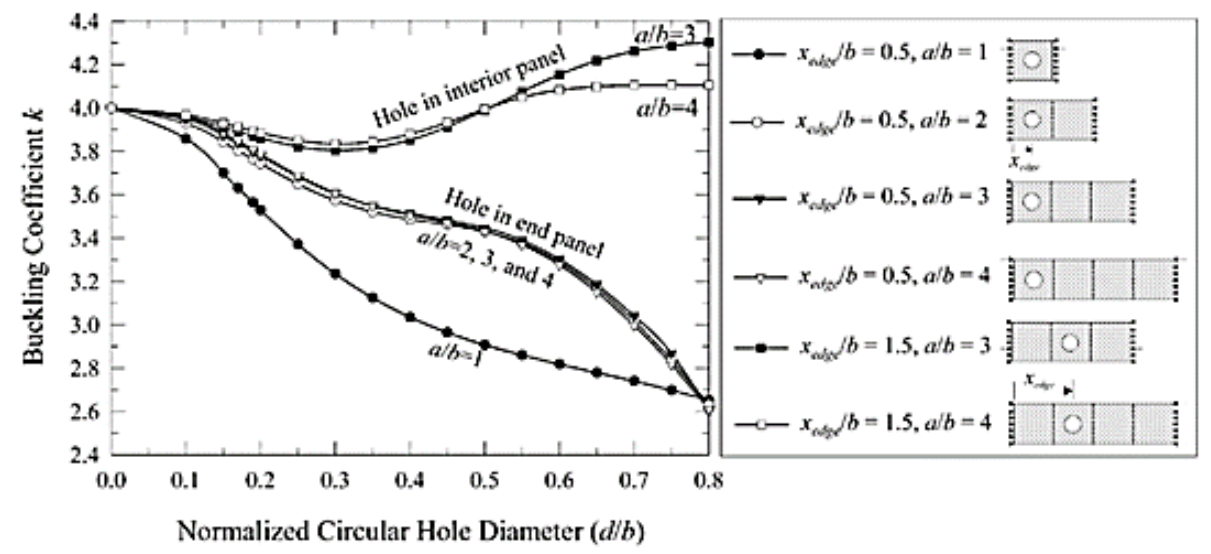

Figure 2.23 - Buckling coefficient $\mathrm{k}$ when the center of the circular hole lies on the plate majos axis and at cross line of maximum amplitude; El Sawy e Nazmy [30].

As castellated beams have particular modes of failure, different of those founded in solid-web members or members with web openings, additional verifications have to be done. On a pure bending state, the tee compression buckling and the web buckling between holes must be verified. More general load cases require even more verifications. Studies on these topics were carried out by Hosain et. al [34], where the deflection of the beam was analyzed with use of the FEM, by modelling a 2D typical element of the beam, as indicated below (Figure 2.24).

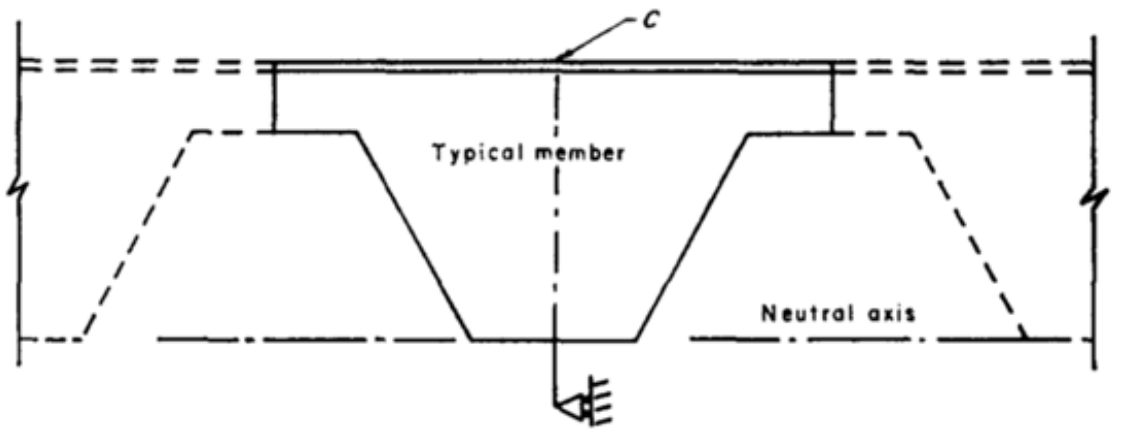

Figure 2.24 - Half beam idealization- Hosain, Cheng and Neis [34] 
Yuan et al. [35] studied the deflection of castellated beams subjected to uniformly transverse loading, making use of the principle of minimum potential energy. They proposed an equation for the beam deflection making based on an analytical model. The results were validated with FEM, showing good agreement.

Many other studies have been developed on the subject, assessing the behavior of castellated beams under several conditions of load and support. Parametric studies allowed to investigate a great number of geometries, encompassing a significant number of practical applications. Using analytical, experimental and numerical methods, extensive research has been carried out on this castellated beams, involving:

- Shear effect of web openings on the dynamic characteristics (Chen[36] and $\mathrm{Gu}[37])$.

- Lateral-torsional buckling analysis (Kerdal and Nethercot[38], Mohebkhah[39]).

- Axially loaded buckling analysis (El-Sawy[40]; Yuan[41]).

- Design of castellated and cellular beams (Knowles[7], Mohebkhah[42]).

- Distortional buckling analysis of castellated beams (Zirakian[43], Ellobody[44]).

- Elasto-plastic bending analysis (Sherbourne et al. [45], Gandomi et al. [46], Soltani et al [47], Erdal et al. [48], Wang et al. [49] ).

\subsection{Finite Element Method (FEM)}

Finite element analysis is a method for numerical solution of field problems, which are determined by a spatial distribution of one or more dependent variables. Mathematically, a field problem is described by differential equations or by an integral expression; FEM formulations can be based on both. In structural mechanics, the displacement-based finite element method is based on integral equations and the dependent variables are displacements and rotations.

FEM's formulation is a process of idealization and discretization, producing a discrete model for analysis. Through a breakdown of the domain into elements, a 
complex structure can become a simple structure. The basic concept in the physical interpretation is the disassemble (partition) of a complex mechanical system into simpler one.

The structure is divided into many smaller parts. The elements are connected by nodes and have independent formulations. Numerically, in displacement-based FEM the problem is represented by a system of algebraic equations, created from functions that simulate the shape of element deflection, called shape functions. The shape function is approximated locally over each element by an interpolation formula.

The number of degrees of freedom per node in an element determines the accuracy of the method's response. These degrees of freedom are represented by the number of independent displacements/rotations that the nodes can experience. As the number of DOF increases, the approximations tends to be closer to the correct results. However, the higher the number of DOF the more computationally expensive the calculations become.

Therefore, a convergence is necessary to optimize mesh partition. This study consists of finding the mesh size that expresses the desired results with enough precision and also with the least computational effort possible.

\subsubsection{FEM model}

To develop a reliable FE model, it is necessary first to represent the real problem by a representative physical model. This idealization of the structure must faithfully represent the geometry and the physical characteristics of the materials.

In the pre-processing, all the characteristics of the structure are defined, such as geometry, properties of the constituent material, imperfections, type of analysis to be executed and generation of the finite element mesh. Then, boundary conditions, loadings and prescribed displacements, if exists, are applied.

Once all the previous steps are complete, the analysis is carried out. The next phase is the post-processing. In this stage, all the results generated can be visualized, interpreted and analyzed. 
It is important to point out that due to the complexity of the structural problems, adequate modeling is essential. Considerations such as the type and quantity of the elements employed as well as the choice of adequate type of analysis are fundamental to obtain reliable solutions.

In the present work, shell elements were adopted and elastic buckling analysis was employed to obtain displacement vectors, deformed configuration of the elastic buckling mode, as well as the elastic critical loads. The critical stresses were obtained based on the eigenvalues and eigenvectors analysis.

\subsubsection{Types of elements}

When talking about linear (bar) elements, the concept of finite element is of simple comprehension. The only variable existing for the finite discretization is the length of the element. Therefore, for more complex geometries, where elements such as plates and shells are employed, other considerations are necessary.

One must pay attention on the shape of the elements as well as how they are connected to each other. There are several types of two-dimensional elements, but here only two of them will be emphasized. They are the linear strain triangle and the eight-node quadrilateral element.

The isoparametric formulation enables the simulation of problems with generic geometries. It is based in a coordinate transformation from the Cartesian $(x-y)$ to the Natural $(\xi-\eta)$ coordinate system. In the Natural coordinate system the element assumes a simple shape, i.e., generic quadrilateral elements become square in shape for example. The same transformation is applied to the element's coordinates and the elements displacements. The resulting isoparametric element has always a simple shape, centered at the origin of isoparametric coordinates, and with equal internal angles $\left(90^{\circ}\right.$ for quadrilaterals and $60^{\circ}$ for triangles). Figure 2.25 illustrates this transformation. 


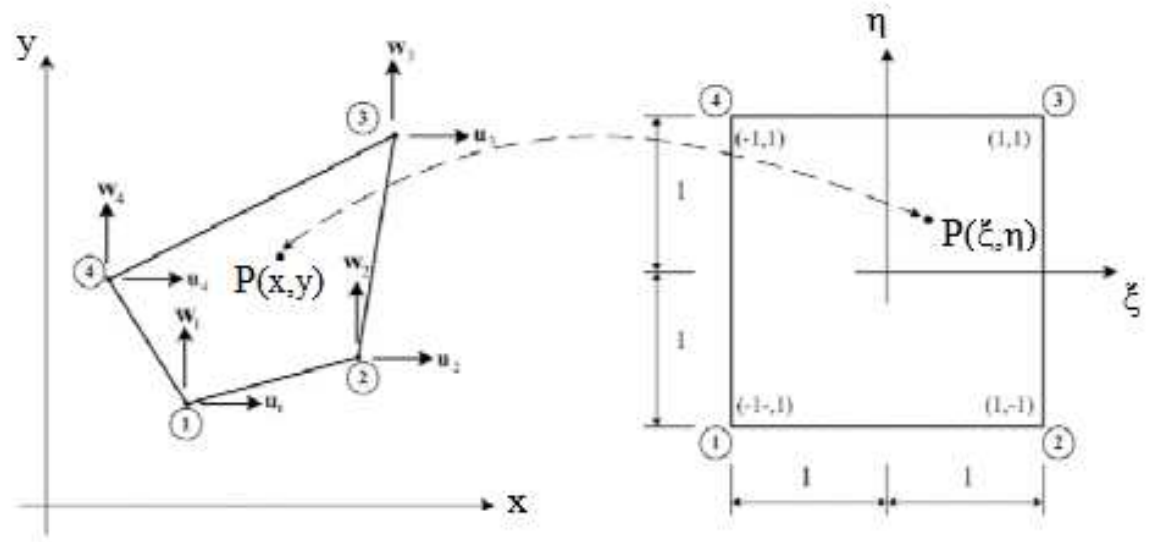

Figure 2.25 - Transformation of arbitrary system of coordinates into parametric space.

Numerical errors gradually increase with element distortion. High aspect ratio (the ratio between the largest length and the shortest length) should be avoided and the angles of the corners should be as similar to each other as possible.

Among the plane elements, the four-node quadrilateral are frequently used. However, these elements are tend to be very rigid when attempting to represent bending problems. This is due to the fact that in these cases, the moment is resisted by a false shear. Therefore, there is greater resistance to deformation. This effect decreases as the mesh is refined. Eight-node quadrilateral elements do not have this problem and that is why they are employed in this work.

Triangular shaped element's are very efficient in mesh refinement and are often used in areas with more complex geometries, such as areas with holes, as shown in Figure 2.26. In the present work, linear strain triangular elements (with six nodes) were used in the neighborhood surrounding the areas where holes are present. 


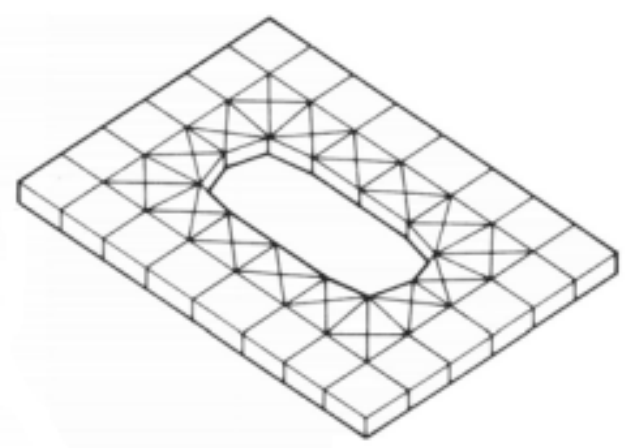

Figure 2.26 - Example of mesh with triangular elements.

\subsubsection{Constraints}

A constraint imposes a relation between degrees of freedom. Through this artifice, it is possible to prescribe the value of a DOF or a relation between DOF's.

Constraint at multiple points simulates a rigid connection and allows rigid body movement between the selected DOF's. The most common methods for applying these constraints are the Master-slave method, Lagrange multipliers, and Penalty function method.

In the present work, constraints were used to help simulate pure bending boundary conditions and guaranteeing the plane sections remained plane after loading. This is discussed in more detail in Chapter 3.

\subsubsection{Numerical integration}

In the implementation of the FEM, the stiffness matrix is obtained using numerical integration. Typically, Gauss quadrature is used because with minimal number of sample points it achieves a desired level of accuracy.

A numerical integration with an number of sampling points smaller than that needed to integrate exactly the stiffness matrix of the element is termed as "Reduced integration". This type of integration is very useful since it uses a smaller number of Gaussian points, resulting in computational economy.

Moreover, this integration disregards the higher order polynomial terms, causing less resistance to deformation. In other words, reduced integration tends to 
make the element more flexible, since some deformation modes offer less resistance by having a smaller number of sampling points. In this way, a more flexible and efficient element is obtained, since displacement-based FEM often produces stiffer responses.

\subsubsection{FEM Convergence requirements}

Moen[29] performed a mesh convergence study for plates with holes, and concluded that the aspect ratio $(\mathrm{a} / \mathrm{b})$ of quadrilateral with eight nodes, should be between 0.5 and 2. The relation was based on ABAQUS recommendations, where the angles between isoparametric lines should be not less than $45^{\circ}$ or greater than $135^{\circ}$ (Figure 2.27), in order to guarantee the accuracy of the numerical integration of the stiffness matrix. These values prevent a high aspect ratio, avoiding large distortions in the element, which could harm the obtained results.

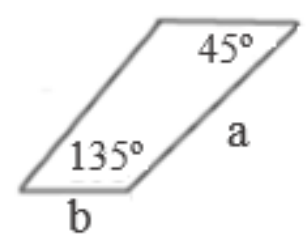

Figure 2.27- Aspect ratio $(\mathrm{a} / \mathrm{b})$

The accuracy of analysis is influenced by decisions taken while implementing the finite element model. Some requirements are necessary to instill confidence in FEM results[50], as:

- Completeness:

Conditions between discrete and mathematical model. The elements must have enough approximation power to capture the analytical solution in the limit of a mesh refinement process.

- Compatibility:

The shape functions should provide displacement continuity between elements. Physically these ensure that no material gaps appear as the elements deform.

- $\quad$ Stability 


\section{3}

\section{Numerical simulation methods}

Numerical Calculus is a collection of numerical methods. It consists of a powerful tool to assist in obtaining numerical solutions, generally approximated, of several problems. The development and application of these methods are linked to computational use.

Numerical modeling is a useful tool for the design and assessment of structures. Commercial finite element software's can be used to capture the realistic behavior of the structure. However, to accomplish this, care must be taken to precisely represent the problem being solved, so that it produces reliable results.

This chapter describes the preliminary studies carried out using the GBTUL software, that performs elastic buckling (bifurcation) and vibration analyses of prismatic thin-walled members. This software can only analyze full-section members. In this work, it was used to analyze the simplifying hypothesis, where the castellated structure was represented as an upper tee section.

This chapter also describes the finite element models developed in this research. Three-dimensional models based on thin shell finite element formulations were used to simulate the response of a castellated beam subjected to pure bending. Python programming language was used in order to expedite the process of performing multiple simulations and parametric studies.

The results obtained in the preliminary studies were used towards the development and validation of the proposed design equation, which is presented in Chapter 4. 


\subsection{GBTUL}

The GBTUL software was developed at the Department of Civil Engineering and Architecture of the Technical University of Lisbon. The program is a numerical implementation of the Generalized Beam Theory (GBT) formulation to perform elastic buckling and vibration analysis of prismatic thin walled members. Bebiano[51] provides a brief overview of the Generalized Beam Theory formulation and of GBTUL's graphic user interface.

GBTUL incorporates local deformation and discretizes a deformed member configuration into a linear combination of cross-section deformation modes with longitudinally varying amplitudes. Therefore, it provides an advantageous representation of the deflection shape, as a combination of structurally meaningful cross-section deformation modes, as a result of its stability analysis.

In addition, to provide information and easy visualization of the member deformation, the program contains a tool that turns possible to select the deformation modes to include in analysis. It also gives the decomposition and identification of the buckling mode (local, distortional, global). Figure 3.1 illustrates how the GBTUL program represents the upper tee buckling modes.

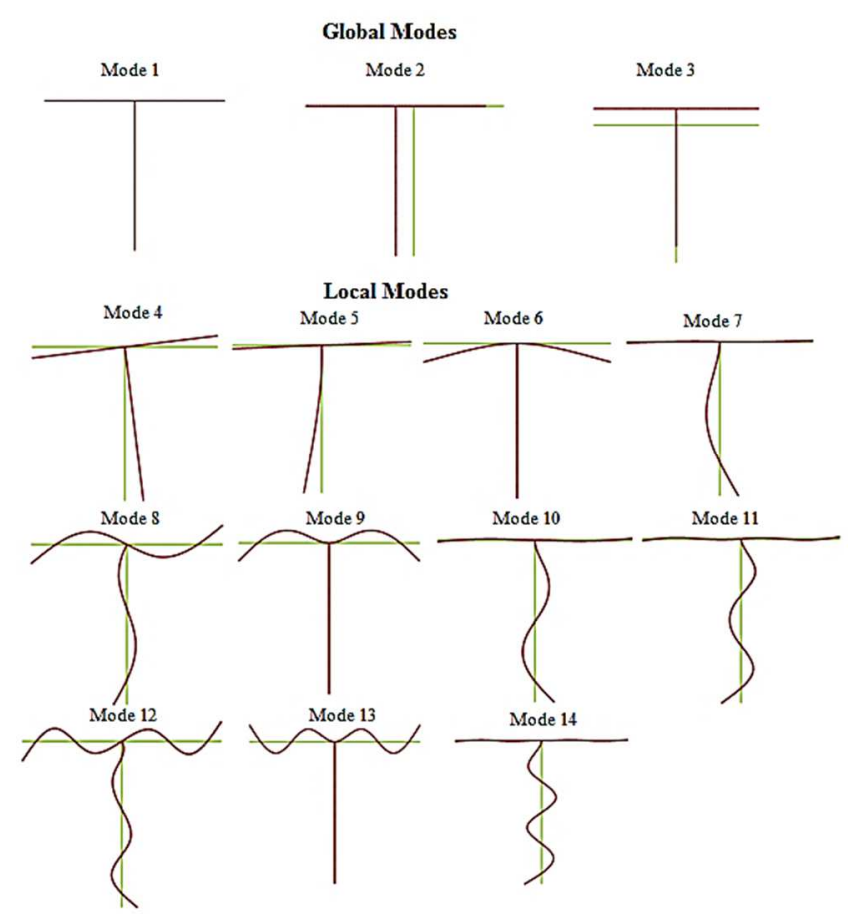

Figure 3.1 -. GBTUL cross-section deformation modes considered for T-section members [5]. 
The features of the code include analysis of several isotropic or orthotropic materials, and exhibiting various common support conditions (simple supports, fixed supports or free ends).

In this study, this tool was very useful. It made it possible to estimate the approximation of the upper tee deflection shape and its respective critical load.

In the buckling analysis, the user is able to specify any combination of axial forces and bending moments at two main directions. As the castellated beam is subjected to pure bending, the case was restrained in the analysis of an upper Tee section submitted to a combination of bending and compression. Figure 3.2 represents the boundary conditions applied in the software, idealizing a simple supported beam subjected to flexural compression.

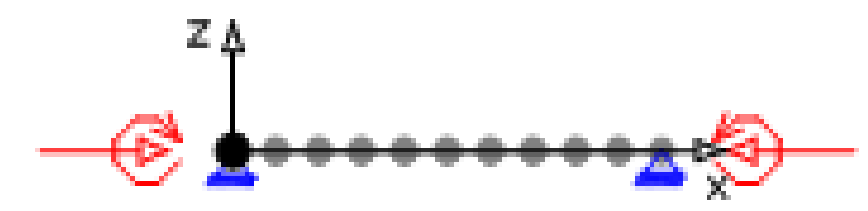

Figure 3.2 - Boundary conditions applied on GBTUL [5].

GBTUL presents the results performed graphically as buckling curve plots, which provide the variation of the buckling load parameter with the member length L, as shown in Figure 3.3. As can be seen in Figure 3.3, it is also informed the modal contribution for each member length. The value of approximately $80 \%$ for torsional mode (mode 4 ) and $20 \%$ for flexural mode (mode 5) was observed. This percentage varies according to different values of flange-to-web thickness ratio.

It also provides a three-dimensional visualization of the deflected. Figure 3.4 shows the deflected shape of an upper tee section. 


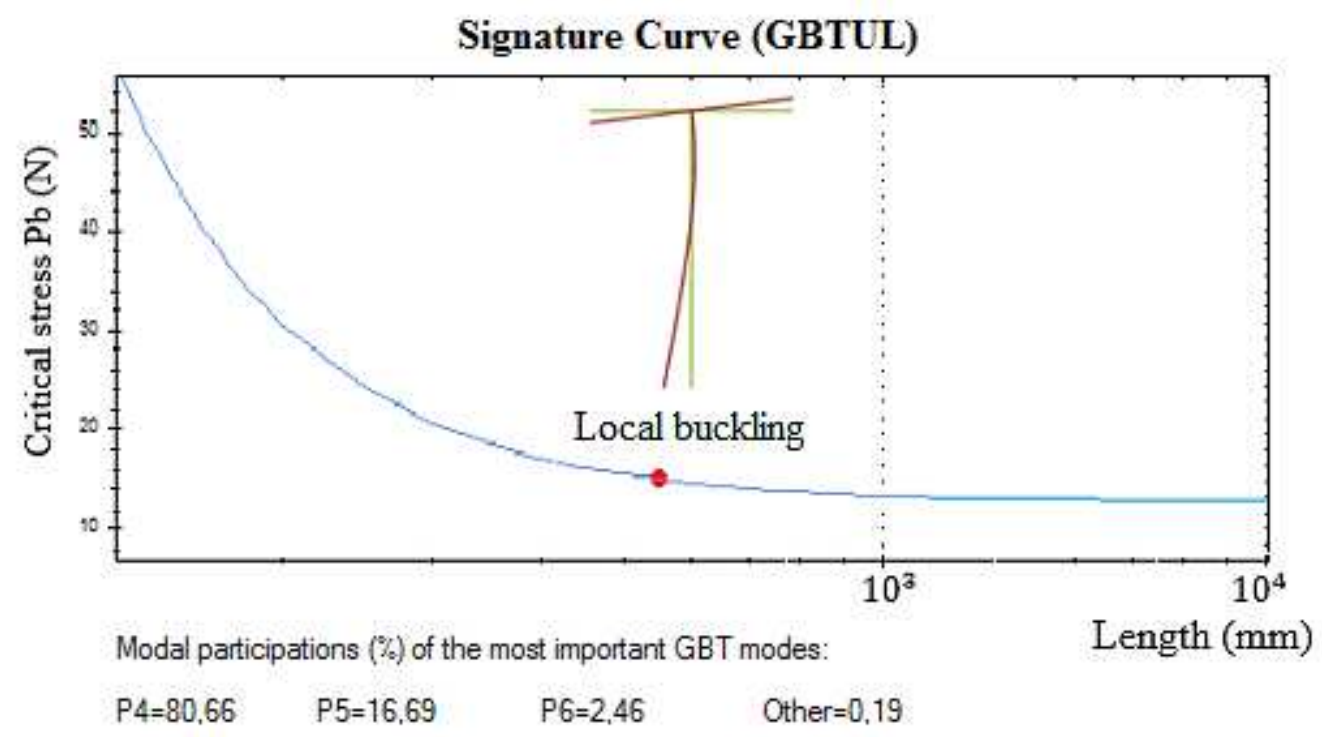

Figure 3.3- Signature curve for T-section members obtained with GBTUL-modes participations for governing local buckling mode [5].

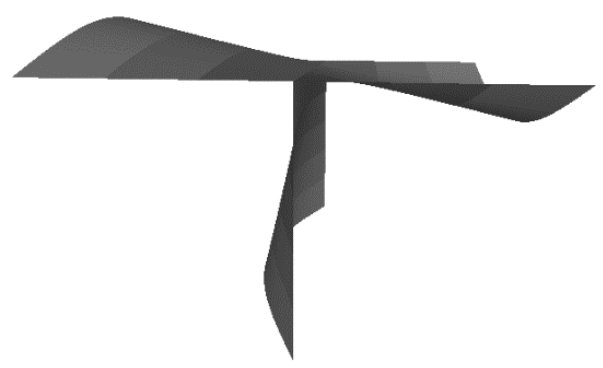

Figure 3.4 - Deflection shape of upper Tee [5].

\subsection{ABAQUS FEM}

This section presents the finite element model developed in this study to investigate the instability of castellated beams using ABAQUS software. The study considered was limited to an elastic buckling analysis of the structure. To expedite the numerous simulations that had to be performed, a pre-processor was developed using the Python programming language. The simulations were used to help formulate the design equation for the critical load of castellated beams subjected to pure bending as it will be seen in Chapter 4 .

Finite element eigen buckling analysis is a valuable tool for studying the elastic buckling properties. The accuracy of the analysis is influenced by decisions made while developing the finite element model, including the choice of element type, mesh refinement and boundary conditions. 
Aiming at validating the finite element models used to capture the local buckling behavior of a castellated beam, two models were developed. The first model considered a beam with a single opening, whereas the second model considered a full castellated beam. Comparison of the results showed that the critical load remained approximately the same for the two cases.

\subsubsection{ABAQUS Scripting Interface - Python}

The ABAQUS Scripting Interface is an extension of the object-oriented language popularly known as Python. This tool has the advantage of automating repetitive processes, allowing the replication of common parts to other models. Therefore, less computational effort is required in the creation of new models. In other words, the scripting interface allows for the creation and modification of parts such as dimensions, materials, loads, meshes, among other components of the models through the parametrization of these variables.

The ABAQUS Scripting Interface has many features. However, unlike ABAQUS Input, Script does not allow customization of elements that are not available in the ABAQUS CAE library, such as the S9R5 element.

Using this tool enables parametric studies to be carried out, since the creation of specific functions allows the replication of several models. Instead of using fixed numbers (i.e., beam dimensions), this tool allows modification shape and size by only changing a small number of constants at the beginning of the Script file. In the present work, it was possible to study a wide range of profiles, through the parameterization of a single model.

\subsubsection{Type of elements}

To perform elastic buckling analysis of thin plates in ABAQUS 6.10-1 [4] the STRI65 and S8R5 elements were used. The first letter of the element number indicates the type of the element. "S" indicates that the element is a shell element, and the last number indicates the number of degrees of freedom. 
The second letter denotes the type of integration. " $\mathrm{R}$ " indicates the use of reduced integration in the analysis, using a reduced number of Gauss integration points to improve computational efficiency and to avoid shear locking.

Thus, STRI65 is a 6-node triangular thin shell element with five degrees of freedom per node. S8R5 is an 8-node doubly curved thin shell, reduced integration, using five degrees of freedom per node. The five degrees of freedom per node correspond to three translational and two rotational displacements. In these elements the drilling degree of freedom is not considered in the ABAQUS shell element formulation.

The chosen elements are based on cubic shape functions for the interpolation of element displacements, allowing for the definition of initial curves in the geometry, even though this was not necessary in the present work.

The triangular element was used around the hole. The element Q8 was used for the rest of the mesh. Both elements exhibit cubic functions to interpolate deformations between nodes.

\subsubsection{Boundary conditions and load application}

The problem being modeled is that of a simply supported castellated beam subjected to pure bending. As mentioned in the previous section the beam itself was modeled using shell elements. Figure 3.5 and Figure 3.6 illustrate the application of the boundary conditions in the model.

To simulate the simply support boundary condition, a simple support was placed at the half height of the web in one end, by restricting the displacement in the y-axis. At the other end, a pin support was placed, also at the half height of the web, by restricting the displacement in the y and z-axes. Simple supports restricting the displacement in the $\mathrm{x}$-axis were also placed at the nodes in the middle of the upper and lower flanges (Figure 3.5) to ensure that only in plane buckling would occur. 


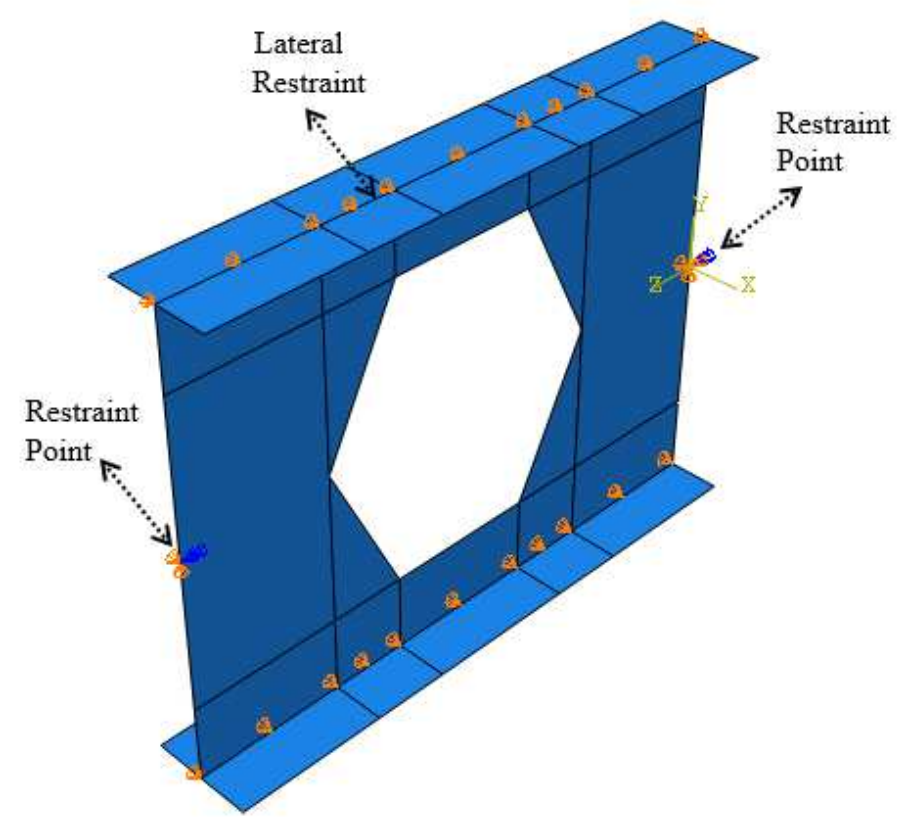

Figure 3.5 - ABAQUS model - lateral restraint of single hole beam.

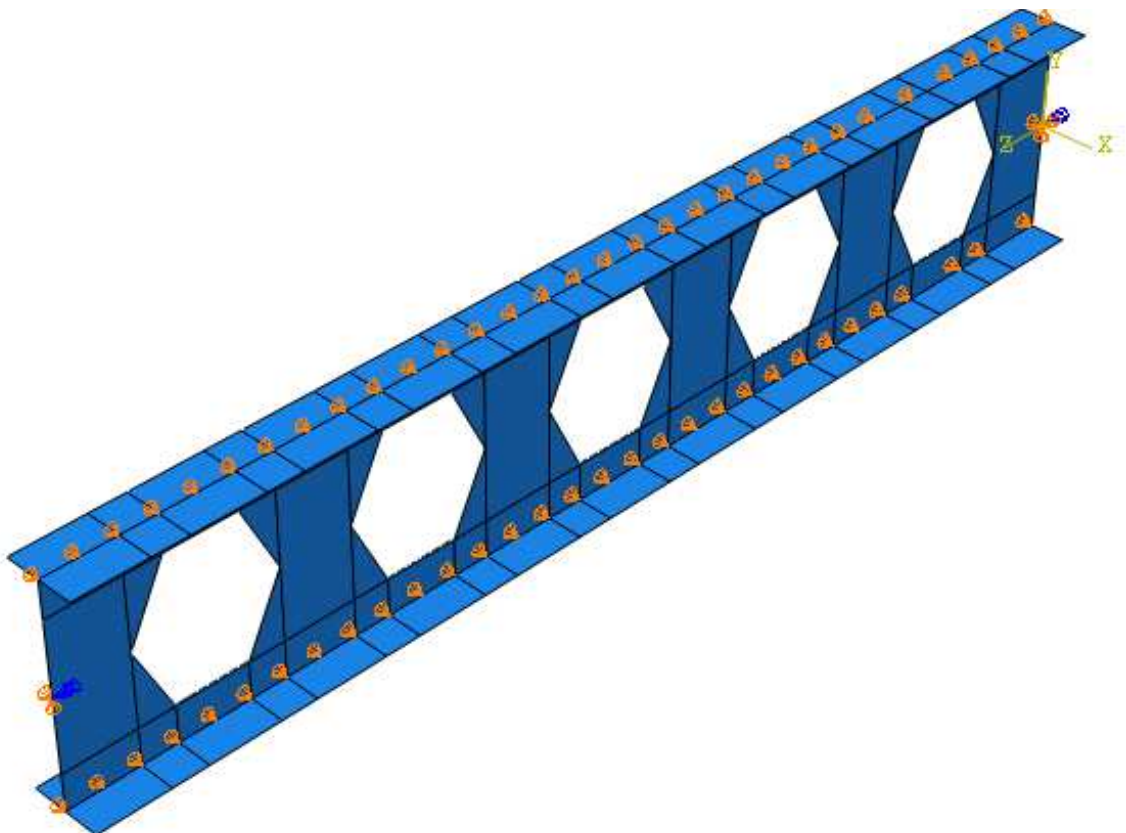

Figure 3.6 - ABAQUS model - lateral restraint of the 5 hole beam.

Pure bending is simulated by applying bending moments at nodes in the half height of the web at both ends. A master-slave method was used to guarantee that the distribution of the moment along the cross-section. The adopted method imposed rotation compatibility between web nodes, thus assuring that plane sections remained plane after deformation. Figure 3.7 and Figure 3.8 illustrate this approach. 


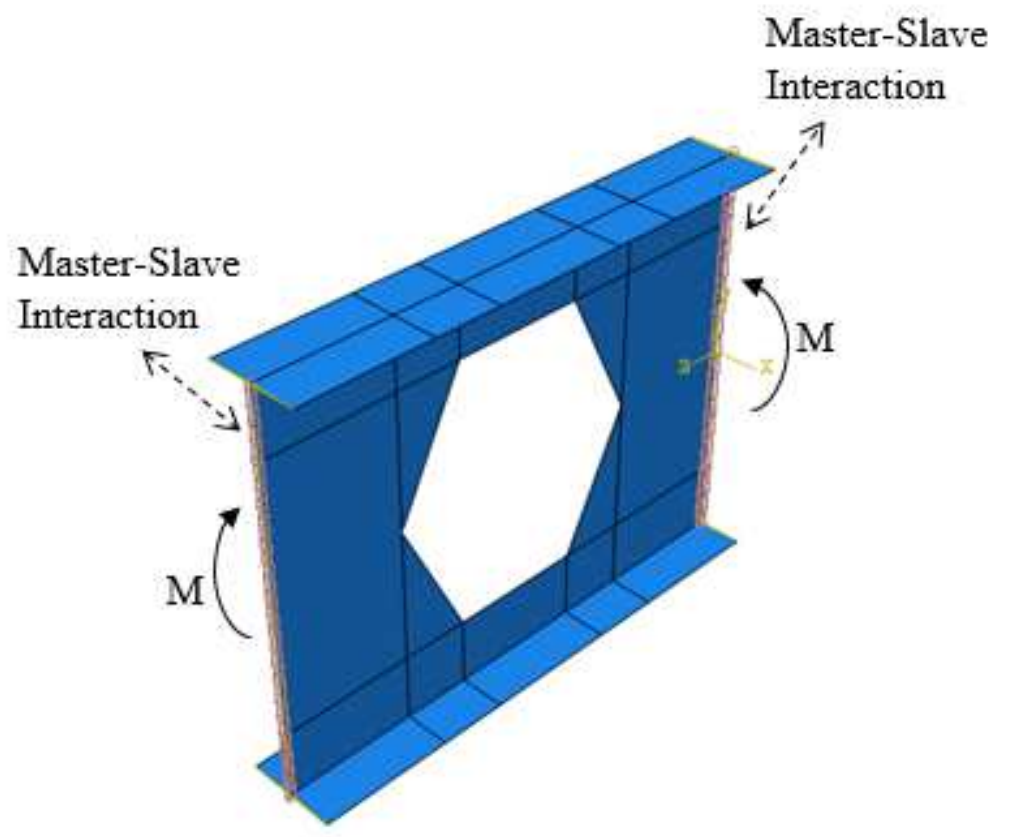

Figure 3.7- Boundary conditions - single hole beam.

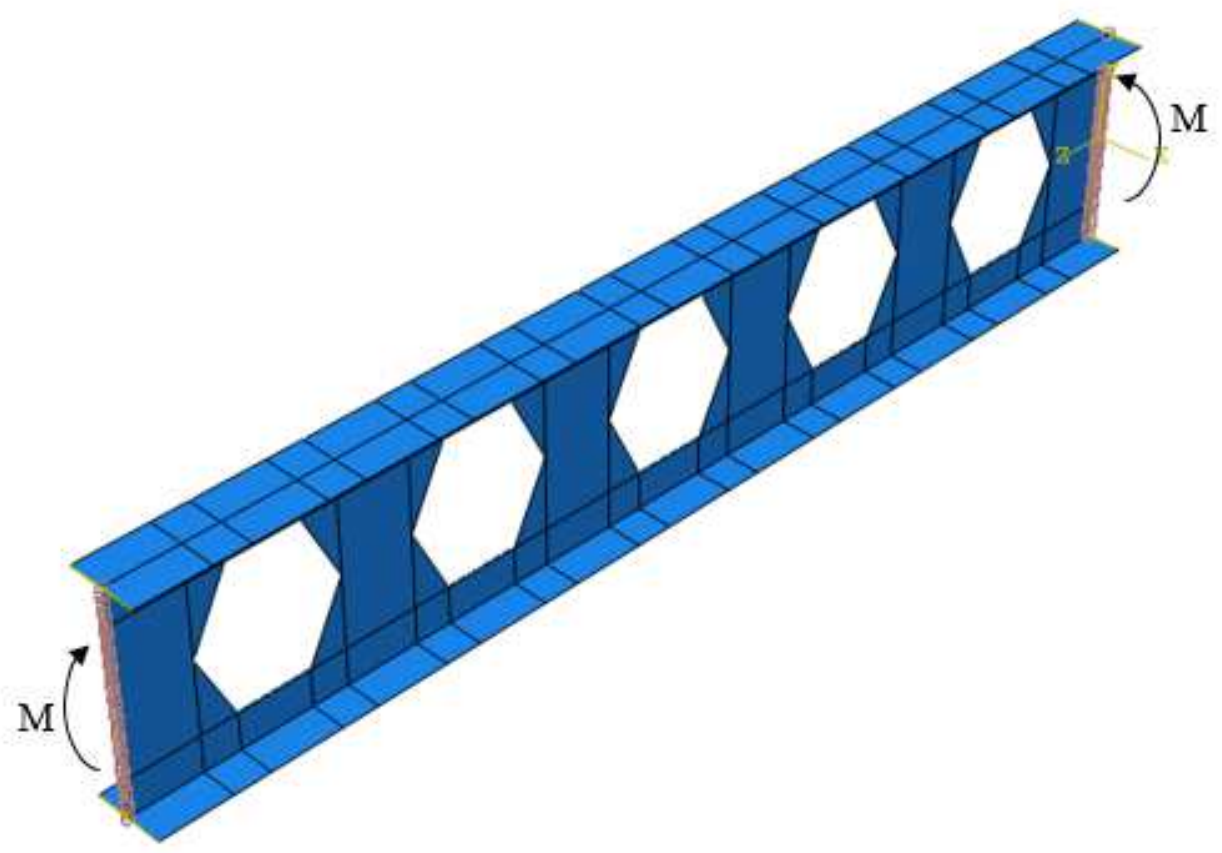

Figure 3.8 - Boundary conditions -5 hole beam.

\subsubsection{Castellated dimensions}

For all the developed finite element models the plate dimensions were varied according to typical project range. The modulus of elasticity adopted was $\mathrm{E}=$ 200GPa and the Poisson coefficient was taken as 0.3. 
The nomenclature used in this work for plate and hole dimensions is summarized in Figure 3.9.

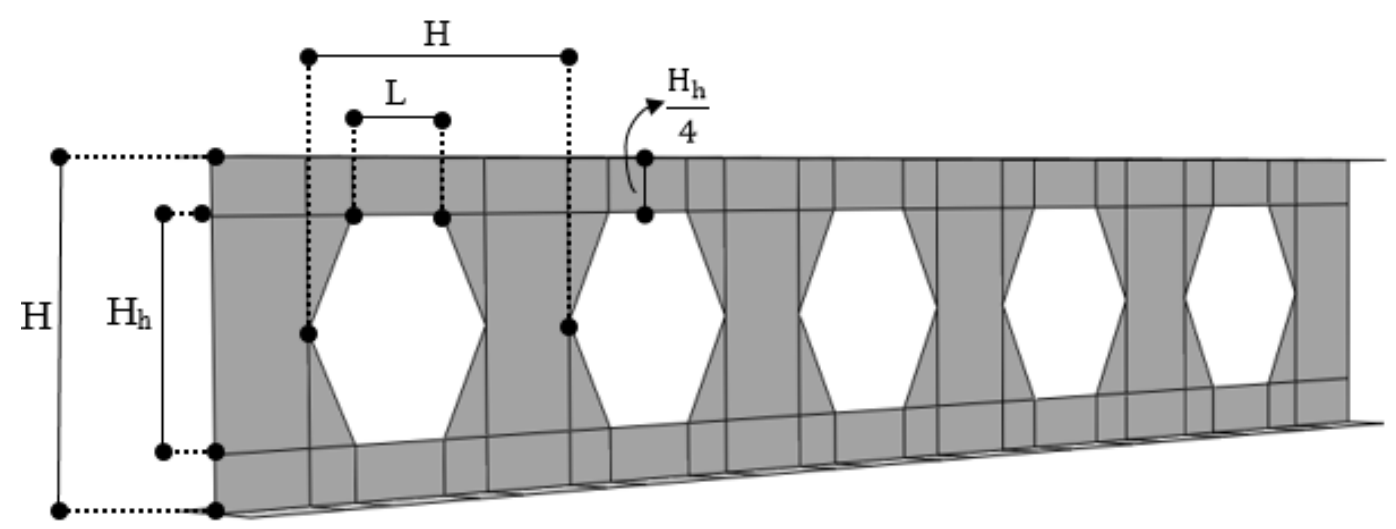

Figure 3.9 - Nomenclature and dimensions

The computational analysis considered only Litzka-Schnittführung castellated beam, which is a common type of castellated beam, described in Chapter 2 .

\subsubsection{Finite element Mesh}

Capturing the buckling behavior of the hole region is the main objective of this study. Thus, great attention was devoted when discretizing this area.

Regions away from the areas of high stress concentration had a smaller mesh density, i.e., adopted larger elements that had an aspect ratio of 8:1. Figure 3.10 and Figure 3.11 show the layout of a typical mesh configuration.

For the convergence study, the aspect ratio of a S8R5 was varied between 0.5 and 2, as mentioned in Chapter 2. The relation was based on ABAQUS recommendations, which also recommends that the angles between isoparametric lines should be not less than $45^{\circ}$ or greater than $135^{\circ}$, in order to guarantee the accuracy of the numerical integration of the stiffness matrix. 


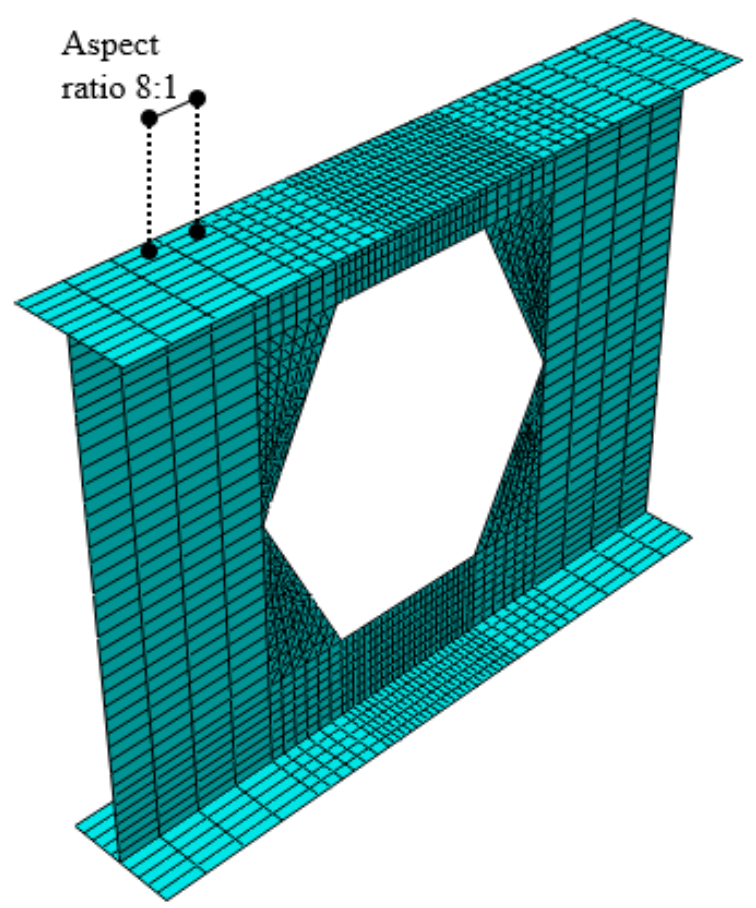

Figure 3.10 - Mesh and aspect ratio

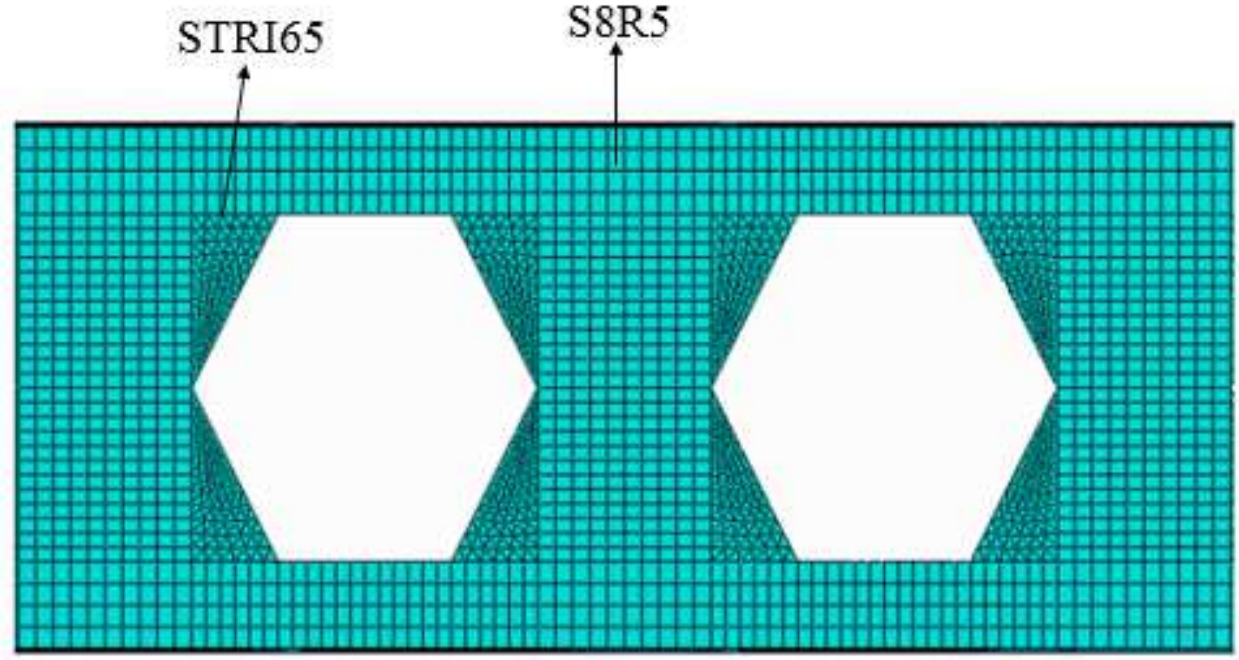

Figure 3.11 - Mesh detail at hole zones.

\subsubsection{Program output}

The critical stress and failure mode based on the local buckling mode were obtained by performing an elastic buckling analysis in ABAQUS. Figure 3.12 and Figure 3.13 illustrate the buckling behavior of the two castellated beam models 
described in this section. Results comparisons and analyses are provided in Chapter 5. Also, as it will be seen in Chapter 4, the buckling shape obtained from ABAQUS confirms the accuracy of the displacement functions assumed to develop the proposed design equation.
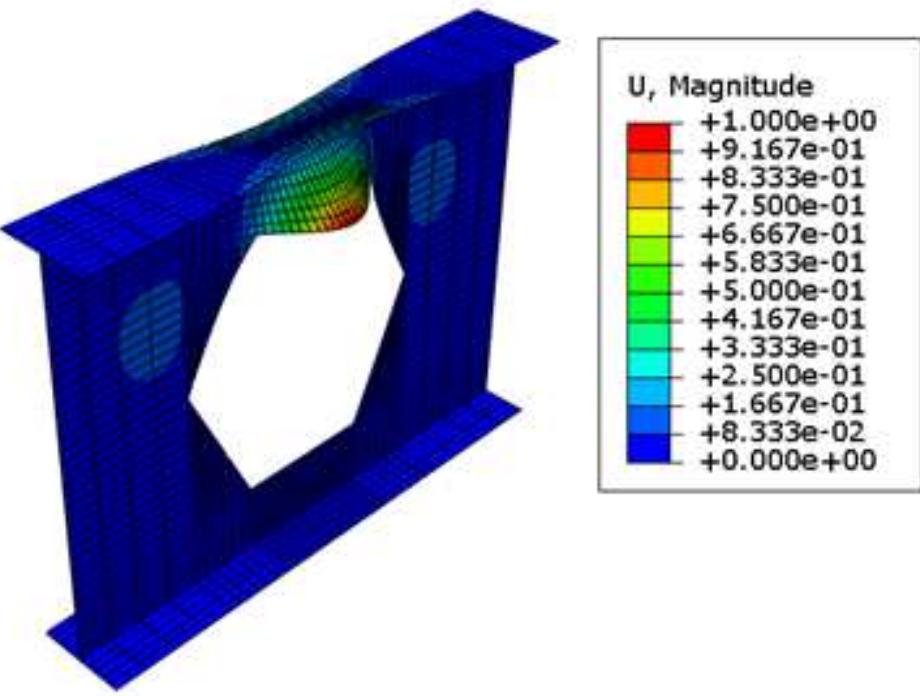

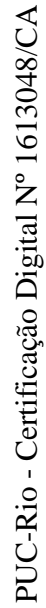

Figure 3.12 - Buckling shape - single hole beam.

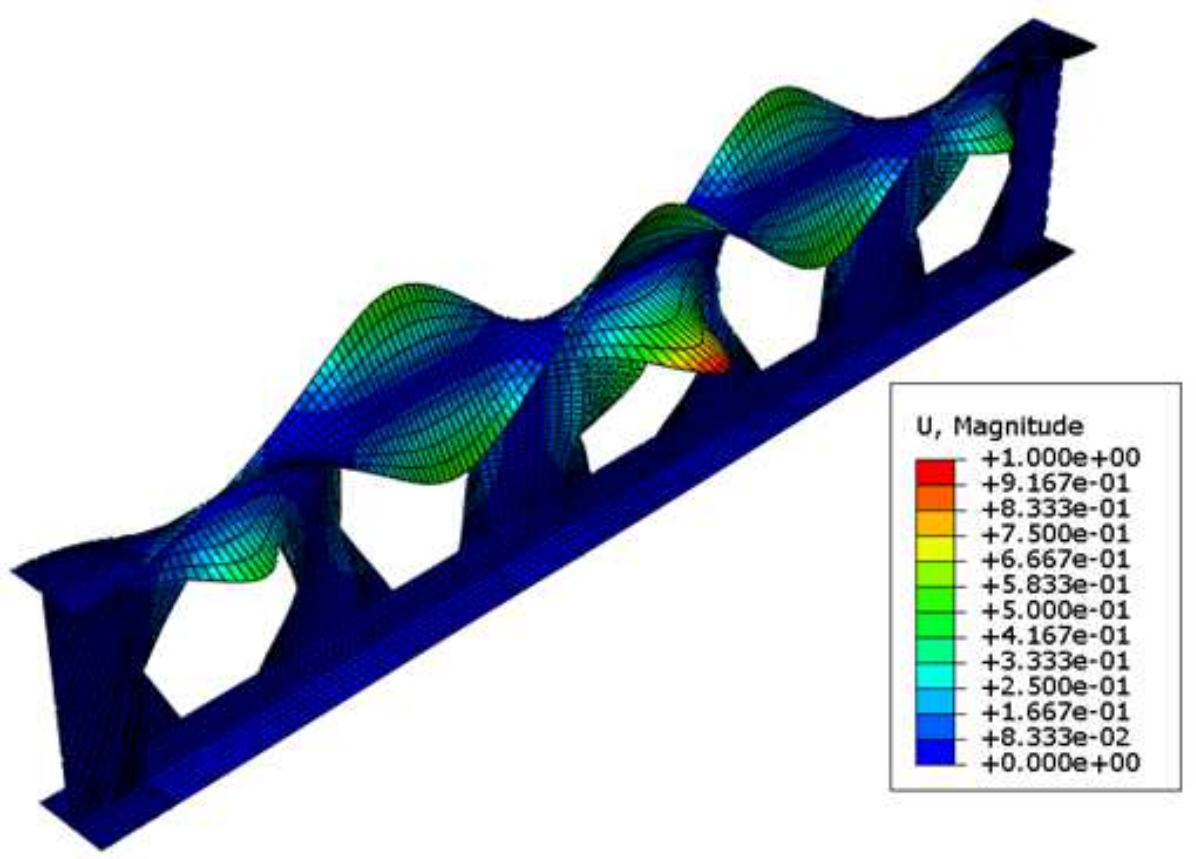

Figure 3.13 - Buckling shape - 5 holes beam. 


\section{4 \\ Prediction Equation for $\sigma_{c r}$}

In this chapter, the local buckling analysis of castellated beams subject to pure bending is studied.

As discussed previously, openings in the webs of girders and other large plate structures are often used, affecting the stress distribution throughout the member and its failure mode. Considering a section cut within a hole region as illustrated in Figure 4.1, two separate T-sections (Tees) are obtained, each subject to compressive or tensile stresses. Throughout this work, the compression Tee will be called top Tee, whereas the tension Tee will be designated as bottom Tee.

It can also be seen in Figure 4.1 that the stress distribution across depth varies linearly with distance from fiber to neutral axis, under the assumption that section remains plane during bending. In the case of a castellated beam with top Tee laterally braced, local buckling mode is dominant and described as a combination of Tee 'torsion' about its shear center and transverse flexure of walls. Very little motions of bottom Tee are observed and will be neglected in this study.

As mentioned in Chapter 2, different approaches may be used to determine critical stress for a plate assembly subject to compressive stresses. In this work, the full-section approach is adopted to derive explicit equations for the critical stress of castellated beams subject to pure bending. To accomplish this task, an energy method is adopted, in which the strain energy and the work produced by external loads are calculated for an assumed approximate and kinematically admissible deflected shape.

Thus, the accuracy of the result is dependent on the quality of the assumed buckled shape, which was chosen based on the typical shapes observed from numerical analyzes using GBT (Generalized Beam Theory) and FEM software both described in Chapter 3. The developed closed-form expressions were based on classical plate theory assumptions. 


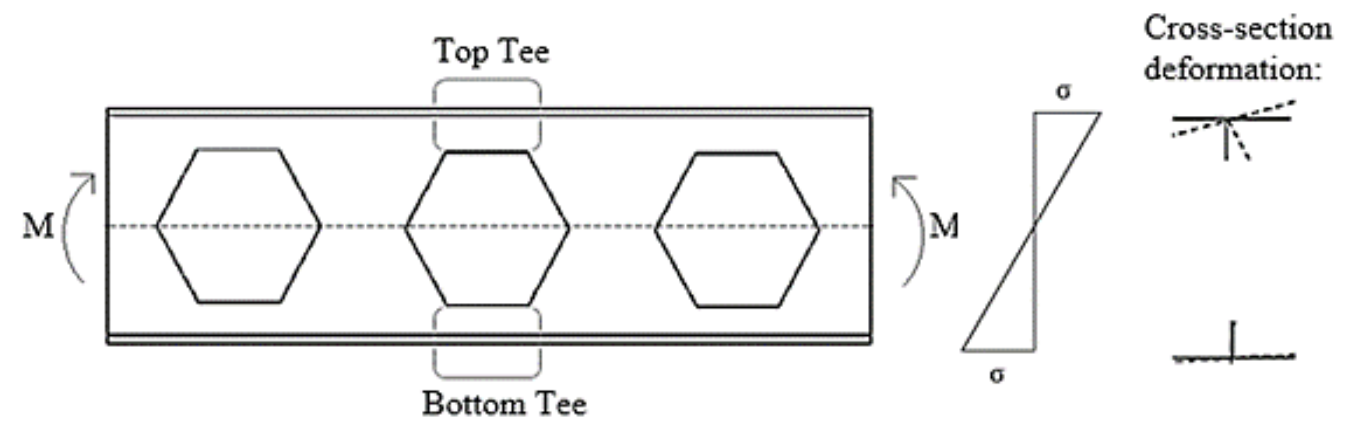

Figure 4.1 - Tee-section simplification

\subsection{Coordinate system and notation}

The geometric notation used in the forthcoming derivations are defined in Figure 4.2. Where $L$ is the length of the hexagon size; $H_{h}$ is the hole height; $b_{w}$ is the web length of top tee; $t_{w}$ is the thickness of the web; $b_{f}$ is the compression flange length; $\mathrm{t}_{f}$ is the thickness of the flange. The parameters $\alpha$ and $\beta$ are proportionality variables and determine the height and the length of the hole, respectively.

The global axis was fixed in the centroid of castellated beam. The local axes was determined as the $\mathrm{x}$-axis is parallel to longitudinal direction (beam axis), and the $y$ - and $z$ - axes refer to the directions to parallel and perpendicular to plate width, respectively. Figure 4.3 represents these local axes.

Before continuing, the following non-dimensional geometric parameters are introduced, as referred Figure 2.4:

$$
\begin{aligned}
& \frac{H}{H_{h}}=\alpha \\
& \beta=\frac{L}{H_{h}}
\end{aligned}
$$

Considering that the flange thickness is much smaller than the other dimensions, the following relationship can be written:

$$
H=2 b_{w}+H_{h}
$$

Substituting Eq.12 into 14 and manipulating, the following equations can be obtained, in terms of Tee web width, $b_{w}$ : 


$$
\begin{gathered}
H=\frac{2 b_{w} \cdot \alpha}{(\alpha-1)} \\
H_{h}=\frac{2 \cdot b_{w}}{(\alpha-1)}
\end{gathered}
$$

Then, substituting Eq. 16 into 13, L can also be written in terms of $b_{w}$ :

$$
L=\beta \cdot H_{h}=\beta \cdot \frac{2 \cdot b_{w}}{(\alpha-1)}
$$

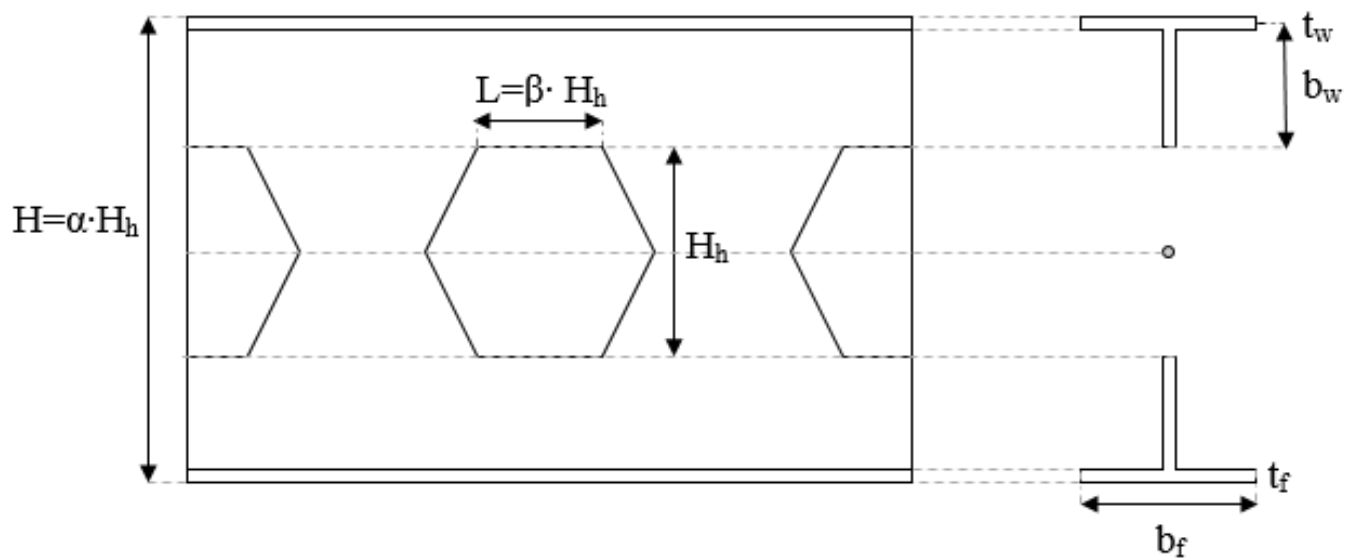

Figure 4.2 - Geometry of a typical castellated beam

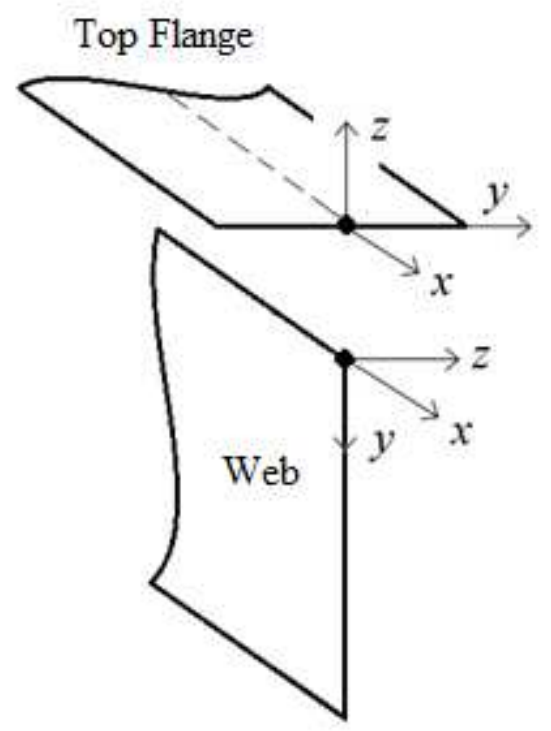

(b)

Figure 4.3 - Local Reference System 


\subsection{General criteria for local instability}

As described in Chapter 2, critical stresses may be written in the following general form:

$$
\begin{gathered}
\sigma_{c r}=k_{\text {local }} \cdot \frac{\pi^{2} \cdot D_{w}}{t_{w} \cdot b_{w}{ }^{3}} \\
D_{w}=\frac{E \cdot t_{w}}{12\left(1-v^{2}\right)}
\end{gathered}
$$

The parameter $D_{w}$ is the longitudinal bending stiffness of the web defined as Eq. 19 and $\mathrm{k}_{\text {local }}$ is the buckling coefficient to be determined. $\mathrm{k}_{\text {local }}$ term is a function of material properties, flange-to-web width ratio $\left(\eta=\frac{b_{f}}{b_{w}}\right)$, flange-to-web thickness ratio $\left(\xi=\frac{t_{\mathrm{f}}}{\mathrm{t}_{\mathrm{w}}}\right), \alpha$ and $\beta$ (as determined previously). In commercially available castellated beams, $\xi$ ranges from 1.0 to 1.8 , whereas $\eta$ ranges from 0.3 to 4.

Depending on the flange-to-web width ratio $\eta$, buckling is governed by either flange or web properties. Thus, the problem may be separated into two ranges of $\eta$ values: for $0.3 \leq \eta \leq 1.2$, the critical mode is governed by the local buckling of the web, whilst for $1.2<\eta \leq 4$ buckling is dominated by flange. However, it is emphasized that, for general applications of castellated beams, $\eta$ typically ranges from 1.2 to 4 , i.e. governed by flange buckling. Figure 4.4 presents the different buckling shape obtained by two different ranges.

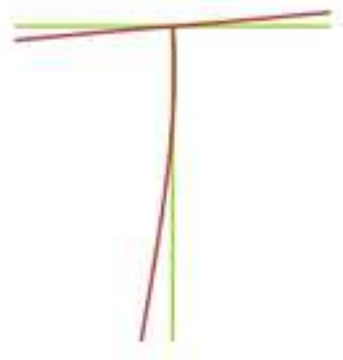

(a)

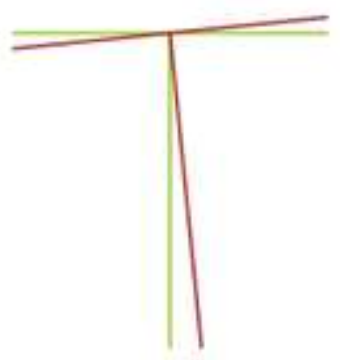

(b)

Figure 4.4 - Buckling shape (a) Web buckling (b) Flange buckling 


\subsection{Energy formulation}

For the energy formulation, it is assumed buckling within elastic range, therefore not dependent on yielding of the material. The total strain energy is defined as sum of the strain energies of web (Eq.20) and flange (Eq.21), determined for deflection functions $\mathrm{w}_{\mathrm{w}}(\mathrm{x}, \mathrm{y})$ and $\mathrm{w}_{\mathrm{fc}}(\mathrm{x}, \mathrm{y})$ described in the next item, as follows:

$$
\begin{gathered}
\mathrm{U}_{\mathrm{w}}=\frac{\mathrm{D}_{\mathrm{w}}}{2} \cdot \int_{0}^{\mathrm{L}} \int_{0}^{\mathrm{b}_{\mathrm{w}}}\left(\left(\frac{\partial^{2} \mathrm{w}_{\mathrm{w}}}{\partial \mathrm{x}^{2}}+\frac{\partial^{2} \mathrm{w}_{\mathrm{w}}}{\partial \mathrm{y}^{2}}\right)-2(1-\mathrm{v})\left(\left(\frac{\partial^{2} \mathrm{w}_{\mathrm{w}}}{\partial \mathrm{x}^{2}}\right)\left(\frac{\partial^{2} \mathrm{w}_{\mathrm{w}}}{\partial \mathrm{y}^{2}}\right)-\left(\frac{\partial^{2} \mathrm{w}_{\mathrm{w}}}{\partial \mathrm{x} \partial \mathrm{y}}\right)^{2}\right) \mathrm{dy}\right) \mathrm{dx} \\
\mathrm{U}_{\mathrm{fc}}=\frac{\mathrm{D}_{\mathrm{fc}}}{2} \cdot \int_{0}^{\mathrm{L}} \int_{\frac{-\mathrm{b}_{\mathrm{f}}}{2}}^{\frac{\mathrm{b}_{\mathrm{f}}}{2}}\left(\left(\frac{\partial^{2} \mathrm{w}_{\mathrm{fc}}}{\partial \mathrm{x}^{2}}+\frac{\partial^{2} \mathrm{w}_{\mathrm{fc}}}{\partial \mathrm{y}^{2}}\right)-2(1-\mathrm{v})\left(\left(\frac{\partial^{2} \mathrm{w}_{\mathrm{fc}}}{\partial \mathrm{x}^{2}}\right)\left(\frac{\partial^{2} \mathrm{w}_{\mathrm{fc}}}{\partial \mathrm{y}^{2}}\right)-\left(\frac{\partial^{2} \mathrm{w}_{\mathrm{fc}}}{\partial \mathrm{x} \partial \mathrm{y}}\right)^{2}\right) \mathrm{dy}\right) \mathrm{dx} \\
U=U_{\mathrm{w}}+\mathrm{U}_{\mathrm{fc}}
\end{gathered}
$$

The work produced by external loads is determined considering a linear

stress distribution due to pure bending. It is important to mention that the compressive stress is assumed constant through flange thickness.

$$
\begin{gathered}
\mathrm{T}_{\mathrm{w}}=\frac{\mathrm{t}_{\mathrm{w}}}{2} \cdot \int_{0}^{\mathrm{L}} \int_{0}^{\mathrm{b}_{\mathrm{w}}} \sigma_{\mathrm{x}} \cdot\left(\frac{\partial \mathrm{w}_{\mathrm{w}}}{\partial \mathrm{x}}\right)^{2} \mathrm{dydx} \\
\mathrm{T}_{\mathrm{fc}}=\frac{\mathrm{t}_{\mathrm{f}}}{2} \cdot \int_{0}^{\mathrm{L}} \int_{\frac{-\mathrm{b}_{\mathrm{f}}}{2}}^{\frac{\mathrm{b}_{\mathrm{f}}}{2}} \sigma \cdot\left(\frac{\partial \mathrm{w}_{\mathrm{fc}}}{\partial \mathrm{x}}\right)^{2} \mathrm{dydx} \\
\mathrm{T}=\mathrm{T}_{\mathrm{w}}+\mathrm{T}_{\mathrm{fc}}
\end{gathered}
$$

The stress distribution is defined in terms of the local coordinate y is given in Eq. 26. It considers that the castellated beam is subjected to pure bending and tee section is subjected to bending with compression:

$$
\sigma_{\mathrm{x}}=\sigma-\frac{\sigma}{\frac{\mathrm{h}}{2}} \cdot \mathrm{y}
$$

By assuming appropriate distributions for $\mathrm{w}(\mathrm{x}, \mathrm{y})$ it is possible to find a equation that minimizes inner potential energy, making it equal to the external work (Rayleigh: $\mathrm{U}=\mathrm{T}$ ). 


\subsection{Local buckling critical stress}

\subsubsection{Assumed buckling shape}

The accuracy of the result is dependent on the quality of the assumed buckled shape, in the sense that the results must be established for the deformed configuration of the structure. Thereupon, an unknown distribution $\mathrm{w}(\mathrm{x}, \mathrm{y})$ should represent the approximate solution of the out-of-plane deflection of a given profile. These approximation is represented by a combination of functions varying along $\mathrm{x}$ and $y$-axes. Regarding, the $\mathrm{x}$-axis represents the longitudinal length, the $\mathrm{y}$-axis is the transversal one and z-axis represents the out of plane axis.

The deflection field was defined considering the mode given by GBTUL (Figure 4.5). A separated deflection field was used for the web and for the compression flange, without neglecting the interaction of them on the stiffness of the group.

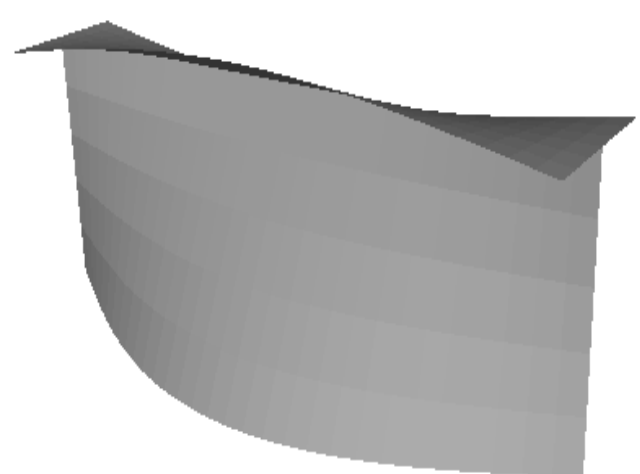

Figure 4.5 - GBTUL - deflection shape

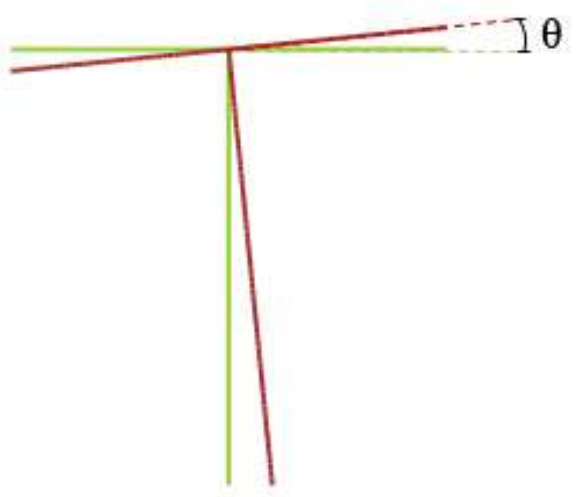

Figure 4.6 - Transverse buckling

For the compression flange, a sinusoidal function was adopted for the deflection shape along the longitudinal axis, combined with a transverse straight linear (local y-axis); in which $\theta$ represents the element rotation compared with the undeformed state (Figure 4.6).

$$
w_{f c}(x, y)=\theta \cdot \sin \left(\frac{\pi x}{L}\right) \cdot y
$$


In order to obtain an accurate approximation for the web displacement, with a good physical representation of the structural behavior, the tee-web was idealized as a frame element, where the stiffness of the flange is represented by a rotational spring, as shown in Figure 4.7.

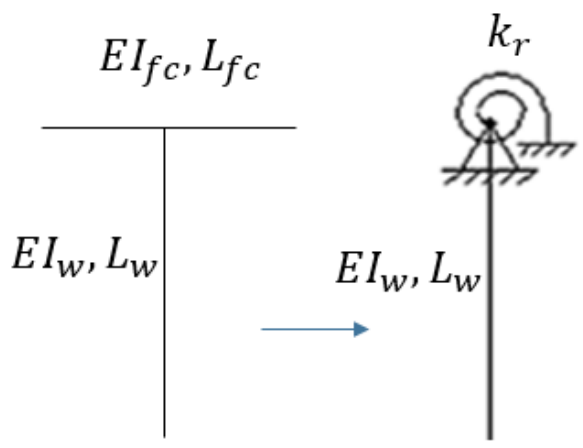

Figure 4.7 - Frame element.

When the relative thickness between web and flange is equal to one, the derivative of the $\mathrm{w}_{\mathrm{w}}(\mathrm{y})$ function at $\mathrm{y}=0$ must be $\theta$. However, as the relative thickness increases, this flange acts as a rotational restraint as shown in Figure 4.8.

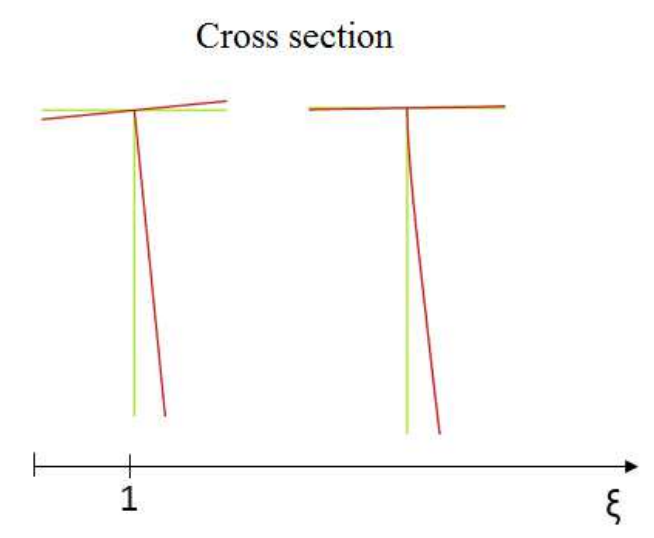

Figure 4.8 - Frame interaction.

This representation allowed a good evaluation of the interaction between web and flange. Then, the web displacement can be obtained by solving the differential equation and applying the appropriate boundary conditions, as described in next paragraphs.

Therefore, a sinusoidal function was adopted for the deflection shape along the longitudinal axis and for transverse axis was considered a y-function. Considering an outstand web depicted in Figure 4.9, which has length $\mathrm{L}$ and height $b_{w}$. The longitudinal supported edge $w_{w e b}(0)$ is elastically restrained, by means of 
rotational spring with stiffness $k_{m}$, and the edge $w_{w e b}\left(b_{w}\right)$ is completely free. Seeking to obtain the desired deflection, a fictional concentrated load is applied at the free extremity and the deflection field for the web can be interpolated by a cubic function as:

$$
\begin{aligned}
& w_{w e b}(y)=C_{1} y^{3}+C_{2} y^{2}+C_{3} y+C_{4}
\end{aligned}
$$

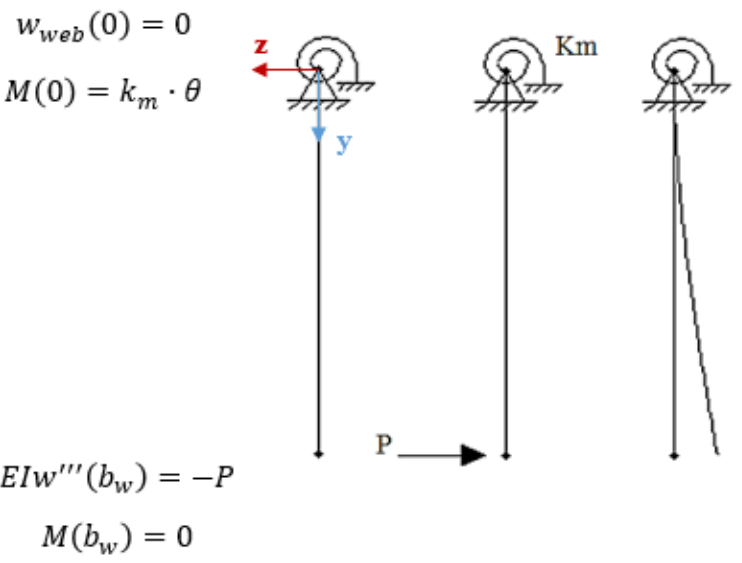

Figure 4.9 - Rotational Spring stiffness

The constants can be defined by applying the boundary conditions and the representative equation of the web deflection field varying with the local y-axis is as follows:

$$
w_{w e b}(y)=\frac{-P}{6 E I_{w e b}} \cdot y^{3}+\frac{P \cdot b_{w}}{2 E I_{w e b}} \cdot y^{2}+\frac{P \cdot b_{w}}{k_{M}} \cdot y
$$

The rotational stiffness $\mathrm{k}_{\mathrm{m}}$ is approximately determined using the flange properties. Considering that the torsional moment is equal to zero on extremities and has its maximum value on the mid-length section, the effective length of the element (L) is taken as half of the 'twisted' span, according to Saint Venant's theory. Besides, the rotational stiffness of the flange is proportional to twice the torsional moment, considering a double contribution along the length $\mathrm{L}$, as Figure 4.10 shows. Thus, the angle and rotational stiffness of the beam is determined through relations such as:

$$
\begin{gathered}
M=k_{m} \cdot \theta \\
k_{m}=M t / \theta=\frac{4 G J}{L}
\end{gathered}
$$


In which $\mathrm{G}$ is transverse modulus of elasticity given according to Eq. 32 and $\mathbf{J}$ is the Saint Venant's constant of torsion, given in Eq. 33:

$$
\begin{gathered}
G=\frac{E}{2(1+v)} \\
J=\frac{b_{f} \cdot t_{f}{ }^{3}}{3}
\end{gathered}
$$

Therefore, the web buckling shape $\mathrm{w}(\mathrm{x}, \mathrm{y})$ can be described as:

$$
w_{w e b}(x, y)=P \cdot \sin \left(\frac{\pi x}{L}\right)\left(\frac{-y^{3}}{6 E I_{w e b}}+\frac{b_{w} \cdot y^{2}}{2 E I_{w e b}}+\frac{b_{w} \cdot y}{k_{M}}\right)
$$

Substituting the approximations of the deflection field on energy equations and applying Rayleigh Quotient method, a closed-form equation for critical stress can be obtained.
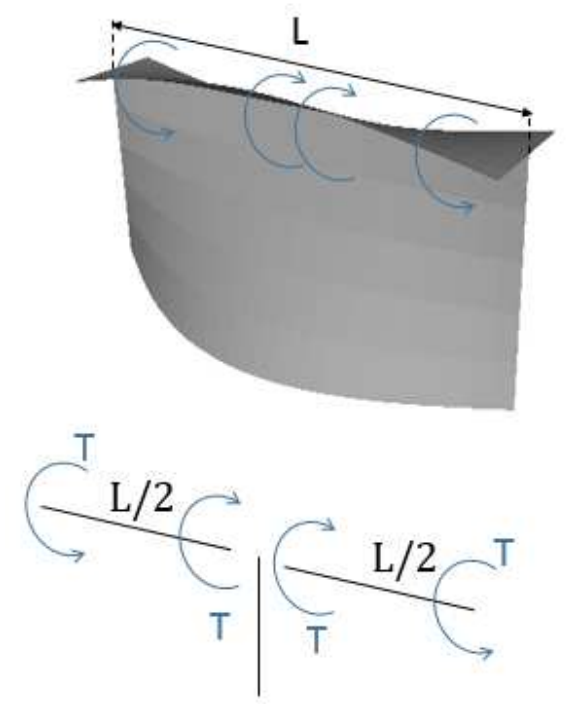

Figure 4.10: Tee section representation

\subsubsection{Behavior governed by web (web buckling)}

For the range of $\eta$ between 0.3 and 1.2, it can be observed from preliminary studies that the buckling behavior of Tee section is governed by web properties. In this case, the deflection shapes adopted are the ones described in Eq. 34.

Figure 4.11 exemplifies the critical behavior governed by the web, whereas the length $\mathrm{L}$ of the hexagon is determined as indicated. The local buckling mode involves out-of-plane deformation of the component plates, and it has a half- 
wavelength of the same order of magnitude as the widths of the plate element. This behavior can be observed in Figure 4.11, where the half-wavelength is approximately the plate web dimension.

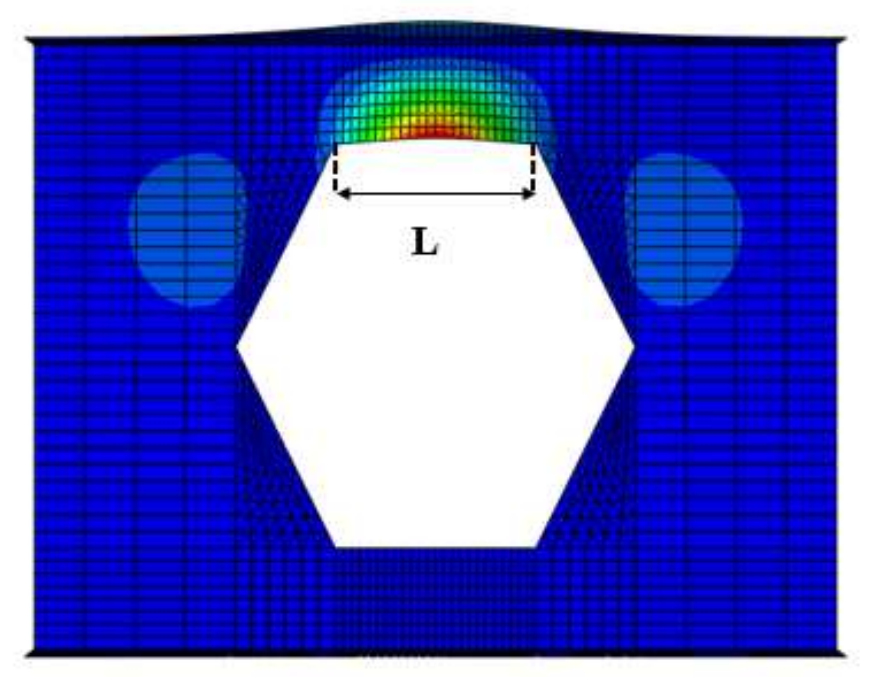

Figure 4.11 - WLB ABAQUS output

Substituting the assumed deflection shape on the energy equations, considering the stationary state $(\mathrm{U}=\mathrm{T})$, the critical stress can be obtained. After algebraic operations and assuming $v=0.3$, the following expression can be obtained:

$$
\sigma_{\mathrm{cr}}=\frac{\pi^{2} \cdot \mathrm{D}_{\mathrm{w}}}{\mathrm{b}_{\mathrm{w}}{ }^{2} \mathrm{t}_{\mathrm{w}}} \cdot\left(\frac{0.3 \eta^{2} \xi^{6}+2.04 \eta \xi^{3}+1.06+0.24 \eta^{2} \xi^{6} \cdot \frac{\beta^{2}}{(\alpha-1)^{2}}+\frac{(\alpha-1)^{2}}{4 \beta^{2}} \cdot\left(0.46 \eta^{2} \xi^{6}+2.12 \eta \xi^{3}+2.51+0.63 \eta^{3} \xi^{3}\right.}{0.63 \eta^{3} \xi+0.46 \eta^{2} \xi^{6}+2.12 \eta \xi^{3}+2.50-\left(\left(1-\frac{1}{\alpha}\right) \cdot\left(0.38 \eta^{2} \xi^{6}+1.67 \eta \xi^{3}+1.88\right)\right)}\right)
$$

The steps of algebraic manipulations used to reduce the equation obtained are presented in Appendix B.

As expected, the expression has the same form as the classical plate buckling equation. It can be seen that critical stress depends on $\xi, \eta, \alpha$ and $\beta$, defined previously.

Assuming Litzka-Schnittführung considerations, the value of $\alpha$ and $\beta$ are determined as 1.5 and 0.5 , respectively. Substituting these values in Eq. 35, the expression of the critical stress reduces to: 


$$
\sigma_{c r}=\frac{\pi^{2} \cdot D_{w}}{b_{w}{ }^{2} t_{w}} \cdot\left(\frac{0.65 \cdot \eta^{2} \xi^{6}+2.57 \cdot \eta \xi^{3}+1.69+0.16 \cdot \eta^{3} \xi^{3}}{0.63 \cdot \eta^{3} \xi+0.33 \cdot \eta^{2} \xi^{6}+1.56 \cdot \eta \xi^{3}+1.87}\right)
$$

\subsubsection{Behavior governed by the flange (flange buckling)}

When Tee buckling is governed by flange properties, the transverse flexure of web is not observed and buckling shape is mainly characterized by torsion about shear center (flange-web junction), as shown in Figure 4.12. For simplicity, the form of deflection for both the web and flange can be represented by a linear function varying along transverse axis (local y-axis) and by a sinusoidal function along longitudinal axis (local $\mathrm{x}$-axis).

Another important issue that needs to be addressed is the Tee length to be adopted. In Figure 4.13, a typical buckling mode obtained using FEM-model is presented. It can be seen that the buckling length, L, is greater than that obtained for 'web buckling' conditions.

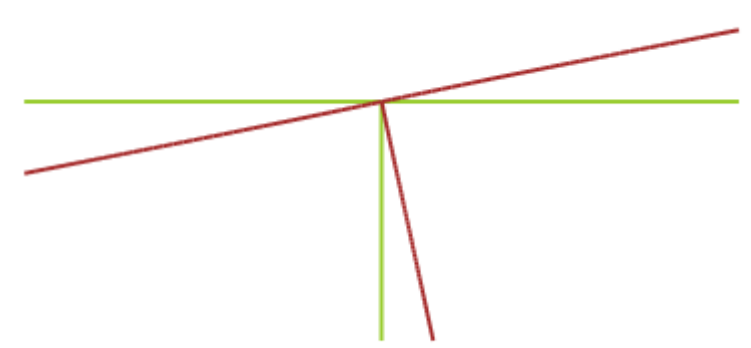

Figure 4.12 - GBTUL transverse deflection

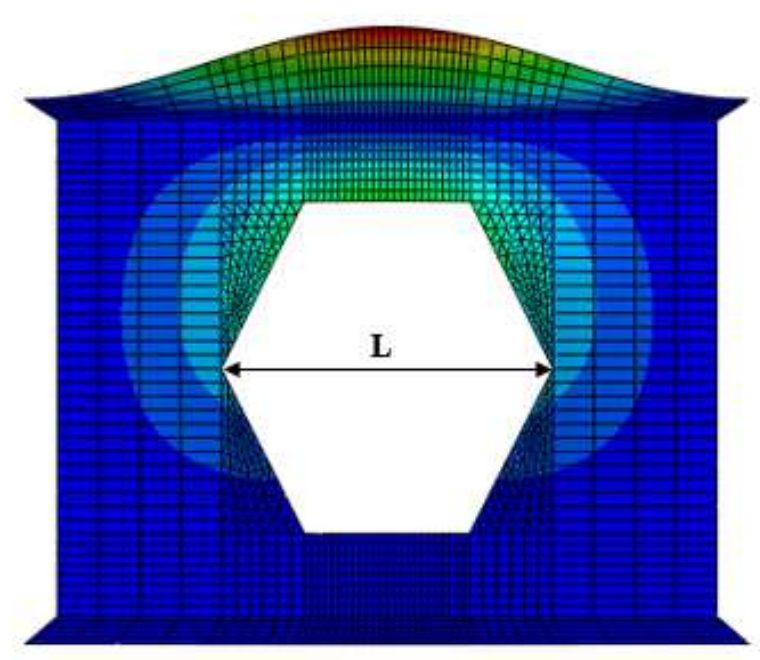

Figure 4.13 - FLB ABAQUS output 
Using energy formulation considering the deflected shapes and buckling length previously described, the critical stress is expressed as follows:

$$
\sigma_{c r}=\frac{\pi^{2} \cdot D_{w}}{b_{w}{ }^{2} t_{w}} \cdot\left(\frac{\frac{(\alpha-1)^{2}}{\beta^{2}}\left(1+0.25 \cdot \eta^{3} \xi^{3}\right)+1.7 \cdot\left(1+\eta \xi^{3}\right)}{\eta^{3} \xi-3 \frac{(\alpha-1)}{\alpha}+4}\right)
$$

For Litzka-Schnittführung considerations, the value of $\alpha$ and $\beta$ are determined as 1.5 and 1.0, respectively, the expression is reduced to:

$$
\sigma_{c r}=\frac{\pi^{2} \cdot D_{w}}{b_{w}{ }^{2} t_{w}} \cdot\left(\frac{1.95+0.06 \cdot \eta^{3} \xi^{3}+1.7 \cdot \eta \xi^{3}}{\eta^{3} \xi+3}\right)
$$




\subsection{Dimensional limits of $\alpha$ and $\beta$}

The influence of the hole size and spacing between holes is still a topic of research and is beyond the scope of the present work. This item presents some analysis about these influences.

Moen and Schafer [52] showed that the presence of openings in a plate lead to specific buckling modes that may increase or decrease the critical load, depending upon the size and spacing of the openings. When the openings are close and relatively small, the local buckling of one hole have great influence on the behavior of the adjacent hole. As the spacing gets higher, the critical load tends to become constant. They attribute the increase in the critical load to the fact that the openings act like a damper on plate buckling. The results obtained with the equation proposed in the present work are shown in Figure 4.14. The figure shows the value of the critical load as a function of the parameter $\beta$, that determines the hexagon length and the hole spacing $\left(\mathrm{L}=\beta \cdot \mathrm{H}_{\mathrm{h}}\right)$, confirming the behavior described previously.

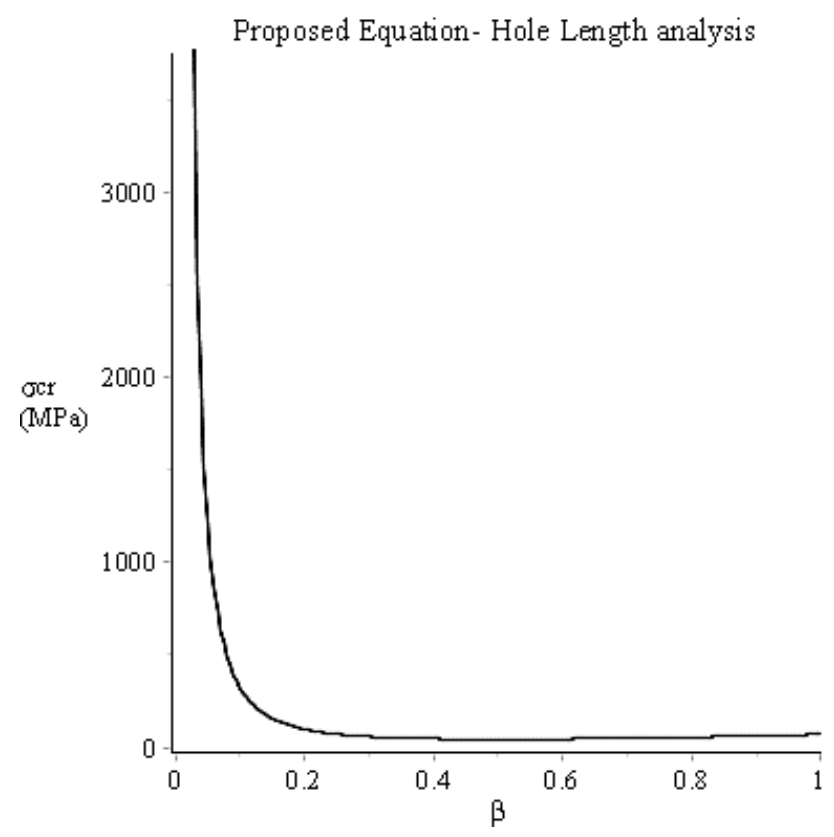

Figure 4.14 - Analysis of $\boldsymbol{\sigma}_{\mathbf{c r}}$ with parameter $\beta$ ranging from 0 to 1

Dinis et al. [53] reported the results of an investigation on the local and global buckling behavior of T-section and cruciform thin-walled steel members. They found that the critical stress decreases monotonically with the beam length 
and it corresponds to single half-wave buckling mode. However, their critical buckling curves are not always associated with single half-wave $(n=1)$ buckling mode. To large lengths, the $\mathrm{L}$ curves $\left(\sigma_{\mathrm{cr}} \times \mathrm{L}\right)$ exhibit local minima and are sometimes associated with multiple half-wave buckling modes.

The results obtained with the proposed equation are shown in Figure 4.15 that relates the critical stress and the length of the hole (L). As can be seen from the figure, the critical load decreases with the beam length (associated with single halfwave $n=1$ ), and for large lengths the deflection shape assumed multiples halfwaves.

It should be emphasized that the expression form that represents the deflection shape for the formulation of the proposed equation was associated with single half-wave $(n=1)$. Thus, the range of parameter $\beta$ is defined between 0 and 1 .

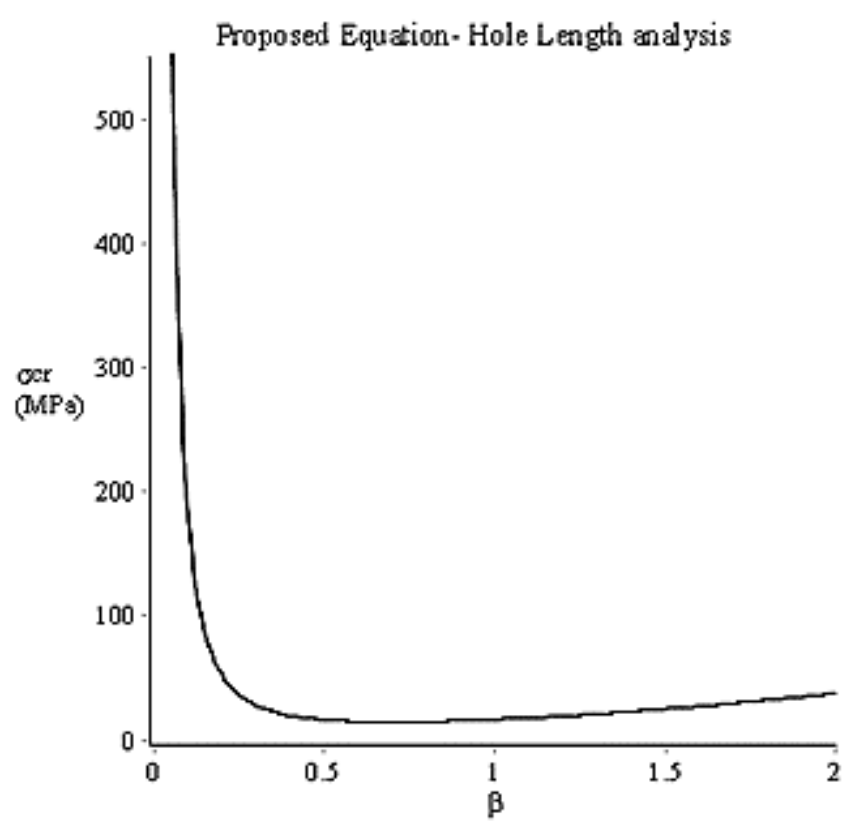

Figure 4.15 - Analysis of $\sigma_{\mathrm{cr}}$ with parameter $\beta$ ranging from 0 to 2 .

Figure 4.16 shows the obtained critical stresses as a function of the parameter $\alpha=\frac{\mathrm{H}}{\mathrm{H}_{\mathrm{h}}}$. It can be observed that, as the height of the opening increases and parameter $\alpha$ rises proportionally, and so does the critical stress.

This behavior can be explained by the argument that the presence of the holes "dampens" the instability of the beam, providing an increase in critical stress. 
When compared to I-profile of the same height, this I-profile tends to be more unstable than the same profile with a hole in the web.

The proposed equation is valid for the following limits of $\alpha$ and $\beta: 1.4 \leq \alpha \leq 2$ e $0 \leq \beta \leq 1$. Note that the described values are in the practical design range and for the Litzka-Schnittführung beam.

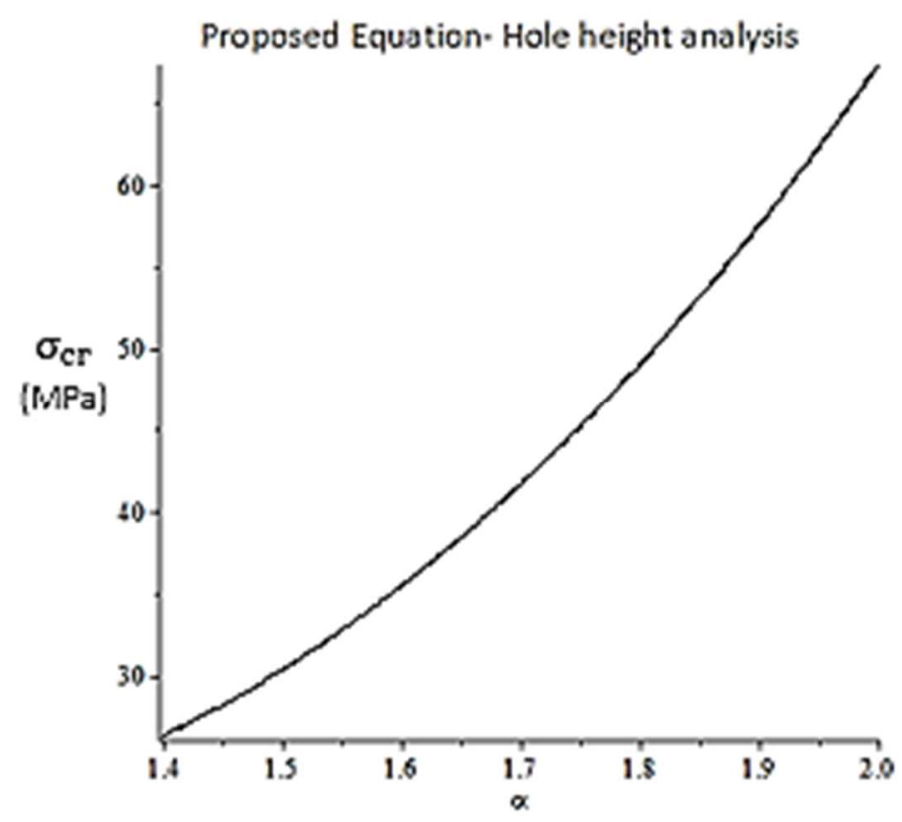

Figure 4.16 - Analysis of $\boldsymbol{\sigma}_{\text {cr }}$ with parameter $\alpha$ 


\subsection{Summary of results obtained}

As discussed in previous sections, the critical stress can be written in a general form, in which a 'basic stress' depending on the web parameters and material properties is multiplied by the local buckling coefficient $\mathrm{k}$. In Table 1, proposed equations for $\mathrm{k}_{\mathrm{cr}}$ are summarized.

\begin{tabular}{|c|c|c|}
\hline \multicolumn{3}{|r|}{ Model 1 - Critical behaviour governed by the web buckling (WLB) } \\
\hline \multirow{3}{*}{$\boldsymbol{k}_{c r}$} & \multirow{2}{*}{$\begin{array}{l}\text { General } \\
\text { Case }\end{array}$} & $0.3 \eta^{2} \xi^{6}+2.04 \eta \xi^{3}+1.06+0.24 \eta^{2} \xi^{6} \cdot \frac{\beta^{2}}{(\alpha-1)^{2}}+\frac{(\alpha-1)^{2}}{4 \beta^{2}} \cdot\left(0.46 \eta^{2} \xi^{6}+2.12 \eta \xi^{3}+2.51+0.63 \eta^{3} \xi^{3}\right.$ \\
\hline & & $0.63 \eta^{3} \xi+0.46 \eta^{2} \xi^{6}+2.12 \eta \xi^{6}+2.50-\left(\left(1-\frac{1}{\alpha}\right) \cdot\left(0.38 \eta^{2} \xi^{6}+1.67 \eta \xi^{3}+1.88\right)\right)$ \\
\hline & $\begin{array}{l}\text { L-S } \\
\text { beam* }\end{array}$ & $\left(\frac{0.65 \cdot \eta^{2} \xi^{6}+2.57 \cdot \eta \xi^{3}+1.69+0.16 \cdot \eta^{3} \xi^{3}}{0.63 \cdot \eta^{3} \xi+0.33 \cdot \eta^{2} \xi^{6}+1.56 \cdot \eta \xi^{2}+1.87}\right)$ \\
\hline \multicolumn{3}{|r|}{ Model 2 - Critical behaviour governed by the flange buckling (FLB) } \\
\hline \multirow{4}{*}{$\boldsymbol{k}_{c r}$} & \multirow[t]{2}{*}{$\begin{array}{l}\text { General } \\
\text { Case }\end{array}$} & $\left(\frac{(\alpha-1)^{2}}{\beta^{2}}\left(1+0.25 \cdot \eta^{3} \xi^{3}\right)+1.7 \cdot\left(1+\eta \xi^{3}\right)\right)$ \\
\hline & & $\eta^{3} \xi-3 \frac{(\alpha-1)}{\alpha}+4$ \\
\hline & L-S & $\left(\underline{1.95+0.06 \cdot \eta^{3} \xi^{3}+1.7 \cdot \eta \xi^{3}}\right)$ \\
\hline & beam $^{*}$ & $\eta^{3} \xi+3$ \\
\hline & $\xi$ & $\frac{t_{f}}{t_{w}}$ \\
\hline & $\eta$ & $\frac{b_{f}}{b_{w}}$ \\
\hline
\end{tabular}

Table 1 - Equations for critical local buckling coefficients, $\mathrm{k}_{\mathrm{cr}}$, for both critical behaviors buckling

In order to facilitate the calculations, the results can also be presented in a tabular format, if desired, for design application. Table 2 presents $\mathrm{k}$ values for certain $\xi$ and $\eta$ of a Litzka-Schnittführung beam. 


\begin{tabular}{|c|c|c|c|c|c|c|c|c|c|c|c|c|c|c|c|c|}
\hline \multirow{2}{*}{$\xi$} & \multicolumn{10}{|c|}{ WLB } & \multicolumn{6}{|c|}{ FLB } \\
\hline & 0,3 & 0,4 & 0,5 & 0,6 & 0,7 & 0,8 & 0,9 & 1 & 1,1 & 1,2 & 1,5 & 2 & 2,5 & 3 & 3,5 & 4 \\
\hline 1 & 1,058 & 1,095 & 1123 & 1,144 & 1,156 & 1,162 & 1,161 & 1,155 & 1,144 & 1,128 & 0,739 & 0,531 & 0,394 & 0,280 & 0,228 & 0,188 \\
\hline 1,2 & 1,149 & 1,203 & 1,245 & 1,277 & 1,299 & 1,314 & 1,322 & 1,324 & 1,321 & 1,314 & 0,952 & 0,698 & 0,502 & 0,393 & 0,307 & 0,255 \\
\hline 1,3 & 1,200 & 1,261 & 1,308 & 1,344 & 1,370 & 1,387 & 1,399 & 1,404 & 1,405 & 1,402 & 1,084 & 0,78 & $0,5 \bar{B}$ & 0,439 & 0,352 & 0,24 \\
\hline 1,4 & 1,252 & 1,319 & 1,370 & 1,408 & 1,437 & 1,457 & 1,471 & 1,479 & 1,483 & 1,493 & 1,222 & 0,898 & 0,651 & 0,500 & 0,402 & 0,337 \\
\hline 1,5 & 1,304 & 1,375 & 1,429 & 1,469 & 1,499 & 1,521 & 1,536 & 1,546 & 1,553 & 1,555 & 1,396 & 1,004 & 0,737 & 0,567 & 0,457 & \begin{tabular}{|l}
0,333 \\
\end{tabular} \\
\hline 1,6 & 1,356 & 1,430 & 1,485 & 1,525 & 1,556 & 1,578 & 1,595 & 1,606 & 1,614 & 1,618 & 1,576 & 1,131 & 0,820 & 0,639 & 0,515 & 0,432 \\
\hline 1,7 & 1,406 & 1,481 & 1,536 & 1,577 & 1,607 & 1,629 & 1,646 & 1,658 & 1,667 & 1,673 & $1,7 B$ & 1,267 & 0,929 & 0,716 & 0,578 & 0,485 \\
\hline 1,8 & 1,454 & 1,529 & 1,583 & 1,622 & 1,652 & 1,674 & 1,690 & 1,708 & 1,712 & 1,719 & 1,790 & 1,414 & 1,036 & 0,798 & 0,645 & 0,542 \\
\hline
\end{tabular}

Table 2 - Values of $\mathrm{k}_{\mathrm{cr}}$ coefficient

The local buckling coefficient are introduced graphically bellow, covering the entire design range.

Local buckling coefficient $k_{\mathrm{r}}(\xi=1)$

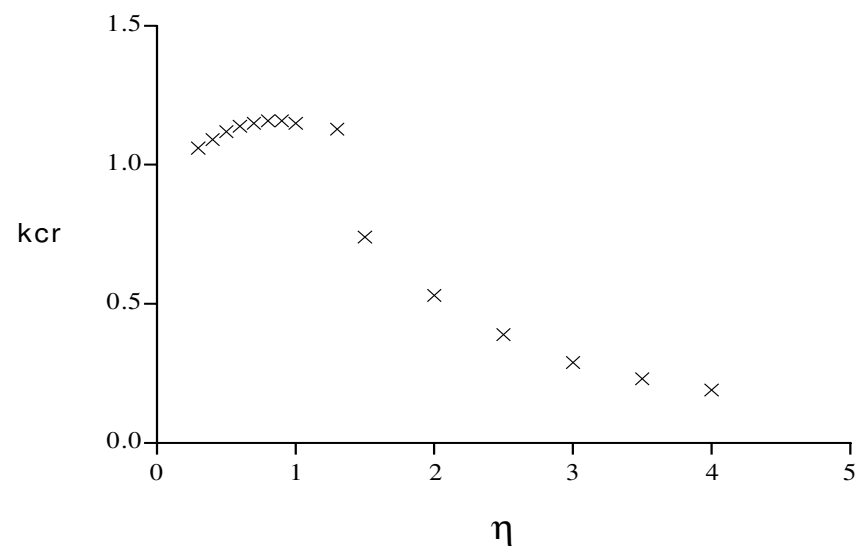

Figure 4.17 - Local buckling coefficient $\xi=1$.

Local buckling coefficient $\mathrm{k}_{\mathrm{r}}(\xi=1.5)$

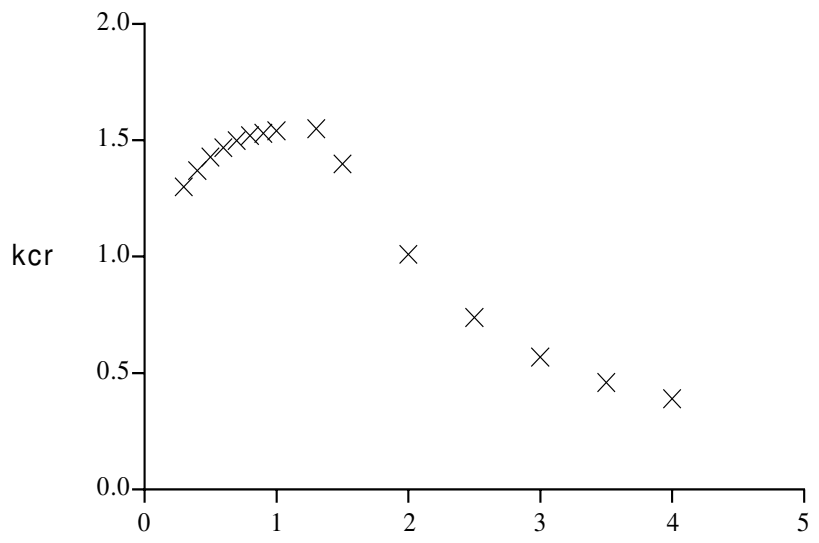

$\eta$

Figure 4.18 - Local buckling coefficient $\xi=1.5$. 


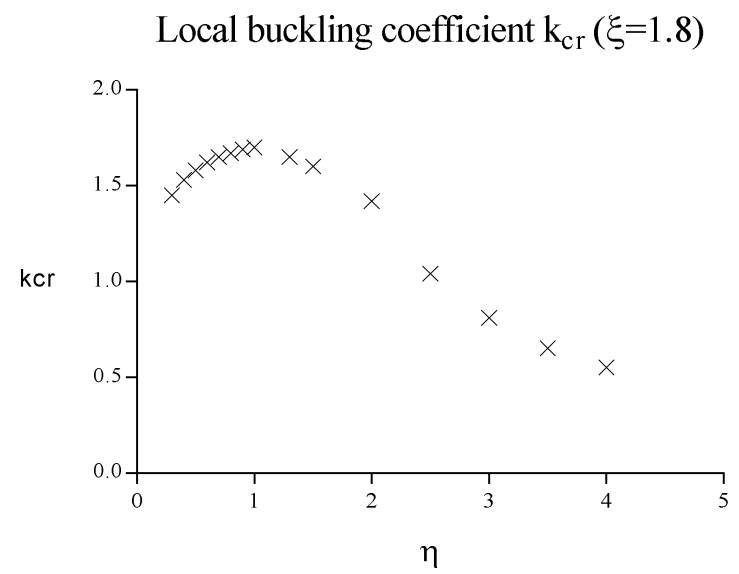

Figure 4.19 - Local buckling coefficient $\xi=1.8$. 


\section{5 \\ Analysis of results}

This chapter presents the results obtained from the local buckling analysis of castellated beams. It provides a comparison of results obtained from ABAQUS, GBTUL and the proposed equation.

As mentioned previously, the present study focused on the buckling behavior of castellated beam subjected to pure bending. For this type of solicitation, the region below the hole hardly ever suffers out of plane deflections, since it is in tension. For this reason, the structure can be represented by an upper tee section. Firstly, a validation of this simplification was carried out by comparing the results obtained from the complete model developed in ABAQUS and the simplified model in GBTUL.

Once the simplifying assumption was validated, a parametric study was performed, varying $\eta$ (ratio between flange width and web height) and $\xi$ (ratio between flange thickness and web thickness), through the whole range of each variable. Thereby, it was possible to validate the equation for all the existing commercial profiles. Both ABAQUS and GBTUL models were analyzed. The results are presented graphically, with a clear distinction between two possible types of buckling, i.e., the one governed by the web and the one governed by the flange. The change in buckling type occurs when $\eta$ equals to 1.2.

In addition, the results were also compared against design code equations, namely the AISC[16] specification and with analytical solutions provide by Timoshenko [14].

Unfortunately, the searched database did not return any work reporting experimental results for comparison.

The results indicate that the proposed equation can effectively calculate the critical stress of castellated beams due to local instability. The validated expression 
and its associated limits are intended to be general within the limits typical of practical applications.

\subsection{Validation as a Tee section}

GBTUL was used to investigate the elastic buckling behavior of the simplification of the upper Tee section. The results were compared with those obtained for the complete finite element model using ABAQUS.

Figure 5.1 and Figure 5.2 show the comparison of critical stresses obtained by GBTUL, using the simplification of tee section, in comparison with the results obtained for the complete model in ABAQUS.The results are shown for profiles within the commercial range, for which $\xi$ can vary from 1.0 to 1.8 and $\eta$ can vary from 0.1 to 4 . The two figures depict the critical stress for different ranges of $\eta$ and therefore different buckling modes. Figure 5.1 is associated with web buckling ( $\eta$ $<1.2)$ and Figure 5.2 is associated with flange buckling $(\eta>1.2)$.

ABAQUSxGBTUL

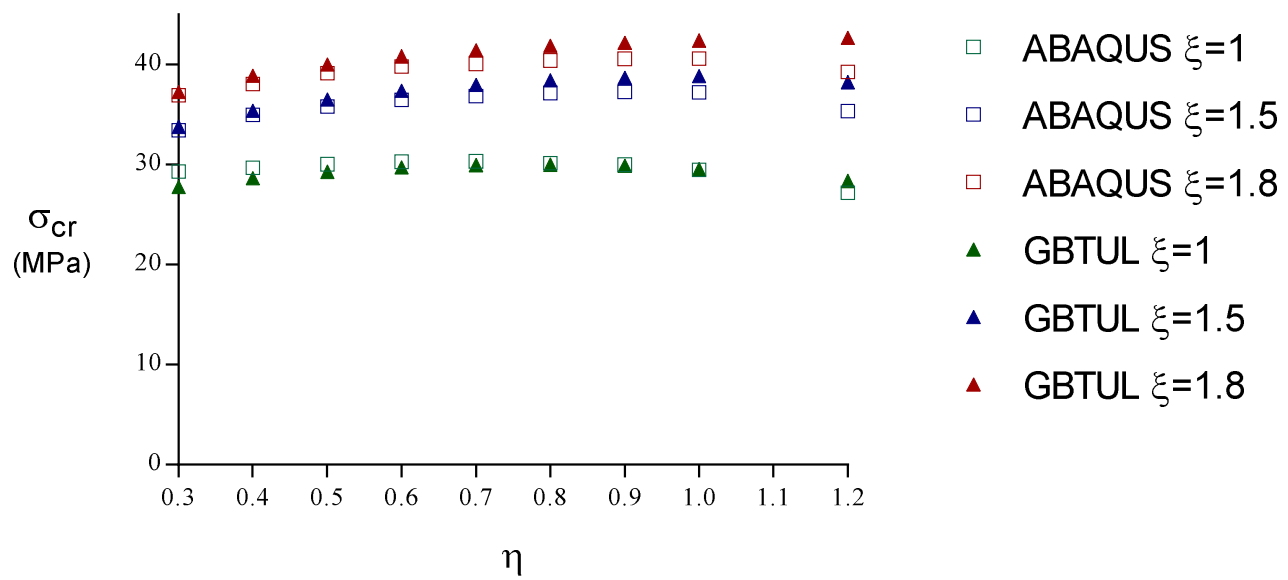

Figure 5.1 - Web buckling - ABAQUS and GBTUL results. 


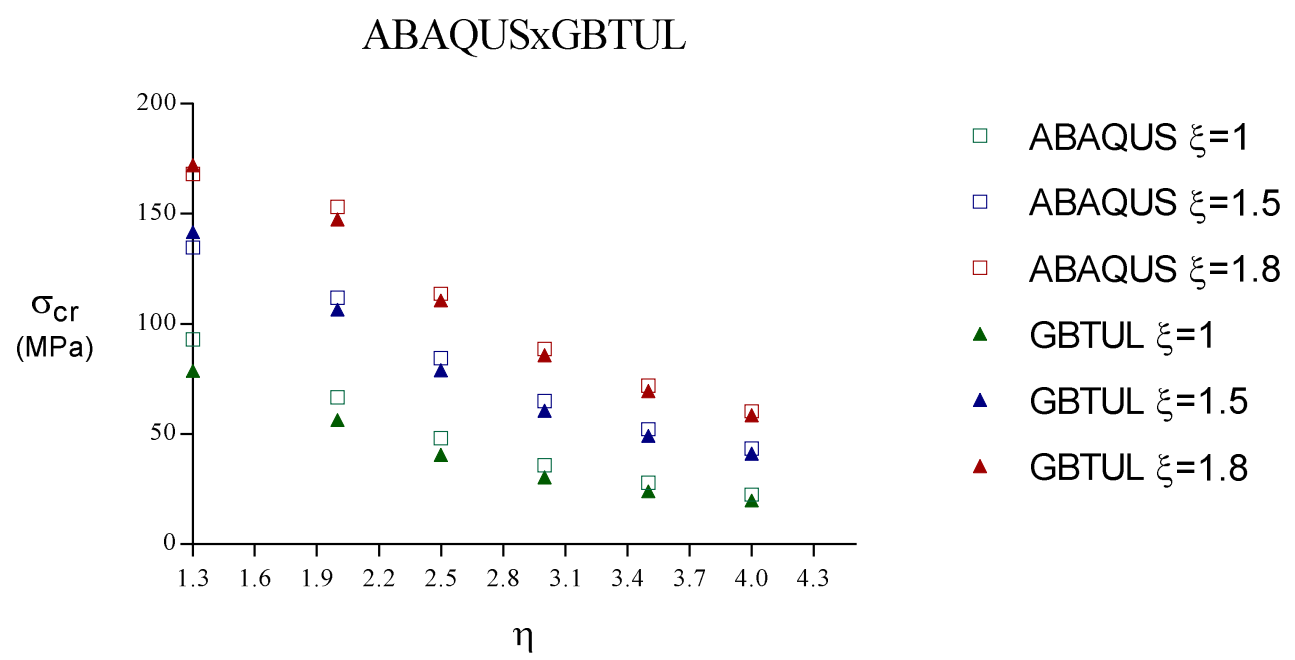

Figure 5.2 - Flange buckling - ABAQUS and GBTUL results.

All the results obtained using ABAQUS and GBTUL software are presented in Appendix A (ABAQUS element-based elastic buckling results and GBTUL output).

As can be seen from these two figures the results converge and the maximum difference obtained is less than $15 \%$. Therefore, it was concluded that the hypothesis of the Tee section is validand and the buckling behavior of a castellated beam under pure bending can be locally analyzed as a Tee section under bending and compression.

To further illustrate the accuracy of the results, normalized graphs are provided, showing the ratio between the GBTUL result over the ABAQUS result. Figure 5.3 through 5.8 illustrate these findings for selected values of $\xi$. 
ABAQUSxGBTUL $\xi=1$

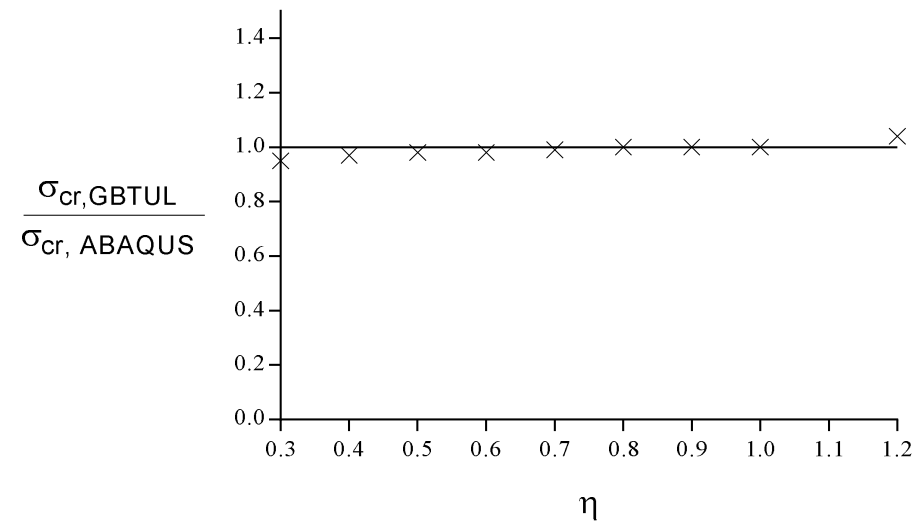

Figure 5.3 - Web buckling - normalized results $-\xi=1.0$

ABAQUSxGBTUL $\xi=1.5$

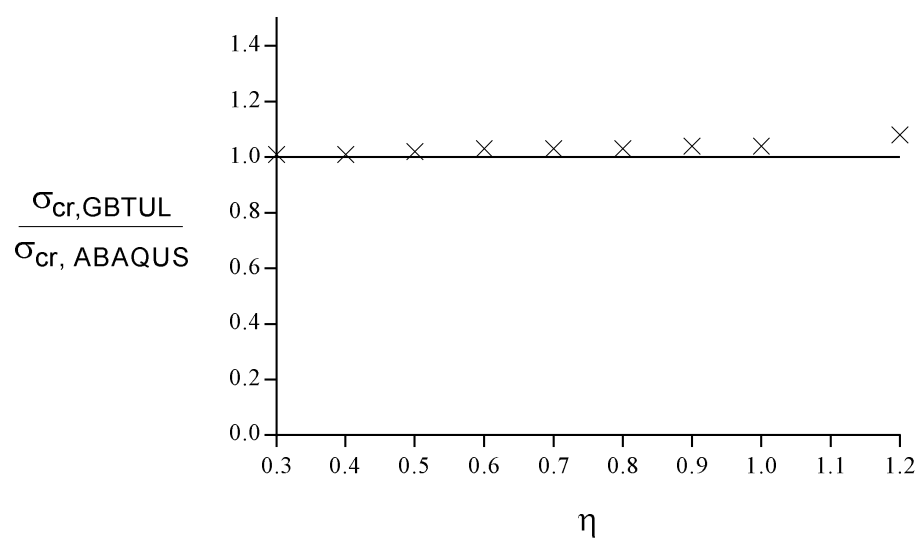

Figure $5.4-$ Web buckling - normalized results $-\xi=1.5$

ABAQUSxGBTUL $\xi=1.8$

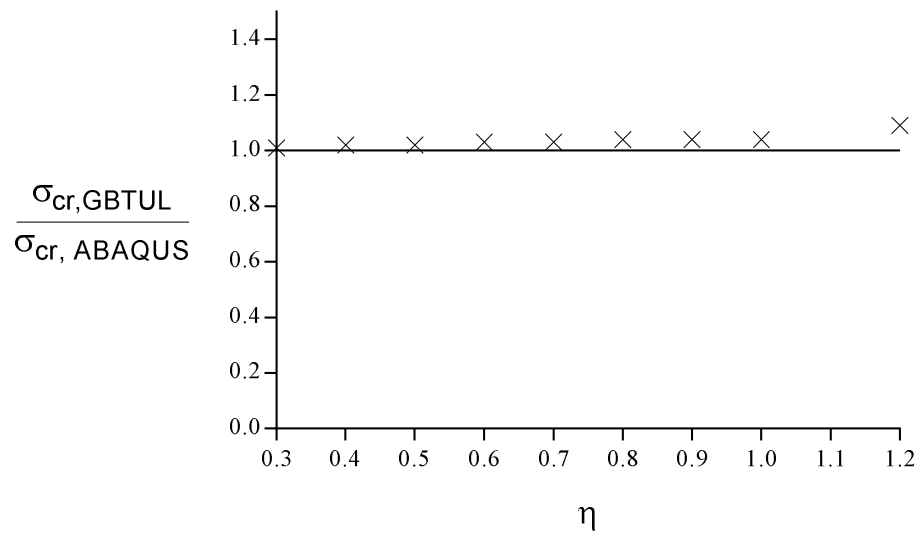

Figure $5.5-$ Web buckling - normalized results $-\xi=1.8$ 


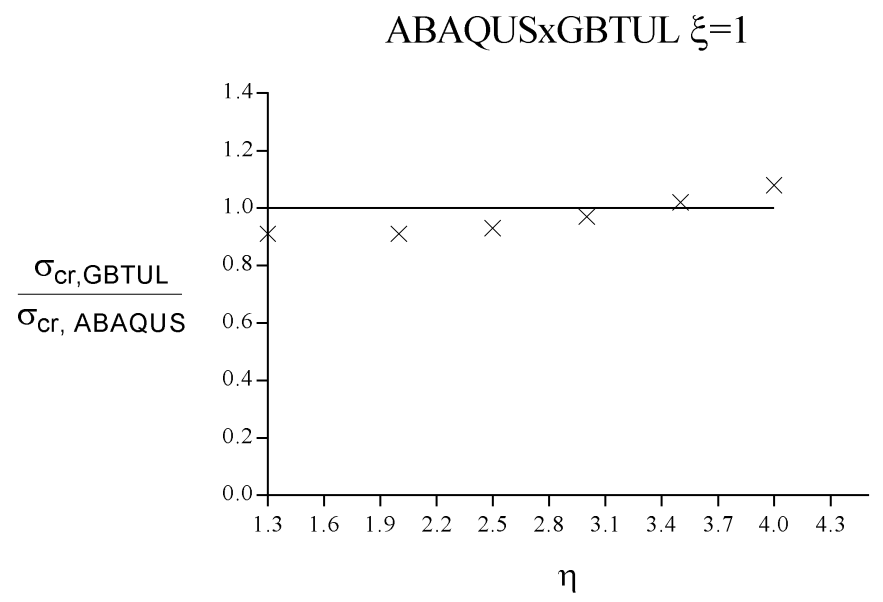

Figure 5.6 - Flange buckling - normalized results $-\xi=1.0$

ABAQUSxGBTUL $\xi=1.5$

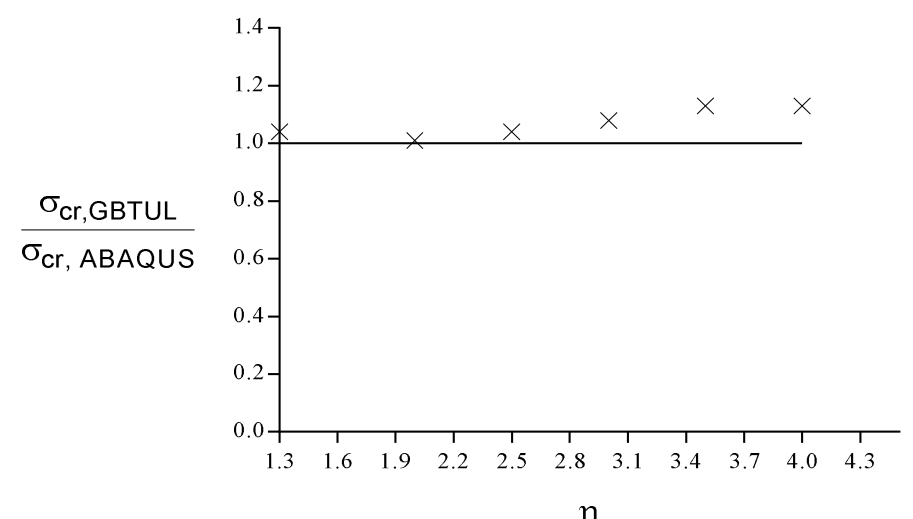

Figure 5.7 - Flange buckling - normalized results $-\xi=1.5$

ABAQUSxGBTUL $\xi=1.8$

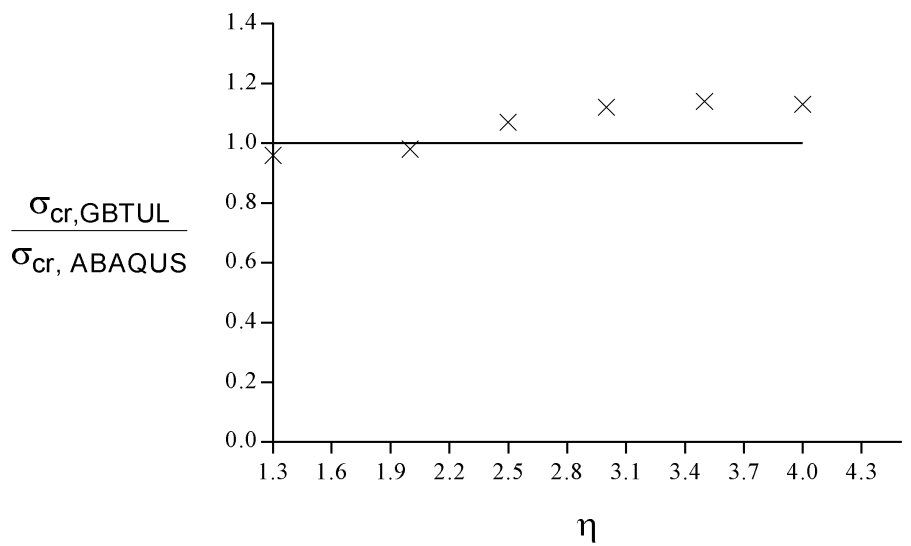

Figure 5.8 - Flange buckling - normalized results $-\xi=1.8$ 


\subsection{Proposed equation validation}

In order to validate the proposed equation, both ABAQUS and GBTUL results are considered. To perform this comparison, several models were created in both softwares, contemplating the whole design range.

A comparison was first done between the proposed equation and GBTUL output, seeking to validate the approximation adopted. Then, the equation was further compared with the results form ABAQUS analysis.

The results obtained for these comparisons, as well as the normalized results, are presented in Figures 5.9 through 5.24.

- Results validation - web buckling governing range:

Proposed Equation x GBTUL

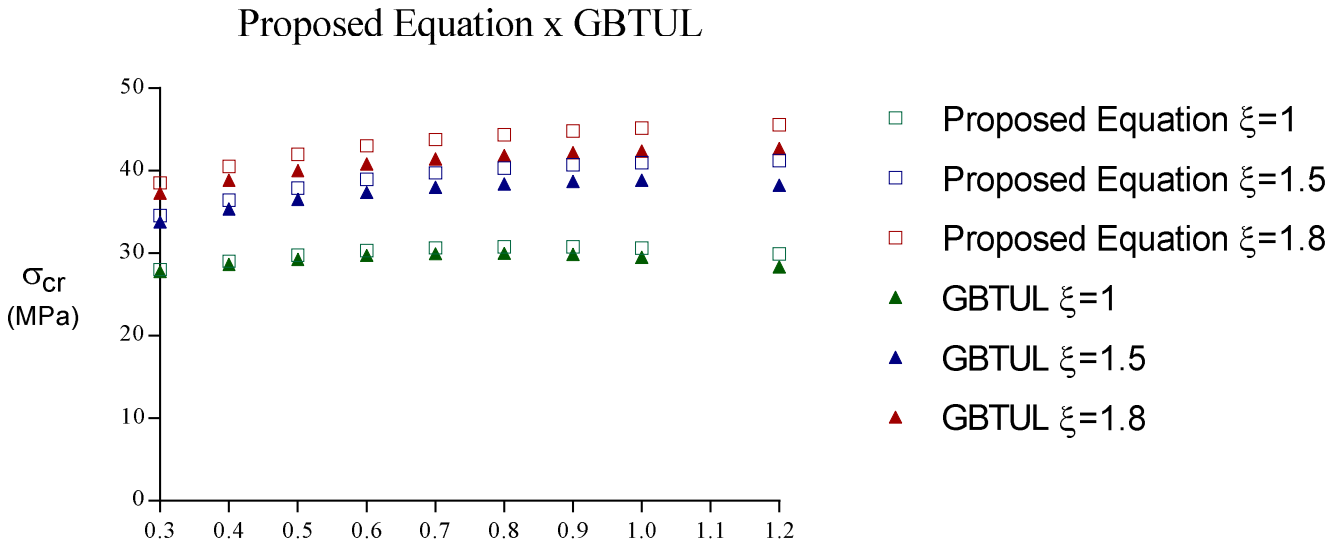

$\eta$

Figure 5.9 - Web buckling - proposed equation x GBTUL

Proposed Equation x GBTUL $\xi=1$

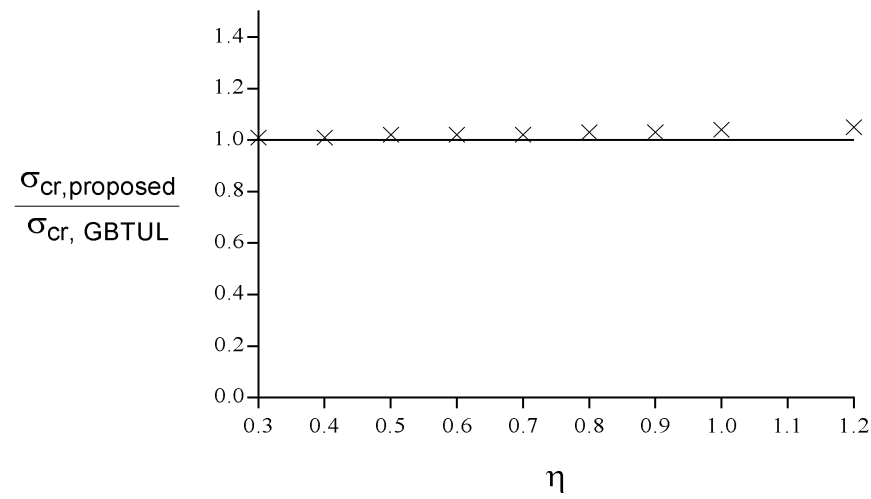

Figure 5.10 - Web buckling normalized results- Proposed equation x GBTUL $\xi=1.0$ 
Proposed Equation $x$ GBTUL $\xi=1.5$

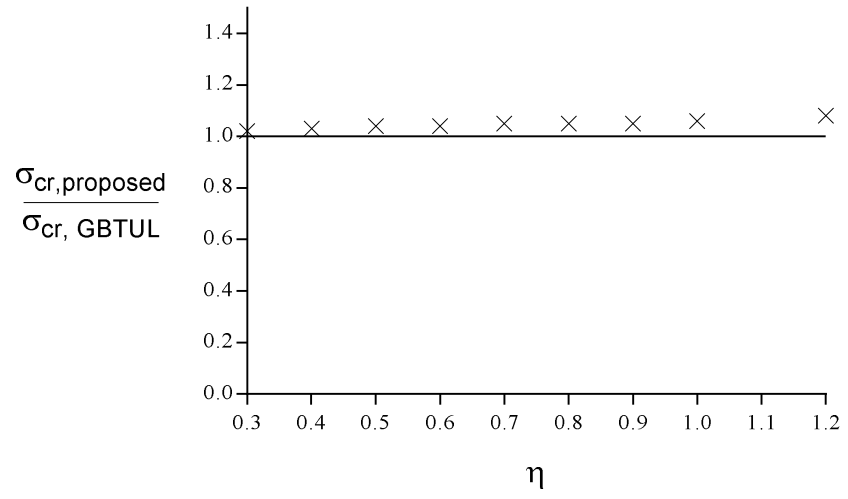

Figure 5.11 - Web buckling normalized results - Proposed equation x GBTUL $\xi=1.5$

Proposed Equation $x$ GBTUL $\xi=1.8$

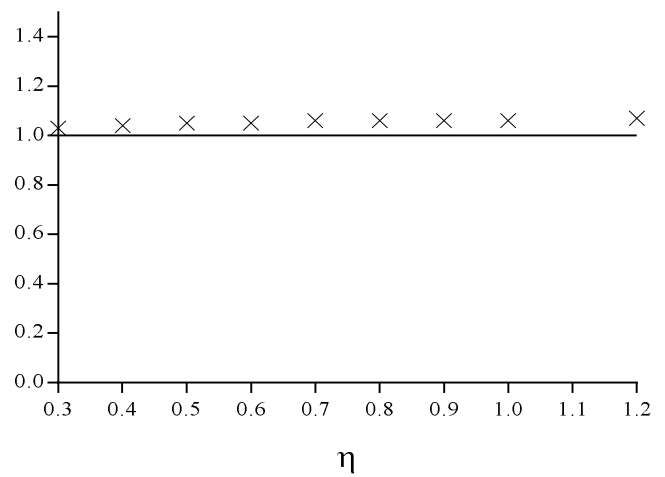

Figure 5.12 - Web buckling normalized results - Proposed equation x GBTUL $\xi=1.8$ 


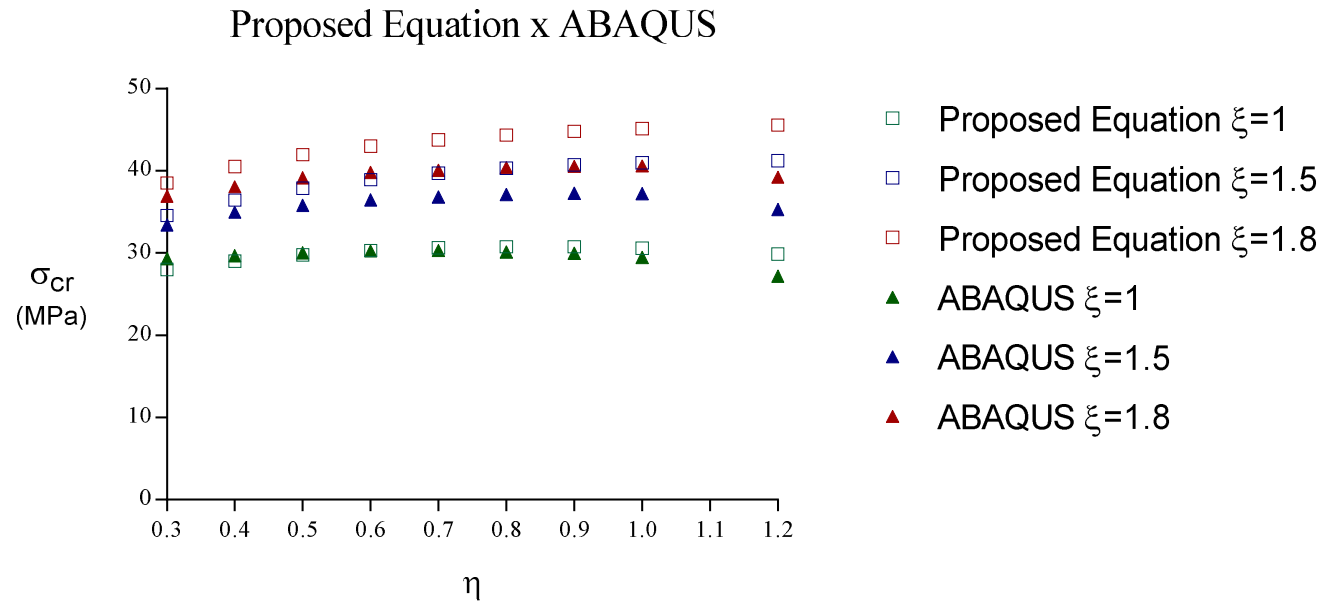

Figure 5.13 - Web buckling - proposed equation x ABAQUS

Proposed Equation $x$ ABAQUS $\xi=1$

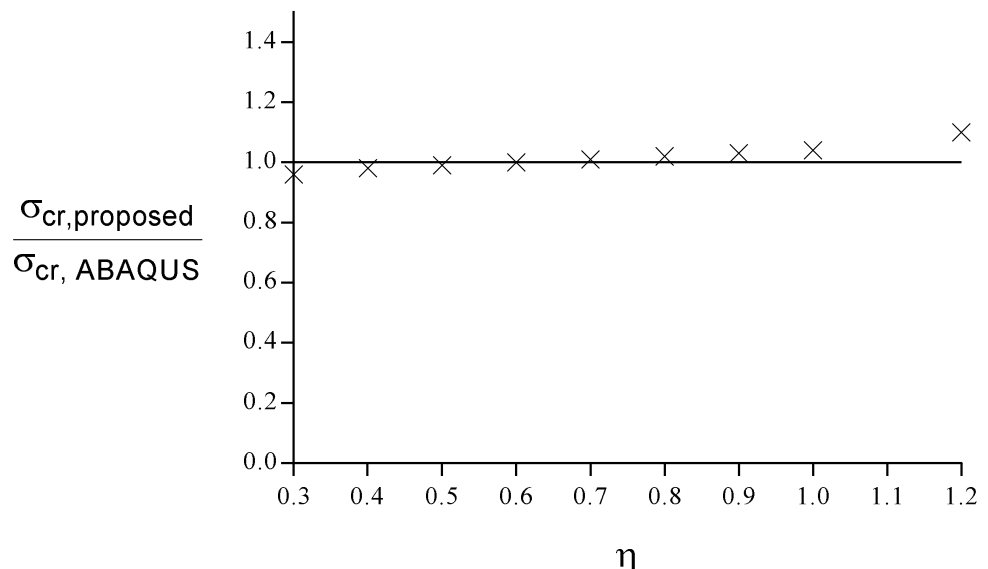

$\eta$

Figure 5.14 - Web buckling normalized results - Proposed equation x ABAQUS $-\xi=1.0$ 
Proposed Equation x ABAQUS $\xi=1.5$

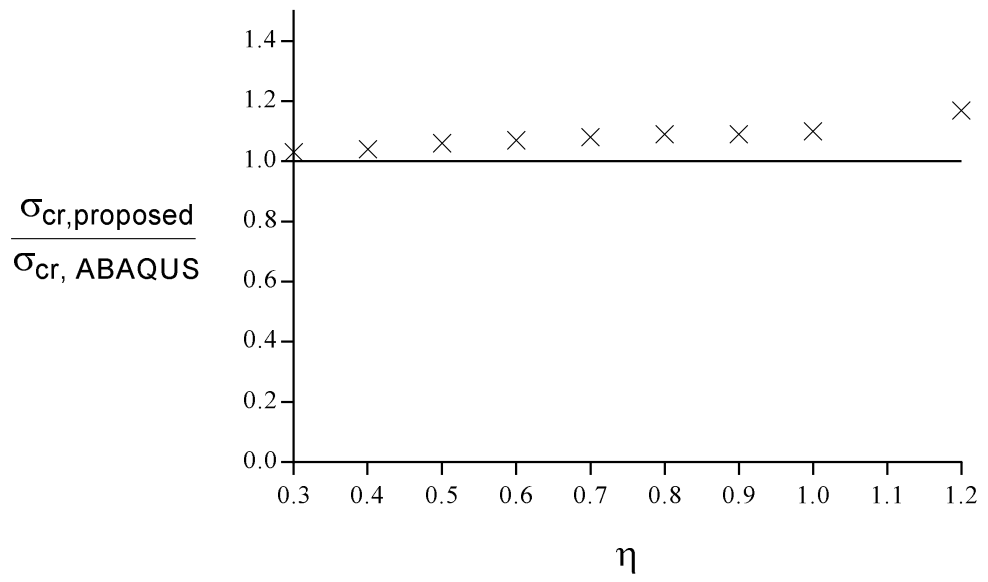

Figure 5.15 - Web buckling normalized results - Proposed equation x ABAQUS $-\xi=1.5$

Proposed Equation $\mathrm{x}$ ABAQUS $\xi=1.8$

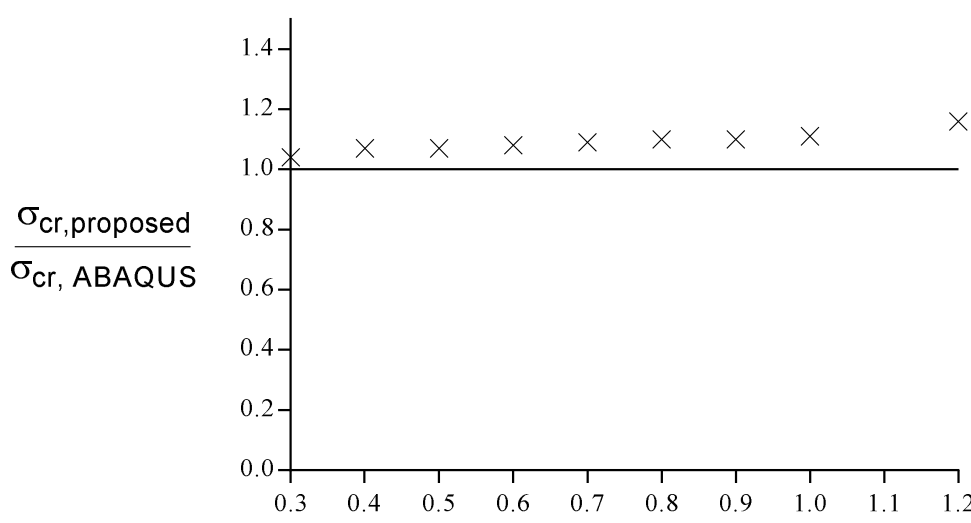

$\eta$

Figure 5.16 - Web buckling normalized results - Proposed equation x ABAQUS $-\xi=1.8$ 
- Results validation - flange buckling governing range:

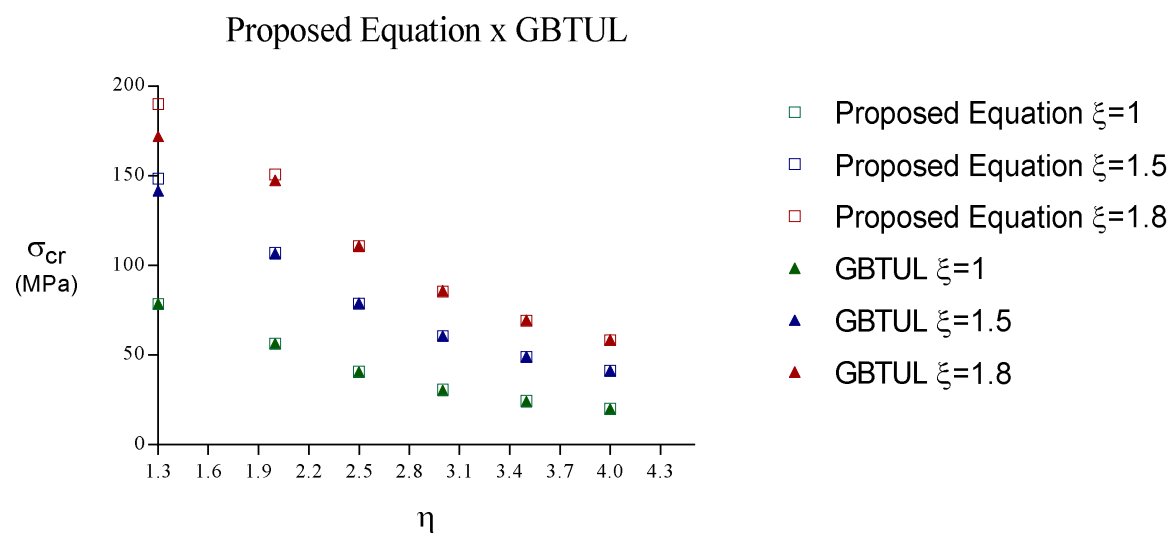

Figure 5.17 - Flange buckling - proposed equation x GBTUL

Proposed Equation x GBTUL $\xi=1.0$

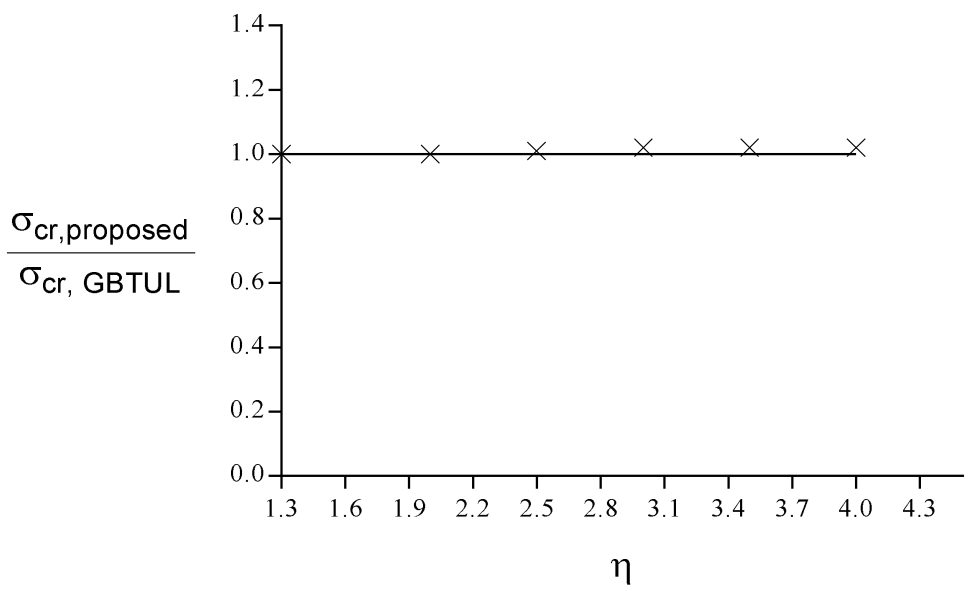

Figure 5.18 - Flange buckling normalized results - Proposed equation x GBTUL

$$
-\xi=1.0
$$


Proposed Equation x GBTUL $\xi=1.5$

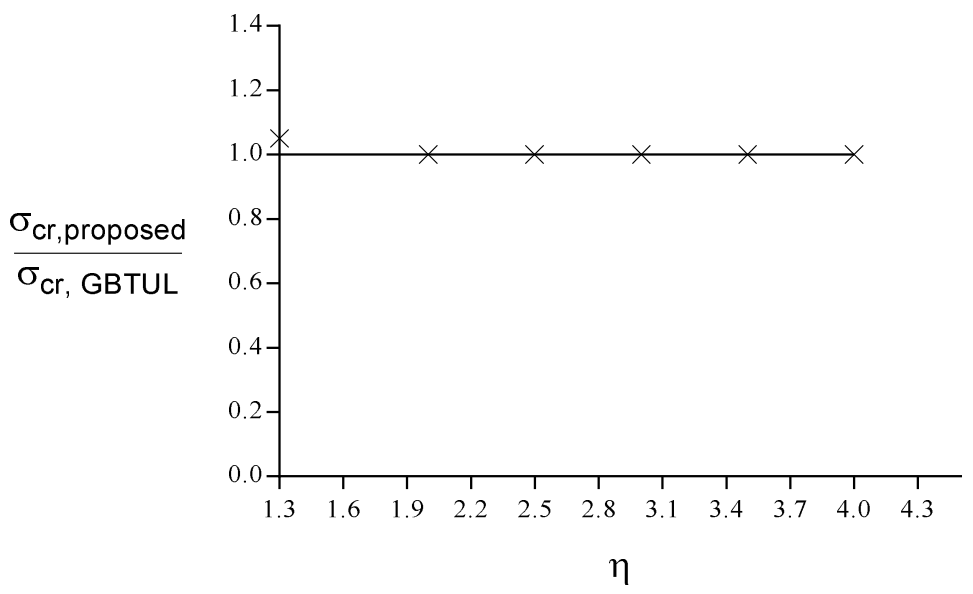

Figure 5.19 - Flange buckling - normalized results - proposed equation $\mathrm{x}$ GBTUL $-\xi=1.5$

Proposed Equation x GBTUL $\xi=1.8$

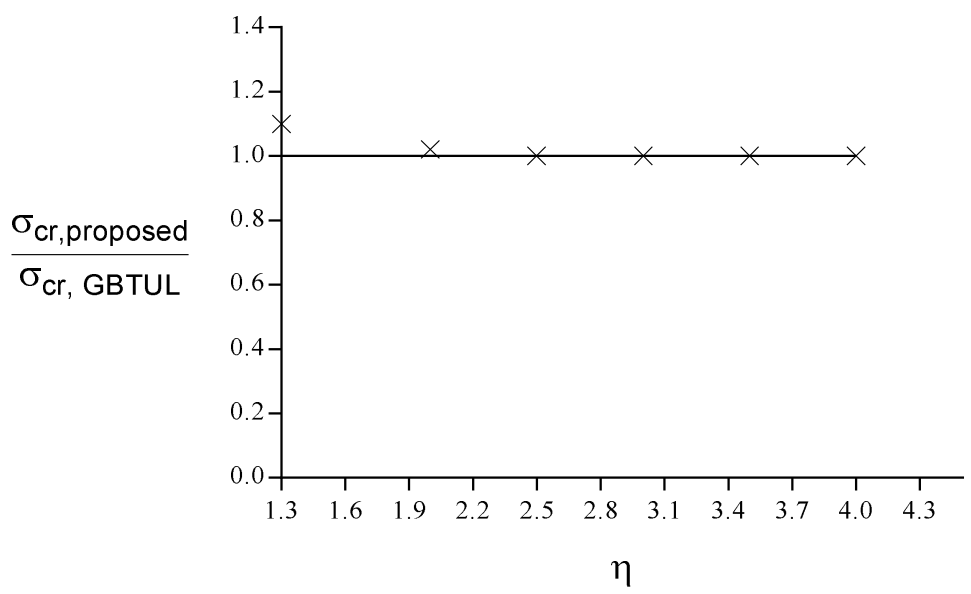

Figure 5.20 - Flange buckling - normalized results - proposed equation $\mathrm{x}$ GBTUL $-\xi=1.8$ 


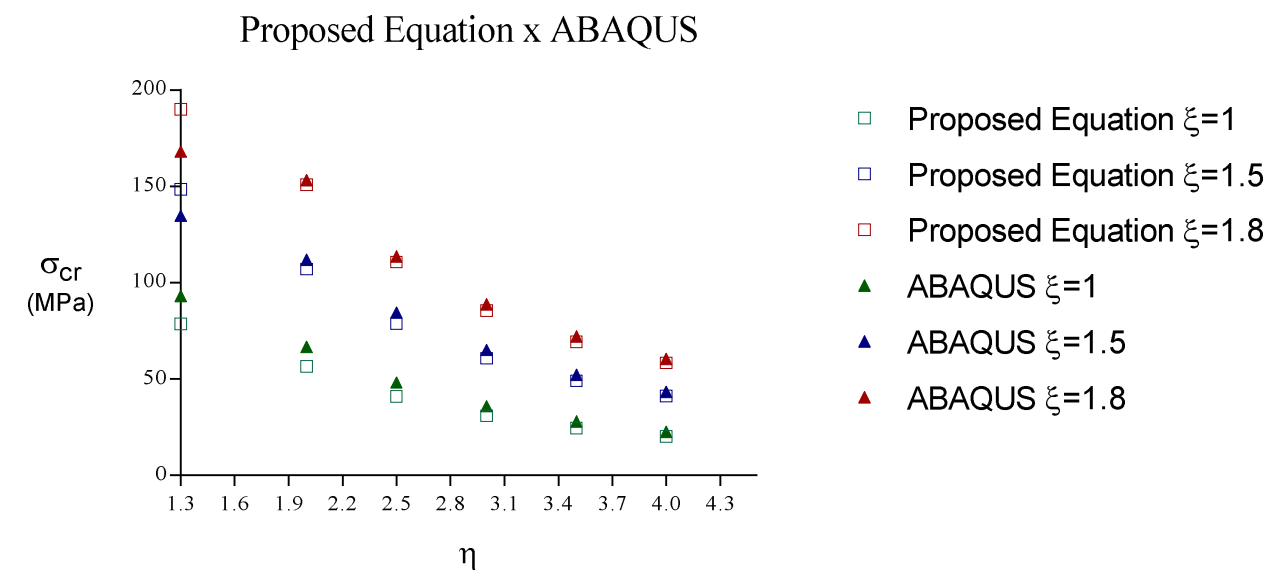

Figure 5.21 - Flange buckling - Proposed equation x ABAQUS

Proposed Equation x ABAQUS $\xi=1.0$

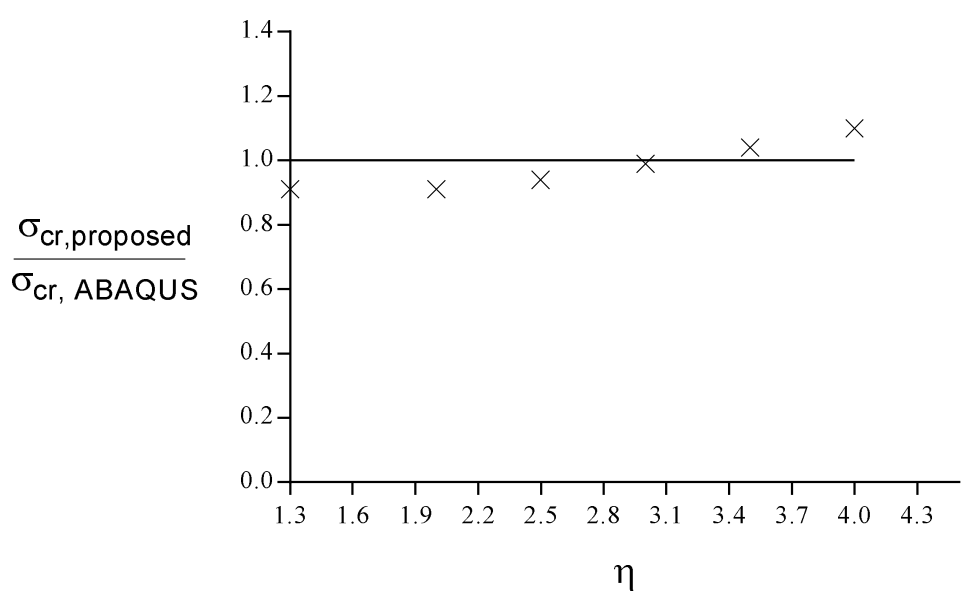

Figure 5.22 - Flange buckling normalized results - Proposed equation $\mathrm{x}$ ABAQUS $-\xi=1.0$ 
Proposed Equation x ABAQUS $\xi=1.5$

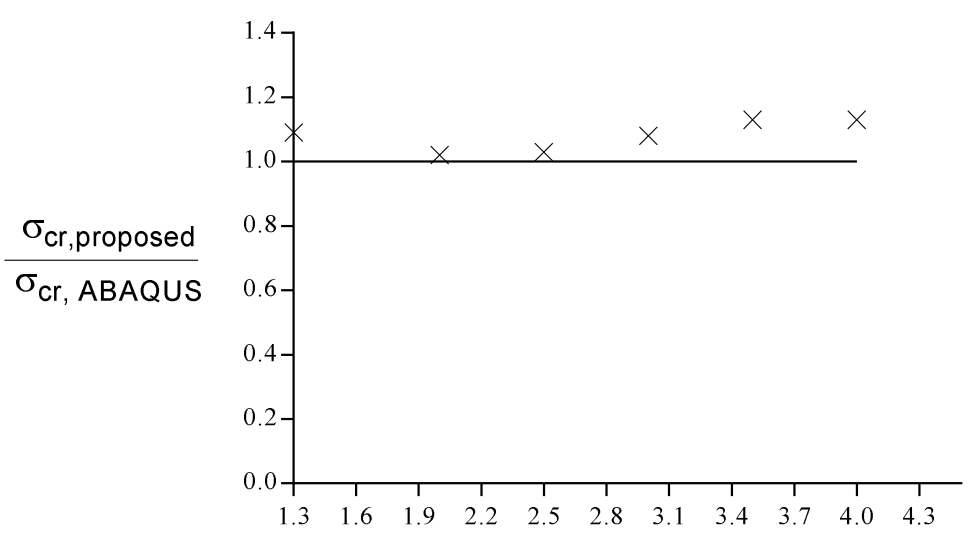

$\eta$

Figure 5.23 - Flange buckling normalized results - Proposed equation $\mathrm{x}$ ABAQUS $-\xi=1.5$

Proposed Equation x ABAQUS $\xi=1.8$

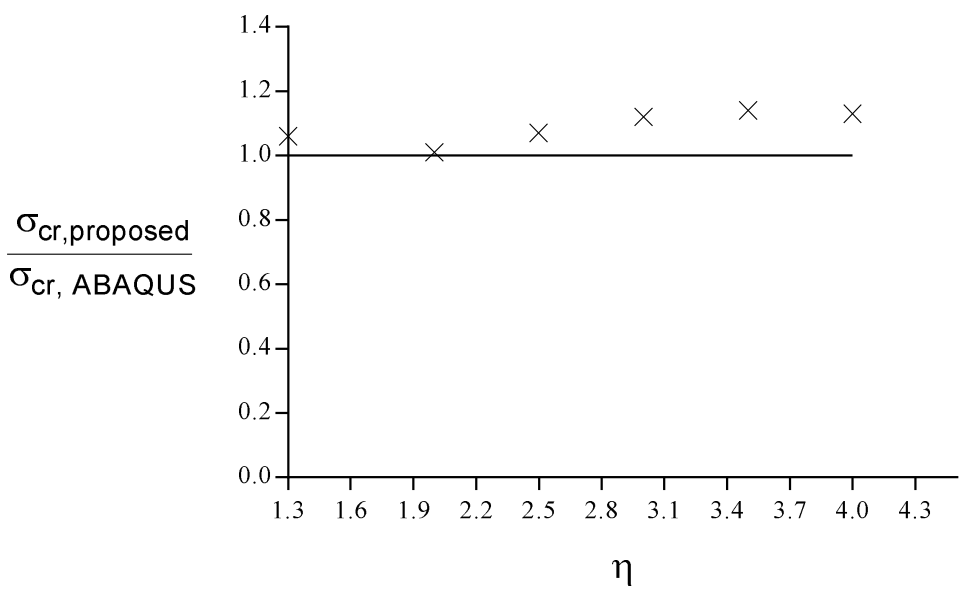

Figure 5.24 - Flange buckling - normalized results - proposed equation $\mathrm{x}$ ABAQUS $-\xi=1.8$

The results show that the proposed equation produces accurate results. The maximum error observed is less than $20 \%$. This loss of accuracy occurs when $\eta$ range between 1.0 and 1.2. At this range, a transitional area between web and flange buckling occurs, neither of the proposed equations are able to represent the behavior precisely. For the other ranges of $\eta$, the maximum error observed was less than $4 \%$. 


\subsection{Standards recommendations and analytical solution}

The AISC design guide 31 [6] is the most recent normative device for castellated and cellular beam. The available axial strength of the top and bottom tees can be calculated by Tee section simplification, thereby reducing the number of calculations. For simplicity, it is acceptable and slightly conservative to treat the assumed uniform compression throughout the top tee section (Figure 5.25). In this case, the problem is analyzed as a tee section strut subjected flexural torsional buckling (Eq. 39 and Eq. 40). More information can be found in chapter $\mathrm{E}$ of the AISC specification[16].

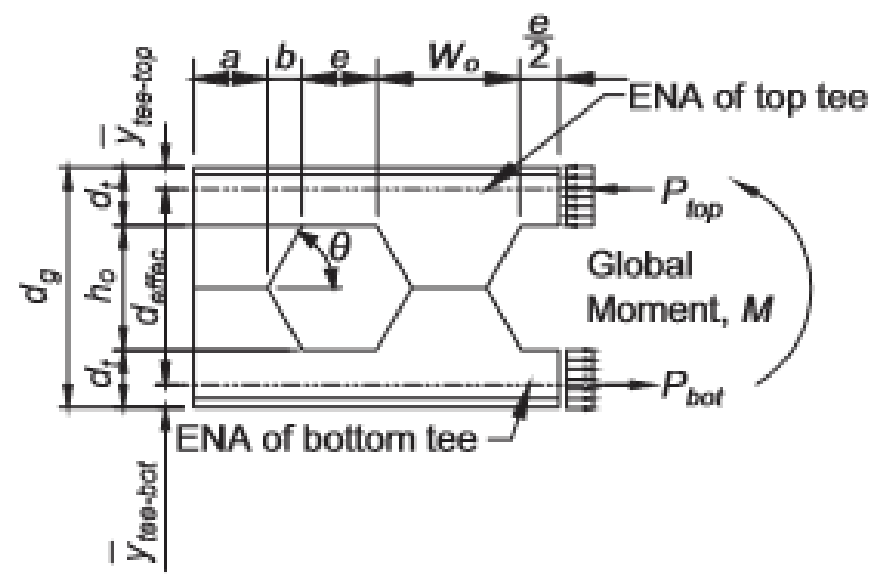

Figure 5.25 - Terminology used in AISC Design Guide 31 [6].

$$
\begin{aligned}
& F_{e}=\left[\frac{\pi^{2} E C_{w}}{\left(L_{e z}\right)^{2}}+G J\right] \frac{1}{A_{g} \cdot{\overline{r_{0}}}^{2}} \\
& {\overline{r_{0}}}^{2}=x_{0}{ }^{2}+y_{0}{ }^{2}+\frac{I_{x}+I_{y}}{A_{g}}
\end{aligned}
$$

In which:

$\mathrm{G}=$ shear modulus of elasticity of steel $=11,200 \mathrm{ksi}(77200 \mathrm{MPa})$

$\mathrm{J}=$ torsional constant, in.4 (mm4)

$\mathrm{C}_{\mathrm{w}}=$ warping constant, in.6 (mm6)

$\mathrm{L}_{\mathrm{cz}}=$ effective length of member for buckling about the longitudinal axis, in. (mm)

$\mathrm{x}_{\mathrm{o}}, \mathrm{y}_{\mathrm{o}}=$ coordinates of the shear center with respect to the centroid, in. $(\mathrm{mm})$

$\mathrm{I}_{\mathrm{x}}, \mathrm{I}_{\mathrm{y}}=$ moment of inertia about the principal axes, in.4 (mm4) 
For the analyzed case the warping constant is zero.

Timoshenko and Gere [14] developed an analytical solution for this case, considering each flange as a uniformly compressed plate supported along three sides and completely free along the fourth side, as shown in Figure 5.26. This investigation shows that the critical stress is obtained according to Eq. 41, where b is the plate length, $\mathrm{t}$ is the plate thickness and $\mathrm{L}$ is the element length.

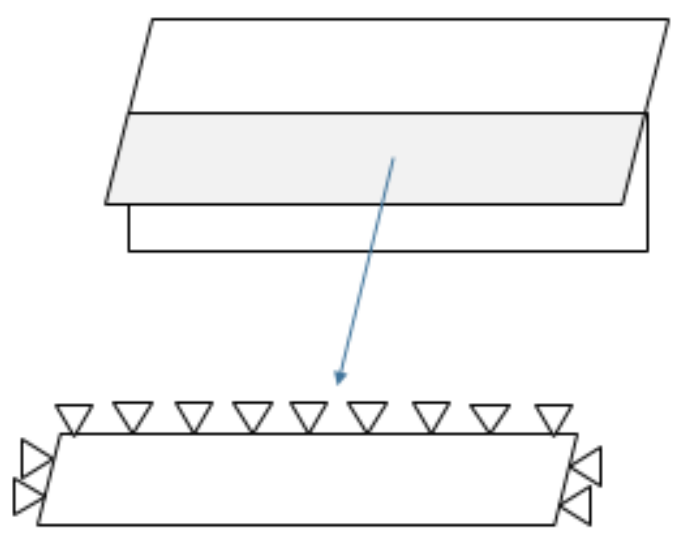

Figure 5.26 - Timoshenko analysis

$$
\sigma_{c r}=\left(0.456+\frac{b^{2}}{L^{2}}\right) \cdot \frac{\pi^{2}}{6 \cdot(1-v)} \cdot \frac{G t^{2}}{b^{2}}
$$

For beams subjected to general loading, the American guide analyzes the structure similarly to a Vierendeel truss, where the moments caused by shear forces on the Tee zones should be checked.

The charts provided in Figures 5.27 through 5.29 show the recommendations of AISC (Flexural-torsional curve) plotted with the results obtained from the proposed equation, ABAQUS and Timoshenko results, for different values of $\xi$. 
Comparison of normative results $\xi=1$

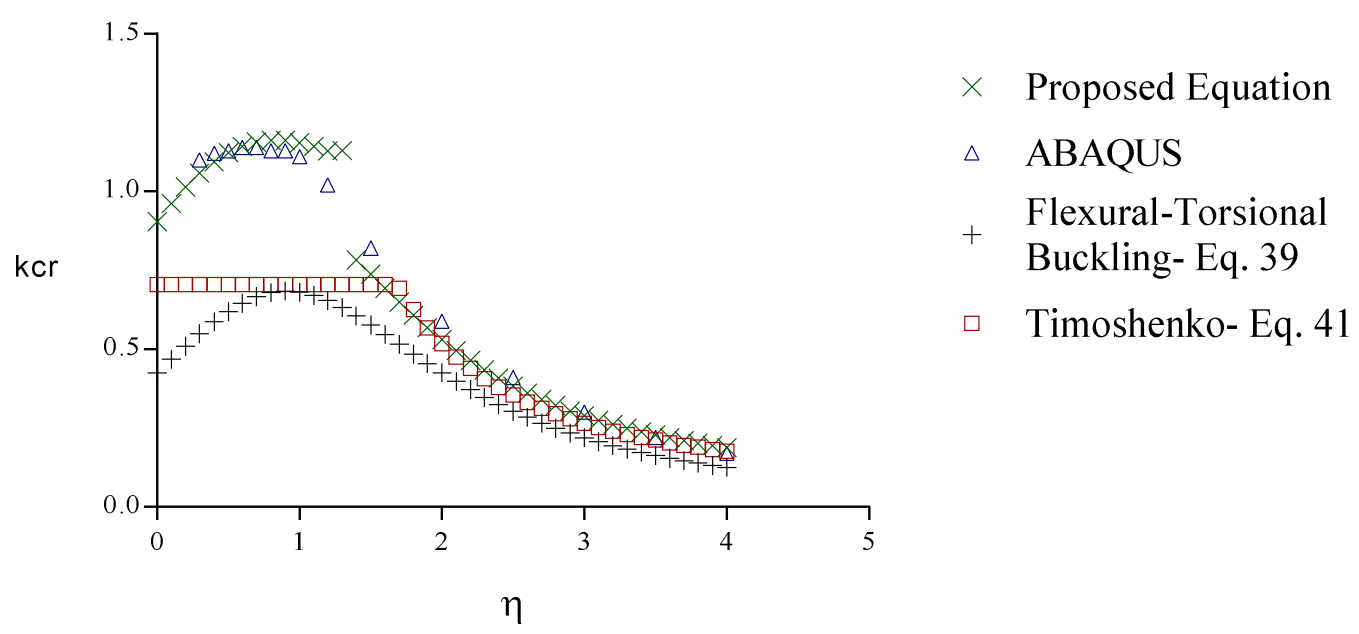

Figure $5.27-$ Comparison of results $-\xi=1.0$

Comparison of normative results $\xi=1.5$

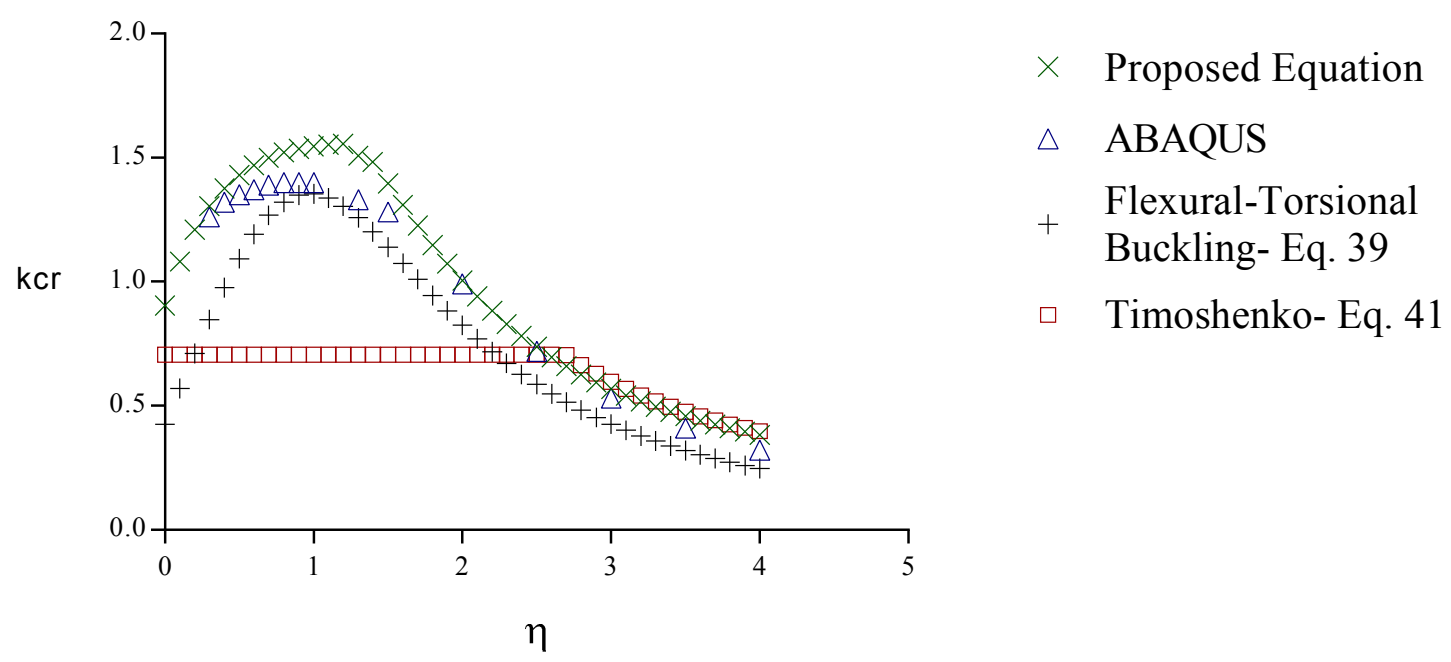

Figure 5.28 - Comparison of results $-\xi=1.5$ 
Comparison of normative results $\xi=1.8$

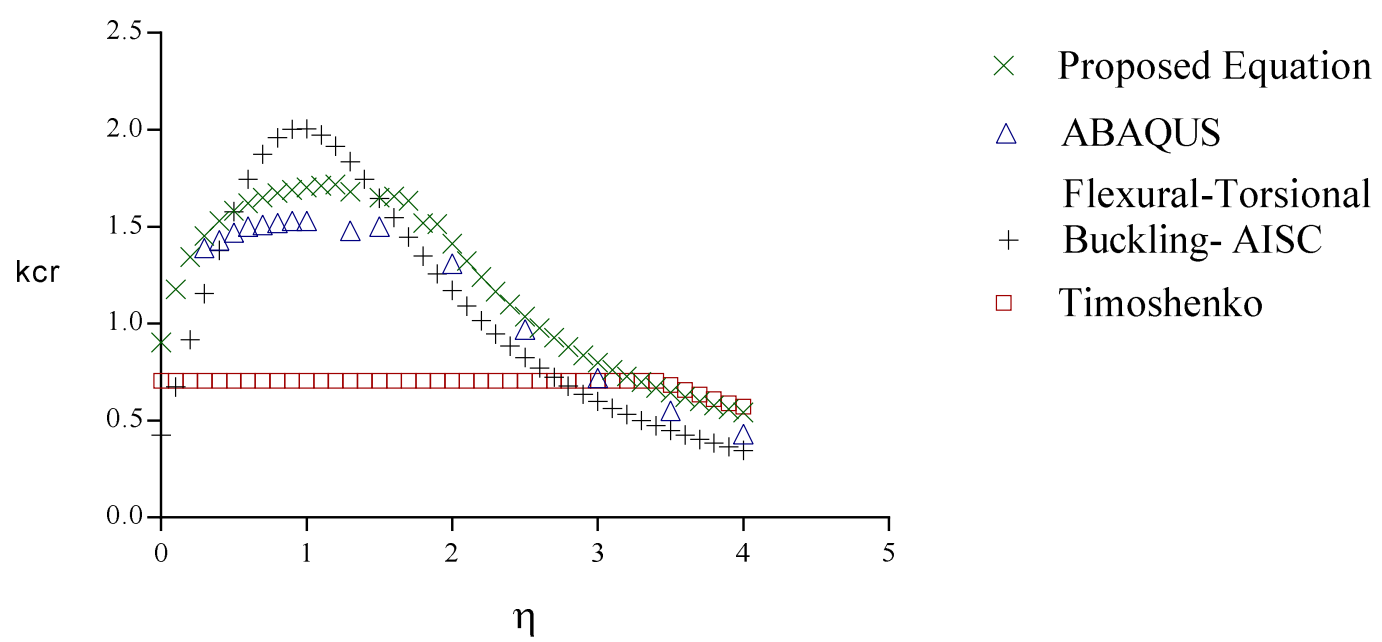

Figure $5.29-$ Comparison of results $-\xi=1.8$

As it can be seen from Figure 5.27 and Figure 5.28, the design code recommendations are conservative for local buckling of the web. Therefore, as can be seen from Figure 5.29 the design code recommendations are non-conservative for $0.5<\eta<1.2$, which is not commonly adopted for castellated beams. These differences may be explained by the fact that actual web buckling modes involve transverse bending of the web (Fig. 5.30 a) and not a simple twisting rotation about the shear center (Fig. 5.30 b).

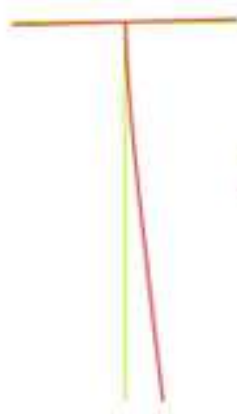

(a)

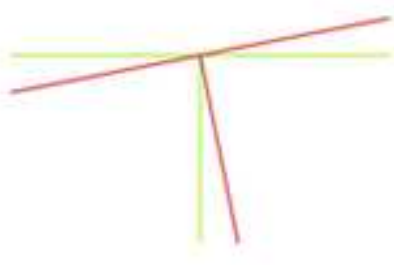

(b)

Figure 5.30 - GBTUL (a) Web local buckling (b) Flange local buckling 


\section{6 \\ Conclusions and further investigations}

\subsection{Conclusions}

In this research empirical equations were developed to predict the elastic buckling stress of castellated beams based on classical plate stability equations. The equations were validated against the results obtained by a finite element model in ABAQUS, a simplified Tee-section model in GBTUL, standards equations, and analytical solutions. The main conclusions from this work are as follows:

- The local buckling is influenced by plate dimensions, which determine if buckling is governed by the flange or by the web. Therefore, two equations were developed for each type of local buckling.

- There is a critical region ( $\eta$ between 1 and 1.5) for which there is a transition between the two types of local buckling. In this region the results obtained by the proposed equations were not as accurate as for the other ranges. However, the error incurred by the proposed equations is below $20 \%$.

- The simplification of the Tee section as a frame, where the stiffness of the flange is represented by a rotational spring, proved to be good idealization of actual local buckling behavior of a castellated beam. The rotational stiffness was determined by geometric properties provided by the compression flange, obtaining a good physical representation of the structural behavior and consequently produced accurate results. The initial attempt without this consideration did not provide good results for different values of $\xi$.

- The validated results of the proposed equations indicate that it can be effectively used to calculate the critical stress of castellated beams due to local instability.

- The proposed expressions and their associated limits are applicable within the limits typical of practical applications.

- The design code recommendations were found to be conservative for local buckling of the web and non-conservative for $0.5<\eta<1.2$, in which the critical behavior is influenced by web flexure. 
- The proposed equations are useful because their parameters have physical meaning that can be easily interpreted.

\subsection{Future research works}

Suggestions for future research in this area are:

- To study the critical load of castellated beams subjected to different loading situations, i.e., considering for example a combination of bending and shear loads.

- To study the effect of welding on castellated beam's behavior.

- To investigate experimentally the failure modes of castellated beams.

- To propose resistance equations for castellated beams.

- To study the behavior of castellated beams under the effect of temperatures.

- To perform nonlinear finite element studies to identify the influence of residual stresses and plastic strains on castellated beams failure mechanisms.

- To propose resistance equations and perform reliability analyses to obtain the partial factors for design.

- To improve the accuracy of the equation by considering additional degrees of freedom along with the Rayleigh-Ritz method. 


\section{References}

[1] F. O. M. da Gama, "Avaliação numérica de estabilidade lateral de vigas casteladas," Universidade do Estado do Rio de Janeiro, 2012.

[2] P. D. H. Estrada, P.E., Ph.D. , J. J. Jimenez, and F. Aguíñiga, "Cost Analysis in the Design of Open-Web Castellated Beams," Aei 2006, no. 361, pp. 5353, 2006.

[3] "LATTEY Civil \& Precast." [Online]. Available: http://latteycivil.co.nz/newlook/precast/structural-items/beams/. [Accessed: 01-Jun-2015].

[4] FEM- ABAQUS/Standard Version 6.10-1. Dassault Systemes S.A., "ABAQUS." 2014.

[5] University of Lisbon, "GBTul Generalised Beam Theory Research Group at Lisbon." .

[6] Sameer S. Fares, J. Coulson, and David W. Dinehart, "Castellated and Cellular Beam Design 31," Am. Inst. Steel Constr., 2016.

[7] P. R. Knowles, “Castellated Beams," ICE Proc., vol. 90, no. 3, pp. 521-536, 1991.

[8] J. Braga and E. Sotelino, "Estudo da estabilidade de Vigas de Aço com Furos," 2015.

[9] "ArcelorMittal." [Online]. Available: http://blog.arcelormittal.com.br/tag/vigas-de-aco/.

[10] L. Amayreh and M. P. Saka, "Failure load prediction of castellated beams using artificial neural networks," Asian J. Civ. Eng. (Building Housing), vol. 6, no. 1-2, pp. 35-54, 2005.

[11] A. Chajes, Principles of Structural Stability Theory, N.M. Newma. New Jersey, 1974.

[12] R. D. Ziemian and J. Wiley, Guide to Stability Design Criteria for Metal Structures. 1998.

[13] Z. P. Bazant and L. Cedolin, Stability of Structures. 2010.

[14] S. P. S. Timoshenko and J. M. J. Gere, "Theory of elastic stability." p. 560, 2012.

[15] D. C. T. Cardoso et al., "Compressive Local Buckling of Pultruded GFRP ISections : Development and Numerical / Experimental Evaluation of an Explicit Equation," vol. 19, no. 2, pp. 1-12, 2015. 
[16] ANSI/AISC 360-10, "Specification for Structural Steel Buildings," Am. Inst. Steel Constr., pp. 1-612, 2010.

[17] NBR8800, "Projeto de estruturas de aço e de estruturas mistas de aço e concreto de edifícios," p. 237, 2008.

[18] Friedrich Bleich, Buckling Strength of Metal Structures. New York, 1952.

[19] George Gerard and Herbert Becker, "HANDBOOK OF STRUCTURAL STABTILITY," Natl. Advis. COMMITTE Aeronaut., no. PART IBUCKLING OF FLAT PLATES, 1957.

[20] E. Stowell, Elbridge Z; Lundquist, "Local instability of columns with I-, Z-, channel, and rectangular-tube sections," NASA Tech. Reports Serv., 1939.

[21] W.D Kroll, G. P. Fisher, and George J. Heimerl, "Charts for calculation of the critical stress for local instability of columns with I-, Z-, channel, and rectangular-tube section.pdf," Natl. Aeronaut. Sp. Admin Langley Res. Centrer, 1943.

[22] J. C. Lundquist, Eugene E Rossman, Carl A Houbolt, "A method for determining the column curve from tests of columns with equal restraints against rotation on the ends," naca-tn-903, 1943.

[23] C. R. C. of Japan., "Handbook of structural stabilityNo Title." Tokyo: Corona Publ. Co., 1971.

[24] D. C. T. Cardoso, K. A. Harries, and E. D. M. Batista, "Closed-form equations for compressive local buckling of pultruded thin-walled sections," Thin Walled Struct., vol. 79, pp. 16-22, 2014.

[25] B. Li, Z, Schafer, "Buckling analysis of cold-formed steel members with general boundary conditions using CUFSM: conventional and constrained finite strip methods (FSM)," Proc. 20th Int. Spec. Conf. cold-formed steel Struct. St. Louis, 2010.

[26] J. L. Dawe and G. L. Kulak, "Plate Instability of W Shapes," vol. 110, no. 6, pp. 1278-1291, 1984.

[27] ANSYS Inc. Theory Reference (version 12.1), “Ansys.” 2012.

[28] F. Stripes, “CUFSM 4.05.” 2014.

[29] Cristopher D. Moen and B.W. Schafer, Direct Strength Design of ColdFormed Steel Members with Perforations, no. March. 2009.

[30] K. M. El-Sawy and A. S. Nazmy, "Effect of aspect ratio on the elastic buckling of uniaxially loaded plates with eccentric holes," Thin-Walled Struct., vol. 39, no. 12, pp. 983-998, 2001.

[31] J. H. Kang and A. W. Leissa, "Exact solutions for the buckling of rectangular plates having linearly varying in-plane loading on two opposite simply supported edges," Int. J. Solids Struct., vol. 42, no. 14, pp. 4220-4238, 2005.

[32] M. Aydin Komur and M. Sonmez, "Elastic buckling of rectangular plates under linearly varying in-plane normal load with a circular cutout," Mech. Res. Commun., vol. 35, no. 6, pp. 361-371, 2008. 
[33] E. Maiorana, C. Pellegrino, and C. Modena, "Elastic stability of plates with circular and rectangular holes subjected to axial compression and bending moment," Thin-Walled Struct., vol. 47, no. 3, pp. 241-255, 2009.

[34] M. U. Hosain, W. K. Cheng, and V. V. Neis, "Deflection analysis of expanded open-web steel beams," Comput. Struct., vol. 4, no. 2, pp. 327336, 1974.

[35] W. bin Yuan, N. ting Yu, Z. shui Bao, and L. ping Wu, "Deflection of castellated beams subjected to uniformly distributed transverse loading," Int. J. Steel Struct., vol. 16, no. 3, pp. 813-821, 2016.

[36] L. L. Chen JK, Kim B, “Analytical approach for transverse vibration analysis of castellated beams,” J. Struct. Stab. Dyn., vol. 14, 2014.

[37] J.-Z. Gu, "Free Vibration of Castellated Beams with Web Shear and Rotary Inertia Effects," Int. J. Struct. Stab. Dyn., vol. 14, no. 6, p. 1450011, Aug. 2014.

[38] D. NETHERCOT and D. Kerdal, "LATERAL-TORSIONAL BUCKLING OF CASTELLATED BEAMS,” Struct. Eng., vol. 60, no. 3, pp. 53-61, 1982.

[39] A. Mohebkhah and M. G. Azandariani, "Lateral-torsional buckling resistance of unstiffened slender-web plate girders under moment gradient," Thin-Walled Struct., vol. 102, pp. 215-221, 2016.

[40] K. M. El-Sawy, A. M. I. Sweedan, and M. I. Martini, "Major-axis elastic buckling of axially loaded castellated steel columns," Thin-Walled Struct., vol. 47, no. 11, pp. 1295-1304, 2009.

[41] W. Bin Yuan, B. Kim, and L. Y. Li, "Buckling of axially loaded castellated steel columns," J. Constr. Steel Res., vol. 92, pp. 40-45, 2014.

[42] A. Mohebkhah and H. Showkati, "Bracing requirements for inelastic castellated beams," J. Constr. Steel Res., vol. 61, no. 10, pp. 1373-1386, 2005.

[43] T. Zirakian and H. Showkati, "Distortional buckling of castellated beams," J. Constr. Steel Res., vol. 62, no. 9, pp. 863-871, 2006.

[44] E. Ellobody, "Interaction of buckling modes in castellated steel beams," $J$. Constr. Steel Res., vol. 67, no. 5, pp. 814-825, 2011.

[45] A. N. Sherbourne and J. Van Oostrom, "Plastic analysis of castellated beamsI interaction of moment, shear and axial force," Comput. Struct., vol. 2, no. 1-2, pp. 79-109, 1972.

[46] A. H. Gandomi, S. M. Tabatabaei, M. H. Moradian, A. Radfar, and A. H. Alavi, "A new prediction model for the load capacity of castellated steel beams," J. Constr. Steel Res., vol. 67, no. 7, pp. 1096-1105, 2011.

[47] M. R. Soltani, A. Boucha??r, and M. Mimoune, "Nonlinear FE analysis of the ultimate behavior of steel castellated beams," J. Constr. Steel Res., vol. 70, pp. 101-114, 2012.

[48] F. Erdal and M. P. Saka, "Ultimate load carrying capacity of optimally designed steel cellular beams," J. Constr. Steel Res., vol. 80, pp. 355-368, 
2013.

[49] M. Najafi and Y. C. Wang, "Behaviour and design of steel members with web openings under combined bending, shear and compression," J. Constr. Steel Res., vol. 128, pp. 579-600, 2017.

[50] Robert D. Cook, D. S. Malkus, M. E. Plesha, and Robert J. Witt, Concepts and Applications of Finite Element Analysis, Fourth Edi. .

[51] R. Bebiano, N. Silvestre, and D. Camotim, "GBTUL - A code for the buckling analysis of cold-formed steel members," 19th Int. Spec. Conf. Recent Res. Dev. Cold-Formed Steel Des. Constr., pp. 61-79, 2008.

[52] C. D. Moen and B. W. Schafer, "Elastic buckling of thin plates with holes in compression or bending," Thin-Walled Struct., vol. 47, no. 12, pp. 15971607, 2009.

[53] P. B. Dinis, D. Camotim, and N. Silvestre, "On the local and global buckling behaviour of angle, T-section and cruciform thin-walled members," ThinWalled Struct., vol. 48, no. 10-11, pp. 786-797, 2010. 


\section{Appendix A \\ ABAQUS elastic buckling results and GBTUL output}

This appendix contains the castellated beams dimensions with their respective critical loads, obtained through the finite element model (ABAQUS [4]) and the results provide by Generalized Beam Theory formulation (GBTUL [5]).

\begin{tabular}{|c|c|c|c|c|c|c|}
\hline \multicolumn{4}{|c|}{ Geometric parameters } & \multicolumn{2}{|c|}{ ABAQUS } & \multirow{2}{*}{$\begin{array}{c}\text { GBTUL } \\
\text { бcr (Mpa) }\end{array}$} \\
\hline$\xi$ & $\eta$ & $\alpha$ & $\beta$ & $\begin{array}{c}\text { Mcr } \\
(\mathrm{Nmm})\end{array}$ & $\begin{array}{c}\sigma c r \\
(\mathrm{Mpa})\end{array}$ & \\
\hline \multirow{9}{*}{1} & 1,2 & 1,5 & 0,5 & $1,69 \mathrm{E}+07$ & 27,17 & 28,35 \\
\hline & 1 & 1,5 & 0,5 & $1,64 \mathrm{E}+07$ & 29,46 & 29,53 \\
\hline & 0,9 & 1,5 & 0,5 & $1,57 \mathrm{E}+07$ & 29,97 & 29,85 \\
\hline & 0,8 & 1,5 & 0,5 & $1,48 \mathrm{E}+07$ & 30,13 & 29,98 \\
\hline & 0,7 & 1,5 & 0,5 & $1,39 \mathrm{E}+07$ & 30,31 & 29,94 \\
\hline & 0,6 & 1,5 & 0,5 & $1,29 \mathrm{E}+07$ & 30,29 & 29,71 \\
\hline & 0,5 & 1,5 & 0,5 & $1,18 \mathrm{E}+07$ & 30,01 & 29,28 \\
\hline & 0,4 & 1,5 & 0,5 & $1,07 \mathrm{E}+07$ & 29,67 & 28,64 \\
\hline & 0,3 & 1,5 & 0,5 & $9,61 \mathrm{E}+06$ & 29,31 & 27,78 \\
\hline \multirow{9}{*}{1,5} & 1,2 & 1,5 & 0,5 & $2,89 \mathrm{E}+07$ & 35,33 & 38,22 \\
\hline & 1 & 1,5 & 0,5 & $2,68 \mathrm{E}+07$ & 37,22 & 38,84 \\
\hline & 0,9 & 1,5 & 0,5 & $2,50 \mathrm{E}+07$ & 37,26 & 38,68 \\
\hline & 0,8 & 1,5 & 0,5 & $2,31 \mathrm{E}+07$ & 37,14 & 38,4 \\
\hline & 0,7 & 1,5 & 0,5 & $2,11 \mathrm{E}+07$ & 36,83 & 37,97 \\
\hline & 0,6 & 1,5 & 0,5 & $1,91 \mathrm{E}+07$ & 36,46 & 37,37 \\
\hline & 0,5 & 1,5 & 0,5 & $1,70 \mathrm{E}+07$ & 35,80 & 36,52 \\
\hline & 0,4 & 1,5 & 0,5 & $1,49 \mathrm{E}+07$ & 34,98 & 35,37 \\
\hline & 0,3 & 1,5 & 0,5 & $1,26 \mathrm{E}+07$ & 33,43 & 33,78 \\
\hline \multirow{9}{*}{1,8} & 1,2 & 1,5 & 0,5 & $3,67 \mathrm{E}+07$ & 39,23 & 42,67 \\
\hline & 1 & 1,5 & 0,5 & $3,32 \mathrm{E}+07$ & 40,59 & 42,41 \\
\hline & 0,9 & 1,5 & 0,5 & $3,08 \mathrm{E}+07$ & 40,57 & 42,18 \\
\hline & 0,8 & 1,5 & 0,5 & $2,83 \mathrm{E}+07$ & 40,41 & 41,86 \\
\hline & 0,7 & 1,5 & 0,5 & $2,57 \mathrm{E}+07$ & 40,06 & 41,42 \\
\hline & 0,6 & 1,5 & 0,5 & $2,32 \mathrm{E}+07$ & 39,81 & 40,82 \\
\hline & 0,5 & 1,5 & 0,5 & $2,05 \mathrm{E}+07$ & 39,13 & 40,01 \\
\hline & 0,4 & 1,5 & 0,5 & $1,77 \mathrm{E}+07$ & 38,05 & 38,87 \\
\hline & 0,3 & 1,5 & 0,5 & $1,50 \mathrm{E}+07$ & 36,92 & 37,25 \\
\hline
\end{tabular}

Table 3 - Results obtained for critical buckling governed by the web 


\begin{tabular}{|c|c|c|c|c|c|c|c|c|}
\hline \multirow{2}{*}{\multicolumn{4}{|c|}{ Geometric parameters }} & \multicolumn{4}{|c|}{ ABAQUS } & \multirow{3}{*}{$\begin{array}{c}\text { GBTUL } \\
\sigma c r(\mathrm{MPa})\end{array}$} \\
\hline & & & & \multicolumn{2}{|c|}{ One Hole } & \multicolumn{2}{|c|}{ Five Holes } & \\
\hline$\xi$ & $\eta$ & $\alpha$ & $\beta$ & $\operatorname{Mcr}(\mathrm{Nmm})$ & $\begin{array}{c}\sigma c r \\
(\mathrm{MPa})\end{array}$ & $\operatorname{Mcr}(\mathrm{Nmm})$ & $\begin{array}{c}\sigma c r \\
(\mathrm{MPa})\end{array}$ & \\
\hline \multirow{6}{*}{1} & 4 & 1,5 & 0,5 & $6,96 \mathrm{E}+07$ & 22,65 & $5,67 \mathrm{E}+07$ & 18,45 & 19,85 \\
\hline & 3,5 & 1,5 & 0,5 & $7,67 \mathrm{E}+07$ & 27,92 & $6,47 \mathrm{E}+07$ & 23,56 & 24,04 \\
\hline & 3 & 1,5 & 0,5 & $8,70 \mathrm{E}+07$ & 35,95 & $7,59 \mathrm{E}+07$ & 31,36 & 30,43 \\
\hline & 2,5 & 1,5 & 0,5 & $1,01 \mathrm{E}+08$ & 48,25 & $9,14 \mathrm{E}+07$ & 43,66 & 40,51 \\
\hline & 2 & 1,5 & 0,5 & $1,18 \mathrm{E}+08$ & 66,79 & $1,10 \mathrm{E}+08$ & 62,27 & 56,48 \\
\hline & 1,5 & 1,5 & 0,5 & $1,34 \mathrm{E}+08$ & 93,06 & $1,25 \mathrm{E}+08$ & 86,81 & 78,75 \\
\hline \multirow{6}{*}{1,5} & 4 & 1,5 & 0,5 & $1,90 \mathrm{E}+08$ & 43,38 & $1,60 \mathrm{E}+08$ & 36,53 & 41,28 \\
\hline & 3,5 & 1,5 & 0,5 & $2,03 \mathrm{E}+08$ & 52,18 & $1,69 \mathrm{E}+08$ & 43,44 & 49,17 \\
\hline & 3 & 1,5 & 0,5 & $2,21 \mathrm{E}+08$ & 65,00 & $1,92 \mathrm{E}+08$ & 56,47 & 60,76 \\
\hline & 2,5 & 1,5 & 0,5 & $2,46 \mathrm{E}+08$ & 84,53 & $2,22 \mathrm{E}+08$ & 76,29 & 79,05 \\
\hline & 2 & 1,5 & 0,5 & $2,71 \mathrm{E}+08$ & 111,98 & $2,55 \mathrm{E}+08$ & 105,37 & 106,64 \\
\hline & 1,5 & 1,5 & 0,5 & $2,60 \mathrm{E}+08$ & 134,72 & $2,63 \mathrm{E}+08$ & 136,27 & 141,7 \\
\hline \multirow{6}{*}{1,8} & 4 & 1,5 & 0,5 & $3,12 \mathrm{E}+08$ & 60,41 & $2,58 \mathrm{E}+08$ & 49,96 & 58,59 \\
\hline & 3,5 & 1,5 & 0,5 & $3,30 \mathrm{E}+08$ & 72,11 & $2,69 \mathrm{E}+08$ & 58,78 & 69,57 \\
\hline & 3 & 1,5 & 0,5 & $3,54 \mathrm{E}+08$ & 88,76 & $3,06 \mathrm{E}+08$ & 76,73 & 85,87 \\
\hline & 2,5 & 1,5 & 0,5 & $3,87 \mathrm{E}+08$ & 113,82 & $3,51 \mathrm{E}+08$ & 103,23 & 110,72 \\
\hline & 2 & 1,5 & 0,5 & $4,31 \mathrm{E}+08$ & 153,27 & $4,22 \mathrm{E}+08$ & 150,07 & 147,5 \\
\hline & 1,5 & 1,5 & 0,5 & $3,74 \mathrm{E}+08$ & 168,16 & $3,97 \mathrm{E}+08$ & 178,69 & 172,01 \\
\hline
\end{tabular}

Table 4 - Results obtained for critical buckling governed by the flange 


\section{Appendix B \\ Steps of deflection field for the web}

The deflection field for the web can be interpolated by a cubic function as:

$$
\mathrm{w}_{\mathrm{web}}(\mathrm{y})=\mathrm{C}_{1} \mathrm{y}^{3}+\mathrm{C}_{2} \mathrm{y}^{2}+\mathrm{C}_{3} \mathrm{y}+\mathrm{C}_{4}
$$

The constants can be defined by applying the boundary conditions:

$$
\begin{gathered}
\mathrm{w}_{\mathrm{web}}(0)=0 \\
\mathrm{C}_{4}=0 \\
\mathrm{M}(0)=\mathrm{k}_{\mathrm{m}} \cdot \theta \\
\mathrm{M}(0)=\mathrm{k}_{\mathrm{m}} \cdot \mathrm{w}^{\prime}(0)=\mathrm{k}_{\mathrm{m}} \cdot \mathrm{C}_{3} \\
\mathrm{M}(0)=\mathrm{P} \cdot \mathrm{b}_{\mathrm{w}} \\
\text { From (i) to (ii): } \mathrm{C}_{3}=\frac{\mathrm{P} \cdot \mathrm{b}_{\mathrm{w}}}{\mathrm{k}_{\mathrm{m}}} \\
\mathrm{EIw}^{\prime \prime \prime}\left(\mathrm{b}_{\mathrm{w}}\right)=-\mathrm{P} \\
\mathrm{EI} \cdot 6 \mathrm{C}_{1}=-\mathrm{P} \\
\mathrm{C}_{1}=\frac{-\mathrm{P}}{6 \mathrm{EI}} \\
\mathrm{w}^{\prime \prime}\left(\mathrm{b}_{\mathrm{w}}\right)=0 \\
\mathrm{C}_{1} \cdot \mathrm{b}_{\mathrm{w}}+2 \mathrm{C}_{2}=0 \\
\mathrm{M}\left(\mathrm{b}_{\mathrm{w}}\right)=0 \\
\mathrm{P} \cdot \mathrm{b}_{\mathrm{w}} \\
2 \mathrm{EI}
\end{gathered}
$$


Therefore, the representative equation of the web deflection field varying with the local y-axis is as follows:

$$
w_{w e b}(y)=\frac{-P}{6 E I_{w e b}} \cdot y^{3}+\frac{P \cdot b_{w}}{2 E I_{w e b}} \cdot y^{2}+\frac{P \cdot b_{w}}{k_{M}} \cdot y
$$




\section{Appendix C \\ Step by step of algebraic manipulations of $\sigma_{c r}$ equations}

\section{C.1 - Behavior governed by web (WLB):}

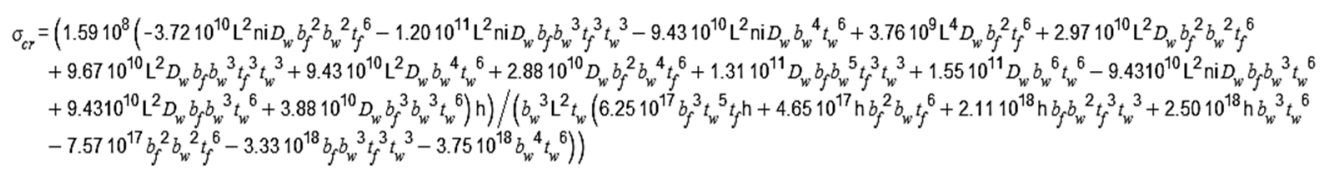

Expressing critical stress in general form:

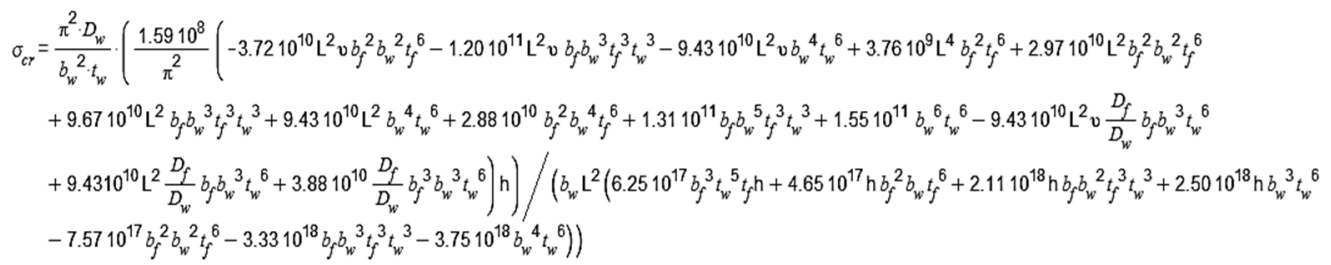

By algebraic manipulations:

$$
\begin{aligned}
& \sigma_{c r}=\frac{\pi^{2} \cdot D_{w}}{b_{w}{ }^{2} \cdot t_{w}} \cdot\left(\frac { 1 . 5 9 } { \pi ^ { 2 } } \cdot b _ { w } \cdot \left(-3.72 \mathrm{~L}^{2} v \frac{b_{f}^{2}}{b_{w}{ }^{4}} \frac{t_{f}^{6}}{t_{w}{ }^{6}}-12.09 \mathrm{~L}^{2} v \frac{b_{f}}{b_{w}{ }^{3}} \frac{t_{f}{ }^{3}}{t_{w}{ }^{3}}-9.43 \mathrm{~L}^{2} v \frac{1}{b_{w}{ }^{2}}+0.37 \mathrm{~L}^{4} \frac{b_{f}^{2}}{b_{w}{ }^{6}} \frac{t_{f}^{6}}{t_{w}{ }^{6}}+2.97 \mathrm{~L}^{2} \frac{b_{f}^{2}}{b_{w}{ }^{4}} \frac{t_{f}^{6}}{t_{w}^{6}}+9.67 \mathrm{~L}^{2} \frac{b_{f}}{b_{w}{ }^{3}} \frac{t_{f}^{3}}{t_{w}{ }^{3}}\right.\right. \\
& \left.\left.+9.43 L^{2} \frac{1}{b_{w}{ }^{2}}+2.88 \frac{b_{f}^{2}}{b_{w}{ }^{2}} \frac{t_{f}^{6}}{t_{w}^{6}}+13.13 \frac{b_{f}}{b_{w}} \frac{t_{f}^{3}}{t_{w}{ }^{3}}+15.52-9.43 L^{2} v \frac{D_{f}}{D_{w}} \frac{b_{f}}{b_{w}{ }^{3}}+9.43 L^{2} \frac{D_{f}}{D_{w}} \frac{b_{f}}{b_{w}{ }^{3}}+3.88 \frac{D_{f}}{D_{w}} \frac{b_{f}^{3}}{b_{w}{ }^{3}}\right) \mathrm{~h}\right) /\left(\mathrm { L } ^ { 2 } \cdot \mathrm { h } \cdot \left(0.62 \frac{b_{f}{ }^{3}}{b_{w}{ }^{4}} \frac{t_{f}}{t_{w}}\right.\right. \\
& \left.\left.+0.46 \frac{b_{f}^{2}}{b_{w}{ }^{3}} \frac{t_{f}^{6}}{t_{w}^{6}}+2.11 \frac{b_{f}}{b_{w}^{2}} \frac{t_{f}^{3}}{t_{w}^{3}}+2.50 \frac{1}{b_{w}}-\frac{0.75}{\mathrm{~h}} \frac{b_{f}^{2}}{b_{w}^{2}} \frac{t_{f}^{6}}{t_{w}^{6}}-\frac{3.33}{\mathrm{~h}} \frac{b_{f}}{b_{w}} \frac{t_{f}^{3}}{t_{w}{ }^{3}}-\frac{3.75}{\mathrm{~h}}\right)\right)
\end{aligned}
$$

Substituting $\xi=\frac{t_{f}}{t_{w}}$ and $\eta=\frac{b_{f}}{b_{w}}$ :

$$
\begin{aligned}
\sigma_{c r}= & \frac{\pi^{2} \cdot D_{w}}{b_{w}{ }^{2} \cdot t_{w}} \cdot\left(\frac { 1 . 5 9 } { \pi ^ { 2 } } \cdot b _ { w } \cdot \left(-3.72 \mathrm{~L}^{2} v \cdot \frac{1}{b_{w}{ }^{2}} \cdot \eta^{2} \cdot \xi^{6}-12.09 \mathrm{~L}^{2} v \frac{1}{b_{w}{ }^{2}} \eta \xi^{3}-9.43 \mathrm{~L}^{2} v \frac{1}{b_{w}{ }^{2}}+0.37 \mathrm{~L}^{4} \frac{1}{b_{w}{ }^{4}} \cdot \eta^{2} \cdot \xi^{6}+2.97 \mathrm{~L}^{2} \frac{1}{b_{w}{ }^{2}} \eta^{2} \cdot \xi^{6}+9.67 \mathrm{~L}^{2} \frac{1}{b_{w}{ }^{2}} \cdot \eta \cdot \xi^{3}\right.\right. \\
& \left.\left.+9.43 \mathrm{~L}^{2} \frac{1}{b_{w}{ }^{2}}+2.88 \eta^{2} \cdot \xi^{6}+13.13 \eta \cdot \xi^{3}+15.52-9.43 \mathrm{~L}^{2} \mathrm{ni} \frac{D_{f}}{D_{w}} \frac{1}{b_{w}{ }^{2}} \cdot \eta+9.43 \frac{\mathrm{L}^{2}}{b_{w}{ }^{2}} \frac{D_{f}}{D_{w}} \cdot \eta+3.88 \frac{D_{f}}{D_{w}} \eta^{3}\right) \mathrm{~h}\right) /\left(\mathrm { L } ^ { 2 } \cdot \mathrm { h } \cdot \left(0.62 \frac{1}{b_{w}} \cdot \eta^{3} \cdot \xi\right.\right. \\
& \left.\left.+0.46 \frac{1}{b_{w}} \eta^{2} \cdot \xi^{6}+2.11 \frac{1}{b_{w}} \cdot \eta \cdot \xi^{3}+\frac{2.50}{b_{w}}-\frac{0.75}{\mathrm{~h}} \eta^{2} \cdot \xi^{6}-\frac{3.33}{\mathrm{~h}} \eta \xi^{3}-\frac{3.75}{\mathrm{~h}}\right)\right)
\end{aligned}
$$

Through algebraic manipulations and replacing $\frac{D_{f}}{D_{w}}=\left(\frac{t_{f}}{t_{w}}\right)^{3}$ :

$$
\sigma_{c r}=\frac{\pi^{2} \cdot D_{w}}{b_{w}{ }^{2} \cdot t_{w}} \cdot \frac{\left(0.30 \mathrm{~L}^{2} \eta^{2} \xi^{6}+2.04 \mathrm{~L}^{2} \eta \xi^{3}+1.06 \mathrm{~L}^{2}+\frac{0.06 \mathrm{~L}^{4} \eta^{2} \xi^{6}}{b_{w}{ }^{2}}+0.46 \eta^{2} \xi^{6} b_{w}{ }^{2}+2.12 \eta \xi^{3} b_{w}{ }^{2}+2.51 b_{w}{ }^{2}+0.63 \eta^{3} \xi^{3} b_{w}{ }^{2}\right)}{\mathrm{L}^{2}\left(0.63 \eta^{3} \xi+0.46 \eta^{2} \xi^{6}+2.12 \eta \xi^{3}+2.50-\frac{0.76 \eta^{2} \xi^{6} b_{w}}{\mathrm{~h}}-\frac{3.34 \eta \xi^{3} b_{w}}{\mathrm{~h}}-\frac{3.76 b_{w}}{\mathrm{~h}}\right)}
$$


Adopting $\mathrm{H}=\frac{2 b_{w} \alpha}{(\alpha-1)}$ and $\mathrm{L}=\beta \cdot \frac{2 b_{w}}{(\alpha-1)}$ :

$\sigma_{c r}=\frac{\pi^{2} \cdot D_{w}}{b_{w}^{2} \cdot t_{w}} \cdot \frac{\left(0.30 \eta^{2} \xi^{6}+2.04 \eta \xi^{3}+1.06+0.06 \eta^{2} \xi^{6} \cdot \frac{4 \cdot \beta^{2}}{(\alpha-1)^{2}}+\frac{(\alpha-1)^{2}}{4 \cdot \beta^{2}} \cdot\left(0.46 \eta^{2} \xi^{6}+2.12 \eta \xi^{3}+2.51+0.63 \eta^{3} \xi^{3}\right)\right)}{\left(0.63 \eta^{3} \xi 0.46 \eta^{2} \xi^{6}+2.12 \eta \xi^{3}+2.50-\left(0.38 \eta^{2} \xi^{6} \cdot\left(1-\frac{1}{\alpha}\right)\right)-\left(1.67 \eta \xi^{3} \cdot\left(1-\frac{1}{\alpha}\right)\right)-\left(1.88 \cdot\left(1-\frac{1}{\alpha}\right)\right)\right)}$

\section{C.2 - Behavior governed by flange (FLB):}

$$
\sigma_{c r}=-\frac{\mathrm{h}\left(-4 D_{w} \pi^{2} b_{w}{ }^{3}-D_{f} \pi^{2} b_{f}{ }^{3}+24 D_{w} \mathrm{~L}^{2} b_{w} v+24 D_{f} \mathrm{~L}^{2} b_{f} v-24 D_{w} \mathrm{~L}^{2} b_{w}-24 D_{f} \mathrm{~L}^{2} b_{f}\right)}{\mathrm{L}^{2}\left(b_{f}{ }^{3} \mathrm{~h} t_{f}-6 b_{w}{ }^{4} t_{w}+4 b_{w}{ }^{3} \mathrm{~h} t_{w}\right)}
$$

Expressing critical stress in general form:

$$
\sigma_{c r}=\frac{\pi^{2} \cdot D_{w}}{b_{w}{ }^{2}} \cdot\left(-\frac{\mathrm{h}\left(-4 b_{w}{ }^{3}-\frac{D_{f}}{D_{w}} b_{f}{ }^{3}+\frac{24}{\pi^{2}} \mathrm{~L}^{2} b_{w} v+\frac{24}{\pi^{2}} \frac{D_{f}}{D_{w}} \mathrm{~L}^{2} b_{f} v-\frac{24}{\pi^{2}} \mathrm{~L}^{2} b_{w}-\frac{24}{\pi^{2}} \frac{D_{f}}{D_{w}} \mathrm{~L}^{2} b_{f}\right)}{\mathrm{L}^{2}\left(\frac{b_{f}{ }^{3}}{b_{w}{ }^{2}} \mathrm{~h} t_{f}-6 b_{w}{ }^{2} t_{w}+4 b_{w} \mathrm{~h} t_{w}\right)}\right)
$$

Through algebraic manipulations and replacing $\frac{\mathrm{D}_{\mathrm{f}}}{\mathrm{D}_{\mathrm{w}}}=\left(\frac{\mathrm{t}_{\mathrm{f}}}{\mathrm{t}_{\mathrm{w}}}\right)^{3}$ :

$$
\sigma_{c r}=\frac{\pi^{2} \cdot D_{w}}{b_{w}{ }^{2} \cdot t_{w}} \cdot\left(-\frac{\left(-4 b_{w}{ }^{3}-\left(\frac{t_{f}}{t_{w}}\right)^{3} b_{f}{ }^{3}+\frac{24}{\pi^{2}} L^{2} b_{w} v+\frac{24}{\pi^{2}}\left(\frac{t_{f}}{t_{w}}\right)^{3} L^{2} b_{f} v-\frac{24}{\pi^{2}} L^{2} b_{w}-\frac{24}{\pi^{2}}\left(\frac{t_{f}}{t_{w}}\right)^{3} L^{2} b_{f}\right)}{\mathrm{L}^{2}\left(\frac{b_{f}{ }^{3}}{b_{w}{ }^{2}} \frac{t_{f}}{t_{w}}-\frac{6 b_{w}{ }^{2}}{\mathrm{~h}}+4 b_{w}\right)}\right)
$$

Adopting $\mathrm{H}=\frac{2 b_{w} \alpha}{(\alpha-1)}$ and $\mathrm{L}=\beta \cdot \frac{2 b_{w}}{(\alpha-1)}$ and applying some manipulations:

$$
\sigma_{c r}=\frac{\pi^{2} \cdot D_{w}}{b_{w}{ }^{2} \cdot t_{w}} \cdot\left(-\frac{\left(-\frac{(\alpha-1)^{2}}{\beta^{2}}-\frac{1}{4} \frac{t_{f}{ }^{3} b_{f}{ }^{3}(\alpha-1)^{2}}{t_{w}{ }^{3} b_{w}{ }^{3} \beta^{2}}+\frac{24}{\pi^{2}} \cdot v+\frac{24}{\pi^{2}}\left(\frac{t_{f}}{t_{w}}\right)^{3} \frac{b_{f}}{b_{w}} v-\frac{24}{\pi^{2}}-\frac{24}{\pi^{2}}\left(\frac{t_{f}}{t_{w}}\right)^{3} \frac{b_{f}}{b_{w}}\right)}{\left(\frac{b_{f}{ }^{3}}{b_{w}{ }^{3}} \frac{t_{f}}{t_{w}}-\frac{3 \cdot(\alpha-1)}{\alpha}+4\right)}\right)
$$

Finally, considering $\xi=\frac{t_{f}}{t_{w}}$ and $\eta=\frac{b_{f}}{b_{w}}$ :

$$
\sigma_{c r}=\frac{\pi^{2} \cdot D_{w}}{b_{w}{ }^{2} \cdot t_{w}} \cdot \frac{\frac{(\alpha-1)^{2}}{\beta^{2}}+\frac{1}{4} \cdot \eta^{3} \cdot \xi^{3} \cdot \frac{(\alpha-1)^{2}}{\beta^{2}}-\frac{24}{\pi^{2}} \cdot\left(v+\eta \cdot \xi^{3} \cdot v-1-\eta \cdot \xi^{3}\right)}{\left(\eta^{3} \cdot \xi-\frac{3 \cdot(\alpha-1)}{\alpha}+4\right)}
$$

